\title{
Activation of MAP3K DLK and LZK in Purkinje Cells Causes Rapid and Slow Degeneration Depending on Signaling Strength
}

\author{
Yunbo Li ${ }^{1}$, Erin M Ritchie ${ }^{1}$, Christopher L. Steinke ${ }^{1}$, Cai Qi ${ }^{1 \#}$, Lizhen Chen ${ }^{1 \$}$, \\ Binhai Zheng ${ }^{2,3}$, Yishi $\mathrm{Jin}^{1,2, *}$
}

1. Neurobiology Section, Division of Biological Sciences, University of California San Diego, La Jolla, CA 92093, USA

2. Department of Neurosciences, School of Medicine, University of California San Diego, La Jolla, CA 92093, USA

3. VA San Diego Healthcare System, San Diego, CA 92161, USA.

Present address:

\# Department of Human Genetics, and the Grossman Institute for Neuroscience, Quantitative Biology and Human Behavior, The University of Chicago, Chicago, IL 60637, USA

\$ Barshop Institute for Longevity and Aging Studies, Department of Cell Systems and Anatomy, University of Texas Health Science Center at San Antonio, San Antonio, TX 78229, USA.

*Correspondence: yijin@ucsd.edu

Running title: MAP3K activation induces Purkinje cell degeneration Keywords: MAP3K12, MAP3K13, JNK, Jun, Celf2, MKK7, Cerebellum, Apoptosis, MAP2, neuronal cytoskeleton

7 Figures, three Tables, 12 supplement Figures, and two supplement videos

Version $10 / 05 / 20$ 


\section{Summary}

The conserved MAP3K Dual leucine zipper kinases can activate JNK via MKK4 or MKK7. Vertebrate DLK and LZK share similar biochemical activities and undergo auto-activation upon increased expression. Depending on cell-type and nature of insults DLK and LZK can induce pro-regenerative, pro-apoptotic or pro-degenerative responses, although the mechanistic basis of their action is not well understood. Here, we investigated these two MAP3Ks in cerebellar Purkinje cells using loss- and gain-of function mouse models. While loss of each or both kinases does not cause discernible defects in Purkinje cells, activating DLK causes rapid death and activating LZK leads to slow degeneration. Each kinase induces JNK activation and caspase-mediated apoptosis independent of each other. Significantly, deleting CELF2, which regulates alternative splicing of $M k k 7$, strongly attenuates Purkinje cell degeneration induced by activation of LZK, but not DLK. Thus, controlling the activity levels of DLK and LZK is critical for neuronal survival and health. 


\section{Introduction}

Mitogen-activated protein kinase (MAPK) signaling pathways play important roles in neuronal development and function, and aberrant regulation of MAP kinases is associated with many neurological diseases, such as Parkinson's disease (PD), amyotrophic lateral sclerosis (ALS) and Alzheimer's disease (AD) (Thomas and Huganir, 2004; Schellino et al., 2019; Hotamisligil and Davis, 2016; Hollville et al., 2019; Adib et al., 2018). The MAPK cascade involves MAP3Ks (MAP kinase kinase kinases), MAP2Ks and MAPKs that together form a phosphorylation relay and activate downstream signaling events in response to external or internal stimuli. The mammalian MAP3K DLK (Dual leucine zipper kinase, or MAP3K12) and LZK (Leucine zipper kinase, or MAP3K13) are members of an evolutionarily conserved family that includes C. elegans DLK-1 and Drosophila DLK/Wallenda (Jin and Zheng, 2019). These MAP3Ks act as upstream kinases for JNK and p38 MAP kinase, and are now known as key players in neuronal stress response network both under acute injury and in chronic neurodegenerative diseases (Jin and Zheng, 2019; Adib et al., 2018; Farley and Watkins, 2018). An emerging theme is that while activation of these kinases triggers seemingly common pathways, the outcome is highly context-specific both in terms of cell types and forms of insults.

Both DLK and LZK show broad expression in the nervous system. Several studies have investigated roles of DLK in the development of the nervous system. Constitutive DIk knockout mice die perinatally, and different regions of developing brain display varying degrees of altered axon fibers, abnormal synapses and increased neuronal survival (Hirai et al., 2006; Hirai et al., 2011; Nakata et al., 2005; Collins et al., 2006; Lewcock et al., 2007). However, mice with adult deletion of Dlk survive and show no detectable abnormalities (Le Pichon et al., 2017; Tedeschi and Bradke, 2013). Under traumatic insults, DLK activity is reported to increase and trigger a variety of cellular responses. For example, sciatic nerve injury induces DLK-dependent pro-regenerative responses in dorsal root ganglia (DRG) sensory neurons (Shin et al., 2012; Shin et al., 2019). In the central nervous system (CNS), optic nerve injury up-regulates DLK expression in retinal ganglion cells (RGC), which triggers cell death in many RGCs and also promotes axon growth from surviving RGCs (Watkins et al., 2013; Welsbie et al., 2013). In a mouse model for stroke, increased DLK expression in pre-motor cortex is suggested to promote motor recovery (Joy et al., 2019). Increased DLK activity is also reported in animal models of neurodegeneration, and genetically or pharmacologically inhibiting DLK in the aged PS2APP mice for AD and the SOD $1^{\mathrm{G} 93 \mathrm{~A}}$ mice for ALS has resulted in some neuroprotective effects (Chen et al., 2008; Le Pichon et al., 2017). Intriguingly, in human iPSC derived neurons treated with ApoE4, a protein associated with an increased risk for AD, DLK is rapidly up-regulated and enhances transcription of APP (Huang et al., 2017). As numerous approaches now target DLK for drug discovery (Siu et al., 
2018), it is important to investigate how the pleiotropic effects of manipulating DLK in different cell types influence disease progression. In comparison, despite the fact that LZK was also discovered 20 years ago (Sakuma et al., 1997; Holzman et al., 1994), the in vivo roles of LZK are only beginning to be explored. In a mouse model of spinal cord injury, LZK is upregulated in astrocytes and mediates reactive astrogliosis (Chen et al., 2018). Emerging studies show that LZK can cooperate with DLK in RGC to promote cell death after optic nerve injury and in DRG for axon degeneration (Welsbie et al., 2017; Summers et al., 2020).

Here, we dissect the roles of the two kinases in the cerebellar Purkinje cells. We analyzed genetic deletion mice for each kinase, and also developed transgenic mice that allow for Cre-mediated expression of DLK or LZK. Biochemical studies have shown that DLK and LZK undergo auto-activation via leucine-zipper mediated dimerization, and such autoactivation is dependent on the protein abundance (Nihalani et al., 2000; Ikeda et al., 2001b). Therefore, elevating expression of DLK or LZK is a proxy to its activation of the downstream signal transduction. We find that deletion of DLK and/or LZK, singly or in combination, from Purkinje cells, does not affect their development and postnatal growth. In contrast, induced expression of DLK in Purkinje cells causes rapid degeneration, whereas elevating LZK expression induces a slow degeneration. Strikingly, we find that deleting the RNA splicing factor CELF2 ameliorates Purkinje cell degeneration induced by LZK, but not DLK, partly via regulating alternative splicing of $M k k 7$, a MAP2K. These findings provide important insights to the understanding of neurodegenerative processes. 


\section{Results}

\section{Normal development of cerebellar Purkinje cells in the absence of DLK and LZK}

Both DLK and LZK are expressed in cerebellar neurons, with high levels of DLK observed in the molecular layer of adult cerebellum (Hirai et al., 2005; Suenaga et al., 2006; Goodwani et al., 2020). Dlk knockout (KO) mice die soon after birth, and cerebellar architecture is grossly normal (Hirai et al., 2006). The roles of $L z k$ in neuronal development remain unknown. To address the function of $L z k$ and further probe into the interactions between the two kinases, we generated an Lzk KO mouse line using CRISPR-editing to delete the entire kinase domain (Figure 1-figure supplement $1 \mathrm{~A}-\mathrm{B}$ ), which also resulted in a frameshift and produced no detectable LZK proteins by immunoprecipitation and western blotting analysis (Figure 1figure supplement $1 \mathrm{C}$ ). The Lzk KO mice are viable, and grow indistinguishably from littermates under standard housing conditions. Histological analysis of cerebellar tissue sections using hematoxylin and eosin staining revealed no discernible defects in overall cellular architecture in two-month old (P60) Lzk KO mice (Figure $1 \mathrm{~A}$ ). Immunostaining using antibodies to Calbindin, which specifically labels Purkinje cells, showed that the position, number and gross morphology of Purkinje cells were comparable between Lzk KO and control (Figure 1 B-D). The molecular layer thickness, which is a sensitive assessment for disruption of the dendrites of Purkinje cells (White et al., 2014; Hansen et al., 2013; White et al., 2016; White and Sillitoe, 2017), was also normal (Figure $1 \mathrm{E}$ ).

It has recently been shown that Dlk and Lzk can act synergistically in injured RGC or DRG neurons (Welsbie et al., 2017; Summers et al., 2020). We therefore tested if loss of both DLK and LZK might affect cerebellar neurons. We bred floxed (fI) Dlk or Lzk KO mice to a parvalbumin-Cre driver line ( $P V^{\text {Cre }}$ ) (Hippenmeyer et al., 2005), and obtained $P V^{C r e /+} ; D I k^{f / f t l} ; L z k^{f / f t l}$ mice, along with $P V^{C r e /+} ; D I k^{f l / f l}$ and $P V^{C r e /+} ; L z k^{f l / f l}$ (Figure 1-figure supplement $1 \mathrm{D}-\mathrm{G})$. Cre recombinase from $P V^{\mathrm{Cre}}$ line is active in Purkinje cells as early as P4 (Hippenmeyer et al., 2005). We detected reduced protein levels of DLK and LZK in cerebellar extracts for $P V^{\mathrm{Cre} /+} ; D I k^{f / f f l} ; L z k^{f f / f l}, P V^{C r e /+} ; D I k^{f / f f l}$ and $P V^{C r e /+} ; L z k^{f l / f l}$ mice, respectively (Figure 1-figure supplement $1 \mathrm{C}, \mathrm{H}$ ). The overall cerebellar tissue organization, revealed by hematoxylin and eosin staining, was indistinguishable among test and control mice of P60 age (Figure $1 \mathrm{~A}$ ). Calbindin immunostaining showed that the total number of Purkinje cells and the molecular layer thickness of cerebellum were comparable in single or double gene deletion of each kinase (Figure $1 \mathrm{~B}-\mathrm{E}$ ). Additionally, GFAP immunostaining for cerebellar astrocytes revealed no detectable difference among different genotypes of mice (Figure 1figure supplement $1 \mathrm{I}-\mathrm{J}$ ). All mutant mice also showed postnatal growth, measured by body weight, comparable to the control mice under same housing conditions (Figure 1-figure supplement $1 \mathrm{~K}$ ). These data show that DLK and LZK are not required for the postnatal development of Purkinje cells. 


\section{Elevating DLK expression in Purkinje cells causes rapid degeneration via apoptosis} Increased expression of DLK or LZK has been reported under traumatic injury or other stress conditions (Shin et al., 2012; Shin et al., 2019; Watkins et al., 2013; Welsbie et al., 2013; Joy et al., 2019; Chen et al., 2018; Huang et al., 2017). We next investigated how elevating expression of DLK and LZK, hence activation of these kinases, affects neurons. To this end, we generated two transgenic mouse lines by inserting a Cre-inducible transgene of DIk or Lzk at the Hipp11 (H11) locus, named H11-DIk ${ }^{\text {iOE }}$ or H11-Lzk ${ }^{i O E}$, respectively (Figure 2-figure supplement $1 \mathrm{~A}-\mathrm{B})$. In each transgene, the induced expression can be readily assessed by a tdTomato reporter fused in-frame to the C-terminus of DLK or LZK through the T2A self-cleaving peptides. By RNA-seq analysis we detected comparable levels of tdTomato mRNAs produced from each transgene following expression of Cre recombinase (Figure 2-figure supplement $1 \mathrm{C}$ ). After outcrossing to C57BL/6J background, these mice were bred to the $P V^{\text {Cre }}$ line. In $P V^{\mathrm{Cre} /+} ; D I k^{\mathrm{iOE} /+}$ or $P V^{\mathrm{Cre} /+} ; L z \mathrm{~K}^{\mathrm{iOE} /+}$ heterozygous mice, we observed tdTomato reporter expression correlating with the timing of parvalbumin expression (Figure 2-figure supplement $1 \mathrm{D}$ ), and increased DLK or LZK expression was detected in cerebellar lysates (Figure 2-figure supplement $1 \mathrm{E}-\mathrm{H}$ ).

Elevating DLK expression in $\mathrm{PV}^{\mathrm{Cr} /+} ; D I \mathrm{~K}^{\mathrm{iOE} / \mathrm{+}}$ mice caused abnormalities noticeable as early as P6. The pups were smaller than littermate controls (Figure 2 A-B), and exhibited abnormal movements (supplement video 1 ). These pups all died around P21. The cerebella of $P V^{C r e /+} ; D^{\prime} k^{i O E /+}$ were much smaller than those of littermate controls (Figure $2 \mathrm{C}$; Figure 2figure supplement $2 \mathrm{~A}$ ). Histological analysis revealed grossly abnormal lobular morphology (Figure 2-figure supplement $2 \mathrm{~B}$ ). By Calbindin immunostaining we detected a rapid degeneration of Purkinje cells, with a nearly complete ( 98\%) cell loss by P21 (Figure 2 DE). The molecular layer of the cerebellum in these mice was significantly thinner than that in the littermate control mice from P10 to P21 (Figure 2 F). Purkinje cell degeneration is known to be associated with increased reactivity of astrocytes and microglia (Cvetanovic et al., 2015; Lobsiger and Cleveland, 2007; Lattke et al., 2017). Indeed, we observed increased expression of GFAP and IBA1 (detecting both microglia and macrophage) in these mice at P21, compared to control mice (Figure 2-figure supplement $2 \mathrm{C}-\mathrm{F}$ ). Some IBA1 positive microglia were closely associated with tdTomato labeled Purkinje cells (Figure 2-figure supplement $2 \mathrm{C}$ ), suggesting that dying cells might be phagocytosed.

To determine if targeted expression of DLK induced activation of the JNK signaling, we co-immunostained for phospho-c-Jun ( $\mathrm{p}-\mathrm{c}-\mathrm{Jun}$ ) and Calbindin on cerebellar tissues of P6 mice. While many $p$-c-Jun signals were likely from granule neurons as they did not overlap with Calbindin ${ }^{+}$Purkinje cells in both mutant and control mice, we observed that DLK activation induced substantially increased p-c-Jun in Purkinje cells of $\mathrm{PV}^{\mathrm{Cre} /+} ; \mathrm{DI} \mathrm{k}^{\mathrm{iOE} / \mathrm{+}}$ mice, 
compared to littermate controls (Figure $3 \mathrm{~A}-\mathrm{B}$ ). We also asked if the loss of Purkinje cells involved apoptosis using the TUNEL assay. During early postnatal cerebellar development, multiple types of cells undergo apoptosis, including those in the granular and the molecular layers of the cerebellar cortex (Cheng et al., 2011). Indeed, in the control littermates, we observed many TUNEL signals at P5, which decreased over the following postnatal days (Figure 3-figure supplement $1 \mathrm{~A}-\mathrm{B}$ ). In the $\mathrm{PV}^{\mathrm{Cre} /+} ; \mathrm{DI} \mathrm{k}^{\mathrm{iOE} / \mathrm{+}}$ mice, the number of apoptotic cells at P5 was comparable to that in control, but continued to rise over the next 10 days, reaching peak levels around P15 (Figure 3-figure supplement 1 A-B). Importantly, some TUNEL signals detected in $\mathrm{P} 15 \mathrm{PV}^{\mathrm{Cre} /+} ; \mathrm{DI}^{\mathrm{iOE/+}}$ mice co-localized with tdTomato-labeled Purkinje cells (Figure 3-figure supplement $1 \mathrm{C}$ ). Furthermore, a significant portion of the Purkinje cells in the $\mathrm{P} 15 \mathrm{PV}^{\mathrm{Cre} /+} ; \mathrm{DI}^{\mathrm{iOE/+}}$ mice were positively stained for cleaved (and thus activated) caspase-3 (Figure 3 C-D), a molecular marker for apoptosis (Elmore, 2007). Collectively, these results show that elevating DLK expression in Purkinje cells activates the JNK pathway and causes early-onset, rapid degeneration through apoptotic cell death.

\section{DLK activation disrupts dendritic cytoskeleton}

DLK is known to be localized to neuronal processes (Suenaga et al., 2006) and regulates microtubule stability (Simard-Bisson et al., 2017; Valakh et al., 2015; Hirai et al., 2011). We performed immunostaining using anti-DLK antibodies on cerebellar section of $P V^{\mathrm{Cre} /+} ; D / k^{\mathrm{iOE} /+}$ mice and detected DLK expression in the somas, dendrites and axons of Purkinje cells (Figure 3-figure supplement 2). In these mice, a substantial portion of Purkinje cells, as visualized by Calbindin, showed dendrite swelling (Figure $3 \mathrm{C}, \mathrm{E}$ ). Moreover, $\sim 65 \%$ of Purkinje cells that were positively stained for cleaved caspase- 3 showed dendrite swelling (Figure 3 F). The percentage of Purkinje cells with dendrite swelling was highest around P15 (Figure $3 \mathrm{E}$ ), consistent with the time course of Purkinje cell death caused by increased DLK expression.

Dendrite swelling is associated with major disorganization of the cytoskeleton network (Cupolillo et al., 2016; Liu et al., 2015; Hoskison et al., 2007). We next assessed how the microtubule cytoskeleton was altered by immunostaining for microtubule-associated protein 2 (MAP2), which is expressed in dendrites of Purkinje cells (Dehmelt and Halpain, 2005). We found that MAP2 levels were significantly decreased in dendrites of Purkinje cells in $\mathrm{PV}^{\mathrm{Cre} /+} ; D / \mathrm{k}^{\mathrm{iOE} /+}$ mice, compared to the levels of Calbindin as well as to control mice at P15 (Figure $3 \mathrm{G}$ ). The neurofilament protein NF-200 is present in both dendrites and axons and implicated in axon growth and regeneration (Wang et al., 2012). By immunostaining, we observed decreased levels of NF-200 in axons and dendrites of Purkinje cells in $\mathrm{PV}^{\mathrm{Cre} / \mathrm{+}} ; \mathrm{DI} \mathrm{k}^{\mathrm{iOE} / \mathrm{+}}$ mice (Figure $3 \mathrm{H}$ ). Together, these data are consistent with the notion that 
DLK regulates the neuronal cytoskeleton, and further suggest that the dendritic cytoskeleton in Purkinje cells is highly susceptible to disruption upon aberrant activation of DLK.

\section{Elevating LZK expression in Purkinje cells causes progressive degeneration}

In contrast to the early lethality of $P V^{\mathrm{Cre/+}} ; D I k^{\mathrm{iOE} /+}$ pups, the $P V^{\mathrm{Cre} /+} ; L z k^{\mathrm{iOE} /+}$ mice survived to older adults (observed up to 8 months). The adult mice had low body weight, compared to control mice (Figure 4-figure supplement $1 \mathrm{~A}-\mathrm{B}$ ). Histological analysis showed the presence of all lobular structures in $\mathrm{P} 120 \mathrm{PV}^{\mathrm{Cre} /+} ; \mathrm{LzK}^{\mathrm{iOE/+}}$ mice (Figure 4-figure supplement $1 \mathrm{C}$ ).

Calbindin immunostaining revealed morphological abnormalities of Purkinje cells around P15, with severity and cell loss increasing from P21 to P120 (Figure 4 A-B). The area of cerebellum and the molecular layer were also reduced significantly (Figure 4 C-D).

Intriguingly, we detected a stronger fluorescence intensity of tdTomato and LZK immunostaining in the anterior cerebellum (Figure $4 \mathrm{E}$; Figure 4-figure supplement $1 \mathrm{D}-\mathrm{E}$ ), reminiscent to a previous report that $P V^{\text {Cre }}$ can induce higher levels of transgene expression in anterior than posterior cerebellum (Asrican et al., 2013). Correlating with the expression levels of LZK, there were more Purkinje cells with severe abnormal cell morphology in the anterior cerebellum than the posterior (Figure $4 \mathrm{E}$ ). Reduced MAP2 levels were also more noticeable in Purkinje cells located in the anterior than those in the posterior cerebellum (Figure 4 E). Additionally, GFAP staining showed significantly increased astrocyte reactivity in $P V^{\mathrm{Cre} /+} ; \mathrm{Lz} \mathrm{K}^{\mathrm{OOE} / \mathrm{+}}$ mice from $\mathrm{P} 21$ (Figure 4-figure supplement $2 \mathrm{~A}-\mathrm{B}$ ), particularly in areas surrounding Purkinje cells (Figure 4-figure supplement $2 \mathrm{C}$ ).

We addressed whether Purkinje cell degeneration caused by LZK involved JNK activation and induction of apoptosis. While no detectable p-c-Jun was observed in Purkinje cells of P90 control mice, LZK activation increased p-c-Jun in Purkinje cells (Figure 4 F). Cleaved caspase-3 immunoreactivity co-localized with Purkinje cells in $\mathrm{PV}^{\mathrm{Cre} /+} ; \mathrm{Lzk}^{\mathrm{iOE} /+}$ mice, but not in control mice (Figure $4 \mathrm{G}-\mathrm{H}$ ). Thus, while elevating LZK expression triggers JNK activation and caspase mediated apoptosis, Purkinje cells undergo a slow degeneration process. These data suggest differential regulation of the signaling network induced by DLK and LZK activation.

\section{Purkinje cell degeneration induced by LZK overexpression is attenuated by loss of CELF2, a regulator of $M k k 7$ alternative splicing}

Biochemical studies have shown that two MAP2K, MKK4 and MKK7 act downstream of DLK and LZK to activate JNK (Hirai et al., 2011; Le Pichon et al., 2017; Huang et al., 2017; Ikeda et al., 2001a; Chen et al., 2016b; Ikeda et al., 2001b; Holland et al., 2016; Merritt et al., 1999). However, in vivo evidence for how each MAP2K contributes to DLK and LZK induced signal transduction cascade in neurons is limited (Yang et al., 2015). Recent studies of T-cell 
activation have reported that the activity of MKK 7 is regulated through alternative splicing of its exon 2, which encodes a small peptide within the JNK docking site in MKK7 (Martinez et al., 2015) (Figure 5-figure supplement 1 A). During T-cell activation, the RNA splicing factor CELF2 promotes skipping of this exon, favoring the production of a short isoform of MKK7 that has high potency to activate JNK (Martinez et al., 2015; Ajith et al., 2016).

To test if this regulation of $M k k 7$ alternative splicing has functional significance in neurons, we generated $P V^{C r e /+} ; C e l f 2^{f / f / l} ; D I k^{i O E /+}$ and $P V^{C r e /+} ; C e l f 2^{f / / f l} ; L z k^{i O E /+}$ mice, along with $\mathrm{PV}^{\mathrm{Cre} / \mathrm{+}}$;Celf2 $2^{\mathrm{flft}}$ control mice (Figure 5 -figure supplement $1 \mathrm{C}$ ). By gross animal appearance and morphology of Purkinje cells, $\mathrm{PV}^{\mathrm{Cre} /+} ;$ Celf ${ }^{f / f t}$ mice were indistinguishable from control mice $P V^{\text {Cre/t }}$ or Celf2 ${ }^{f / f f}$ (Figure 5-figure supplement $1 \mathrm{D}-\mathrm{H}$ ). Purkinje cell degeneration

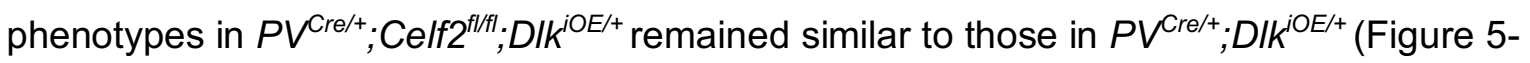
figure supplement $1 \mathrm{D}-\mathrm{F}$ ). Deletion of Celf2 did not alter the levels of DLK (Figure 5-figure supplement $1 \mathrm{I}$ ), nor the induction of p-C-Jun (Figure 5-figure supplement $1 \mathrm{~J}-\mathrm{L}$ ). All pups of $\mathrm{PV}^{\mathrm{Cre} /{ }^{+}} ;$Celf2 ${ }^{\mathrm{f} / \mathrm{fl} /} ; \mathrm{DI}^{\mathrm{iOE/+}}$ had smaller cerebellum (Figure 5 -figure supplement $1 \mathrm{G}$ ), showed morbidity and low body weight (Figure 5-figure supplement $1 \mathrm{H}$ ), and died around P21.

In contrast, $\mathrm{PV}^{\mathrm{Cre} /+} ; \mathrm{Celf2} 2^{\mathrm{fl/fl} ;}: \mathrm{Lzk}^{\mathrm{iOE/+}}$ mice showed significantly improved composite behavioral phenotypes, compared to $\mathrm{PV}^{\mathrm{Cre} /+} ; \mathrm{Lzk}^{\mathrm{iOE/+}}$ from P30 to P120 (Figure $5 \mathrm{~A}-\mathrm{E}$ ), although the reduced body weight remained in $\mathrm{PV}^{\mathrm{Cre} /+} ; \mathrm{Celf2}{ }^{\mathrm{fl/fl}} ; \mathrm{Lzk}^{\mathrm{iOE/+}}$ mice (Figure $5 \mathrm{~F}$ ). At the cellular level, Celf2 deletion dramatically reduced Purkinje cell degeneration induced by LZK, with significant improvement in the dendrite morphology at P120 (Figure 5 G-J). Celf2 deletion also significantly inhibited astrogliosis and microgliosis in P120

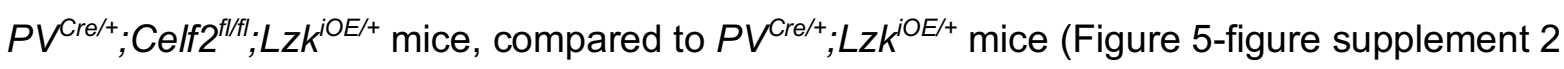
A-D). We detected a few cases where microglia appeared to contain dying Purkinje cells in $P V^{\mathrm{Cre} /+} ; \mathrm{LzK}^{\mathrm{iOE} /+}$ mice but not in $P V^{\mathrm{Cre} /+} ; \mathrm{Celf} 2^{\mathrm{fl/fl} ;} ; \mathrm{Lz}^{\mathrm{iOE} /+}$ mice (Figure 5-figure supplement $2 \mathrm{C}$ ). Consistent with the suppression on Purkinje cell degeneration, Celf2 deletion also rescued the reduction of MAP2 and NF-200 in the molecular layer of cerebellum caused by LZK activation (Figure 5-figure supplement $3 \mathrm{~A}-\mathrm{B}$ ). Additionally, immunostaining to parvalbumin and neurofilament enabled the visualization of the basket cells, which form specialized structures, the pinceau, onto the axon initial segment (AIS) of Purkinje cells. In

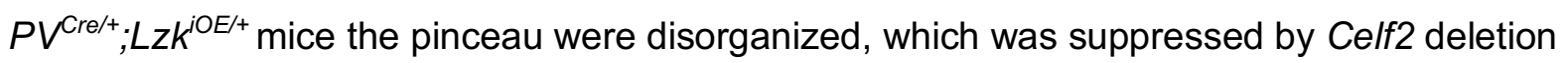
(Figure 5-figure supplement $3 \mathrm{~B}-\mathrm{C}$ ).

To address whether CELF2 was involved in LZK signaling in Purkinje cells, we examined Mkk7 exon 2 splicing. By qRT-PCR analysis we detected that Celf2 deletion reduced the ratio of mRNA of the short isoform (Mkk7-S) to the long isoform (Mkk7-L) by

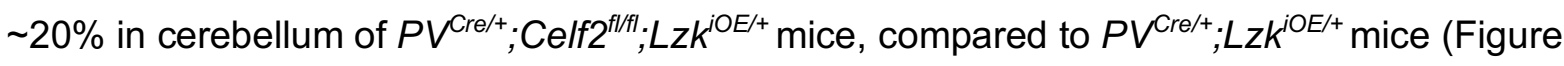
5 -figure supplement $1 \mathrm{~B}$ ). The overall expression levels of $L Z K$ in cerebellum were not altered by Celf2 deletion (Figure 6-figure supplement 1 A-B). We then immunostained for $p$ - 
c-Jun in cerebellum of P120 mice. LZK overexpression induced p-c-Jun in most of Purkinje cells, and Celf2 deletion significantly attenuated the intensity of p-c-Jun in Purkinje cells of

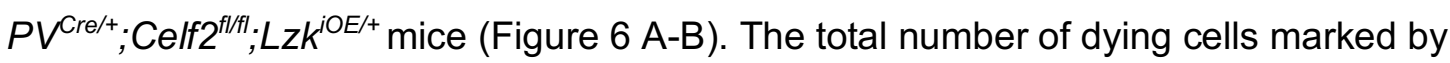
TUNEL signals in $\mathrm{PV}^{\mathrm{Cre} /+} ;$ Celf ${ }^{f / f / l} ; \mathrm{Lzk}^{\mathrm{iOE} /+}$ mice cerebellum was significantly reduced, compared to that in $\mathrm{PV}^{\mathrm{Cre} /+} ; \mathrm{Lzk}^{\mathrm{iOE} /+}$ mice (Figure 6-figure supplement $1 \mathrm{D}-\mathrm{E}$ ). A few TUNEL signals (approximately one cell / section) were co-localized with tdTomato-labeled Purkinje cells in $\mathrm{PV}^{\mathrm{Cre} /+} ; \mathrm{Lzk}^{\mathrm{iOE} /+}$ mice, but not in $\mathrm{PV}^{\mathrm{Cre} /+} ; \mathrm{Celf2}{ }^{\mathrm{fl/fl}} ; \mathrm{LzK}^{\mathrm{iOE} /+}$ mice (Figure 6-figure supplement $1 \mathrm{~F}$ ). Cleaved caspase- 3 signals were rarely detected in Purkinje cells of

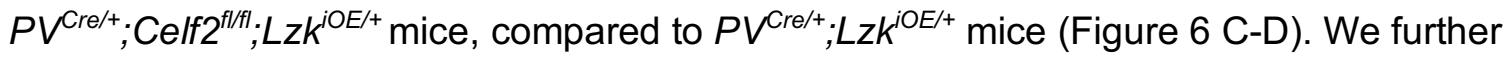
assessed expression levels of Bcl-xL (B-cell lymphoma-extra Large), which as a full-length protein prevents caspase activation, but the cleaved product promotes apoptosis (Gross et al., 1999). Western blot analysis of cerebellar protein extracts from P21 mice when minimal Purkinje cell degeneration was detected in $P V^{\mathrm{Cre} /+} ; \mathrm{LzK}^{\mathrm{iOE} /+}$ showed increased pro-apoptotic cleavage products of $\mathrm{Bcl}-\mathrm{xL}$, compared to control samples (Figure 6-figure supplement $1 \mathrm{~A}$, C). All together, these data support a conclusion that Celf2 deletion attenuates LZK-induced JNK signaling, and provide in vivo evidence that MKK7 is a functional mediator of LZK signaling in Purkinje cells.

\section{DLK and LZK can induce Purkinje cell degeneration independent of each other}

DLK and LZK have a nearly identical kinase domain, and are reported to bind and be coimmunoprecipitated from mouse brain (Pozniak et al., 2013). Recent studies have shown that in injured RGCs or DRGs the two kinases may have redundant or synergistic interactions (Welsbie et al., 2017; Summers et al., 2020). We next addressed whether the Purkinje cell degeneration caused by elevating DLK or LZK activity depends on the presence

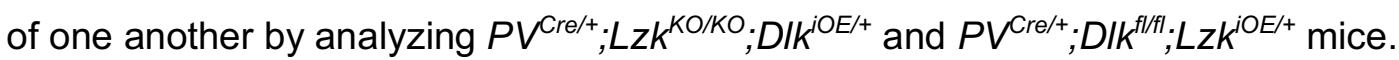

In $P V^{\mathrm{Cre} /+} ; \mathrm{LZK}^{\mathrm{KO} / K O} ; D I \mathrm{~K}^{\mathrm{iOE} /+}$ mice, Purkinje cell degeneration and astrogliosis proceeded temporally and spatially similar to that of $\mathrm{PV}^{\mathrm{Cre} /+} ; \mathrm{DIk}^{\mathrm{iOE} /+}$ (Figure $7 \mathrm{~A}-\mathrm{E}$ ). The elevated $\mathrm{p}$-C-Jun levels in Purkinje cells in $\mathrm{PV}^{\mathrm{Cre} /+} ; D / k^{\mathrm{OOE} /+}$ mice at $\mathrm{P} 10$ were not affected by deleting $L z k$ (Figure 7-figure supplement $1 \mathrm{~A}-\mathrm{B}$ ). All pups of $P \mathrm{~V}^{\mathrm{Cre} /+} ; \mathrm{Lzk}^{\mathrm{KO} / \mathrm{KO}} ; \mathrm{DI} \mathrm{k}^{\mathrm{iOE} /+}$ died by $\mathrm{P} 21$. Conversely, the $P V^{\mathrm{Cre} /+} ; D I k^{\mathrm{flff} ;} ; L z k^{\mathrm{iOE/+}}$ mice resembled $P V^{\mathrm{Cre} /+} ; L z k^{\mathrm{iOE} /+}$ mice in the progressive degeneration of Purkinje cells. Both $P V^{\mathrm{Cre} /+} ; D I k^{\mathrm{flfl} l} ; L z k^{\mathrm{iOE} /+}$ and $P V^{\mathrm{Cre} /+} ; L z k^{\mathrm{iOE} /+}$ mice had low body weight (Figure 7-figure supplement $1 \mathrm{C}$ ) and small cerebellum area at P60 (Figure $7 \mathrm{I}$ ), compared to control mice. Immunostaining with Calbindin and GFAP antibodies showed that removing DIk did not alter Purkinje cell degeneration or astrogliosis caused by LZK expression (Figure $7 \mathrm{~F}, \mathrm{H}, \mathrm{J}$ ). The levels of $\mathrm{p}$-c-Jun induced by LZK expression in Purkinje cells remained comparable, with or without endogenous DLK (Figure 7-figure supplement 1 
D-E). Together, these data show that targeted activation of each kinase induces Purkinje cell degeneration largely independent of each other.

\section{Discussion}

In this study, we have used cerebellar Purkinje cells to gain a systematic understanding of the function of DLK and LZK, two closely related kinases that have emerged as key players in neural protection under injury and disease (Adib et al., 2018; Jin and Zheng, 2019; Farley and Watkins, 2018). We employed both conditional KO and transgenic mouse models to manipulate levels of DLK and LZK expression. We find that while deleting one or both kinases in Purkinje cells postnatally did not affect neuronal development and animal health, activating DLK or LZK, through elevating their expression, causes Purkinje cell degeneration. Our Cre-inducible DLK and LZK transgenes have the same design and are inserted in the same $\mathrm{H} 11$ locus to avoid position effect on transgene expression. Despite the similarly targeted transgenes, we found that DLK elevation triggers rapid degeneration of Purkinje cells, while LZK elevation causes slow degeneration. Each kinase activates JNK signaling, measured by increased phosphorylated c-Jun, and induces apoptosis. Each kinase can induce neuron degeneration in the absence of the other. Importantly, we show that deletion of Celf2 strongly attenuates Purkinje cell degeneration caused by LZK, but not DLK, activation, providing further evidence for a signaling pathway-specific effect for each kinase activation rather than a generic, secondary effect of overexpressing any kinase. As Purkinje cells and cerebellum are not essential for animal viability, we interpret that the lethality of $P V^{\mathrm{Cre} /+} ; D I k^{\mathrm{iOE} /+}$ pups is likely due to disruption of other parvalbumin-expression neurons, with the underlying basis remaining to be addressed in future studies. All together, these data demonstrate the utility of our transgenic mice for dissecting cell-type specific roles of these kinases and their signaling pathways.

DLK and LZK share a kinase domain that is $~ 90 \%$ identical and can activate the JNK signaling pathway through two MAPKK, MKK4 or MKK7 (Hirai et al., 2011; Le Pichon et al., 2017; Huang et al., 2017; Ikeda et al., 2001a; Chen et al., 2016b; Ikeda et al., 2001b; Holland et al., 2016; Merritt et al., 1999). Several studies have supported MKK4 as a major mediator for DLK in RGCs and DRGs (Yang et al., 2015). Currently, little is known which MAPKK mediates LZK signaling. Our data show that DLK activation in Purkinje cells leads to robust JNK signaling, compared to LZK activation. The observation that Celf2 deletion did not affect any phenotypes caused by DLK activation could be due to a combination of the strong JNK activation and the rapid time course of cell death. In contrast, deletion of CELF2 significantly reduced the activation of c-Jun and almost completely rescued the Purkinje cell degeneration caused by LZK activation. These data are consistent with the role of Celf2 in 
regulating alternative splicing of $M k k 7$ (Martinez et al., 2015), and support that MKK7 is a functional downstream kinase for LZK in vivo.

Numerous studies have revealed roles of DLK in axon growth, regeneration and/or degeneration (Tedeschi and Bradke, 2013; Jin and Zheng, 2019). However, not much is known about roles of LZK in neurons. Our data show that LZK activation decreased neurofilament levels in the molecular layer of cerebellum and caused disorganization of the pinceau at the axon initial segment of Purkinje cell. DLK is known to regulate microtubule stability (Simard-Bisson et al., 2017; Valakh et al., 2015; Hirai et al., 2011), and several microtubule-associated proteins such as SCG10, DCX and MAP2 are JNK substrates (Chang et al., 2003; Gdalyahu et al., 2004; Tararuk et al., 2006; Björkblom et al., 2005). We find that both DLK and LZK overexpression significantly decreased MAP2 levels in dendrites

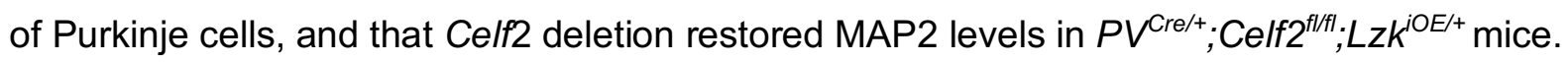
In addition, DLK activation caused dendrite swelling of Purkinje cells, and many of the swollen dendrites also had cleaved caspase-3 signals. Activated caspase- 3 in dendrites has been shown to cause cleavage of microtubules and local pruning of dendrites and spines (Ertürk et al., 2014; Khatri et al., 2018). These data are consistent with known roles of JNK regulation of microtubule associated proteins.

Taken together, our findings indicate that DLK-induced signal transduction cascade triggers a strong response under injury or other stress, while LZK induces modest activation of JNK and apoptosis, which may manifest in chronic neurodegenerative diseases. Besides the kinase domain and leucine-zipper domain, both MAP3Ks have large uncharacterized Cterminus, which may play significant roles in regulating the signaling strength of each protein. There is mounting evidence in the literature on the upregulation of the DLK and LZK signaling pathway in CNS injury and neurodegeneration (Watkins et al., 2013; Welsbie et al., 2013; Joy et al., 2019; Chen et al., 2008; Le Pichon et al., 2017; Huang et al., 2017; Chen et al., 2018), indicating that altered signaling of this pathway may be a prevalent feature in CNS injury and diseases. Along this line, genetic studies of DLK in both invertebrate and vertebrate species revealed prominent developmental defects with DLK activation rather than inactivation (Zhen et al., 2000; Schaefer et al., 2000; Wan et al., 2000; Grill et al., 2016). As DLK and LZK activity exhibits high cell-type and context-dependent specificity, our transgenic mice offer valuable gain of function models to study their signaling pathways with the ease for temporal and spatial manipulation. The knowledge learned will advance our understanding of how diverse neuronal types respond to insults to the nervous system. 


\section{Materials and methods}

\section{Mice}

All animal protocols were approved by the Animal Care and Use Committee of the University of California San Diego. Wild-type C57BL/6J mice and PV Cre mice (Stock No: 017320) were purchased from The Jackson Laboratory.

Lzk knockout mice were generated in the UCSD Transgenic and Knockout Mouse Core, using CRISPR-Cas9 technology (Ran et al., 2013). Briefly, sgRNA sequences targeted to the kinase domain were designed using online tools (http://crispr.mit.edu) (Table 1). The selected sgRNAs were annealed, and then cloned into PX330 backbone digested with Bbsl. Effectiveness of sgRNAs was tested using Surveyor nuclease assay (Surveyor Mutation Detection Kit, IDT, 706020). To make sgRNAs, DNA fragments containing T7 promoter followed by sgRNA were first amplified using primers YJ12532-12535. The purified DNAs were then in vitro transcribed using MEGAscript T7 Transcription Kit (Invitrogen, AMB13345), and the resulting transcripts were purified using MEGAclear-96 Transcription Clean-Up Kit (Invitrogen, AM1909). The sgRNAs and Cas9 mRNA were injected into zygotes from C57BL6, which were then implanted into the CD1 surrogate mothers. Two KO mouse lines were obtained and the one containing a deletion of the entire kinase domain was used in this study. $L z k^{f l}$ and $D I k^{f l}$ mice were reported in (Chen et al., 2016b). Dlk ${ }^{f l}$ mice were a kind gift of Dr. Lawrence B. Holzman (Univ. Penn). Celf2 ${ }^{f l}$ mice were described previously (Chen et al., 2016a). Primers for genotypes are listed in Table 2.

Transgenic conditional overexpressing $D I k^{i O E}$ and $L z k^{i O E}$ mice were made by Applied StemCell, Inc (Milpitas, CA), using TARGATT ${ }^{\mathrm{TM}}$ Technology (Tasic et al., 2011). A mixture of plasmid pBT378-LSL-3X Flag-DIk-T2A-tdTomato, or pBT378-LSL-1X Flag-Lzk-T2AtdTomato DNA, and in vitro transcribed $\phi C 31$ integrase mRNA was microinjected into the pronucleus of zygotes from a FVB strain that has the Att recombination landing site inserted in $H 11$ locus, which were then implanted into the CD1 surrogate mothers. The founder heterozygous mice were bred three times to pure C57BL/6J background.

\section{Histology and immunocytochemistry}

Mice were transcardially perfused with $0.9 \%$ saline solution and then $4 \%$ paraformaldehyde (PFA) in phosphate-buffered saline (PBS) ( $\mathrm{pH}$ 7.2-7.4). Brains were dissected, post-fixed in $4 \%$ PFA overnight at $4^{\circ} \mathrm{C}$, and then transferred to $30 \%$ sucrose in PBS, prior to embedding using O.C.T compound (Fisher Healthcare, 4585) on dry ice. $25 \mu \mathrm{m}$ thick sagittal sections were collected on a cryostat (Leica, CM1850) into PBS with $0.01 \% \mathrm{NaN}_{3}$. For histology analysis, free floating tissue sections were loaded to the slide, and then sequentially stained with hematoxylin and eosin (H\&E staining Kit, abcam, ab245880). For immunostaining, free floating tissue sections were washed twice in PBS with $0.2 \%$ Triton X-100, blocked with $5 \%$ 
goat serum in PBS with $0.4 \%$ Triton X-100 for 2 hours at room temperature, then incubated with primary antibodies (Table 3 ) diluted in PBS with $0.2 \%$ Triton $\mathrm{X}-100$ and $2 \%$ goat serum overnight at $4{ }^{\circ} \mathrm{C}$. Alexa Fluor 488 -conjugated and Alexa Fluor 647 -conjugated secondary antibodies (Invitrogen) were incubated for 2 hours at room temperature, followed by staining with DAPI (14.3 $\mu \mathrm{M}$ in PBS, Thermo Fisher Scientific, D1306) for $10 \mathrm{~min}$. Stained sections were mounted with prolong diamond antifade mountant (Thermo Fisher Scientific, P36970).

\section{TUNEL staining}

The DeadEnd Fluorometric TUNEL System (Promega, G3250) was used with a modified protocol. Free floating tissue sections were washed twice in PBS, and then loaded to the slide. The slides were dried at $65^{\circ} \mathrm{C}$ for $5 \mathrm{~min}$, then immersed into PBS with $0.5 \%$ Triton X100 and incubated at $85^{\circ} \mathrm{C}$ for $20 \mathrm{~min}$, followed by three times rinsing with PBS. The slides were incubated with equilibration buffer at room temperature for $5 \mathrm{~min}$, and then incubated with reaction mix (equilibration buffer: nucleotide mix: $r T d T$ enzyme $=45: 5: 1$ ) at $37^{\circ} \mathrm{C}$ for 1 hour in a humidity chamber. The reactions were stopped by incubating the slide with $2 \mathrm{X}$ saline-sodium citrate (SSC) buffer at room temperature for $10 \mathrm{~min}$. After three washes with PBS, the slides were incubated with DAPI (14.3 $\mu \mathrm{M}$ in PBS) at room temperature for 15 min, followed by three washes with $\mathrm{ddH}_{2} \mathrm{O}$, and then mounted with prolong diamond antifade mountant (Thermo Fisher Scientific, P36970).

\section{Image acquisition and analysis}

The slides of H\&E staining were scanned with Nanozoomer 2.0-HT digital slide scanner (Hamamatsu) in brightfield at 20X magnification. The images were processed using NDP.view2 Viewing software (Hamamatsu) and ImageJ software (NIH). Fluorescence images of paired WT and mutant samples were acquired on a Zeiss LSM 710 confocal microscope. The images were taken as Z-stack under identical settings, and the maximum intensity projection images were processed using ImageJ software $(\mathrm{NIH})$. For image quantification, three midline parasagittal sections per brain and at least 3 brains per genotype of given age were analyzed and data was averaged. Cells were counted using the cell counter plugin for ImageJ (NIH). Analyses of cell numbers for Calbindin ${ }^{+}$PCs, p-C-Jun ${ }^{+}$ PCs, dendrite swelling ${ }^{+}$PCs or cleaved caspase $-3^{+}$PCs were performed by counting the soma of each PC in the entire lobules. The thickness of the molecular layer visualized by Calbindin staining was assessed for lobule V/VI in midline sections by measuring the perpendicular distance from the molecular layer-facing edge of a Purkinje cell soma to the outer edge of the molecular layer. Cerebellum area was calculated by outlining the perimeter of the outer edges of the sagittal sections of cerebellum. TUNEL ${ }^{+}$cells were counted by analyzing particles after adjustment of threshold and watershed. The particles with area 
larger than $8 \mu \mathrm{m}^{2}$ were measured. TUNEL ${ }^{+}$cell density was calculated the number of $\mathrm{TUNEL}^{+}$cells in entire cerebellum divided by entire cerebellum area. GFAP or IBA1 immunofluorescence intensity density was calculated by dividing the GFAP or IBA1 immunofluorescence intensity of entire cerebellum by the entire cerebellum area. For p-cJun immunofluorescence intensity quantification, 50 sampling area surrounding a single $p$-cJun $^{+}$nucleus (ROI being $347.543 \mu \mathrm{m}^{2}$ ) per section were measured. For LZK immunofluorescence intensity quantification, 30 sampling area surrounding a single soma of Purkinje cells (ROI being $352.943 \mu \mathrm{m}^{2}$ ) were measured in the region of interest per section. Integrated density was averaged after subtraction of background signal and adjustment of threshold.

\section{Immunoprecipitation and western blotting}

Dissected cerebella from mice of indicated age were homogenized in an appropriate volume of cell lysis buffer (50 mM Tris.Cl (pH 7.4), 1\% Triton X-100, 0.1\% SDS, 1 mM EDTA (pH 7.0), $150 \mathrm{mM} \mathrm{NaCl}, 1 \% \mathrm{n}$-Octyl $\beta$-D-glucopyranoside, $1 \mathrm{x}$ protease inhibitor cocktail (Roche, 05892970001)) using TissueRuptor II (QIAGEN, 9002756), then lysed for 1 hour on ice, and cleared by centrifugation at $13,000 \mathrm{rpm}$ for $10 \mathrm{~min}$ at $4^{\circ} \mathrm{C}$. Supernatants were collected and protein concentrations were determined by Pierce BCA protein assay kit (Thermo Fisher Scientific, 23225). For immunoprecipitation experiments, antibody-bound beads were prepared using $2 \mu \mathrm{g}$ rabbit anti-MAP3K13 polyclonal antibody (Sigma-Aldrich, HPA016497) in $800 \mu \mathrm{l}$ of lysis buffer with $50 \mu \mathrm{l}$ of $50 \%$ Protein G agarose bead slurry, with gentle rotation at $4^{\circ} \mathrm{C}$ for 1 hour. $\sim 1 \mathrm{mg}$ protein lysates were pre-cleared with $50 \mu \mathrm{l}$ of $50 \%$ Protein $\mathrm{G}$ agarose bead slurry, then incubated with the antibody-bound beads overnight at $4^{\circ} \mathrm{C}$. The beads were washed three times with lysis buffer, and then resuspended in $60 \mu$ lysis buffer and $20 \mu \mathrm{l} 4 \mathrm{x}$ Laemmli Sample Buffer (Bio-RAD, 161-0747), heat shocked in a thermomixer (Eppendorf) at $95^{\circ} \mathrm{C}$ for $10 \mathrm{~min}$ and analyzed by western blotting. Immunoprecipitated samples were separated by SDS-PAGE using Any kD Mini-PROTEAN TGX Precast Protein Gels (Bio-Rad, 4569034), and then blotted to a PVDF membrane $(0.2 \mu \mathrm{m}$, Bio-RAD, 1620177) by Mini Trans-Blot Cell (Bio-RAD, 170-3930) at $100 \mathrm{~mA}$ for 1 hour. Blots were blocked in 10\% non-fat dry milk in PBST (PBS with 0.05\% Tween-20) for 1 hour at room temperature, and then incubated with an appropriate concentration of primary antibody in $1 \%$ non-fat BSA in PBST at $4^{\circ} \mathrm{C}$ for overnight. Afterwards, the membrane was incubated with Horseradish Peroxidase (HRP)-conjugated secondary antibody (GE healthcare, NXA931V or NA934V) in 1\% non-fat BSA in PBST at room temperature for 1 hour, followed by detection using enhanced chemiluminescence (ECL) reagents (GE Healthcare, RPN2106).

\section{RNA extraction, RT-PCR and qRT-PCR}


Total RNA from mouse cerebellum was extracted using TRIzol (Invitrogen, 15596018) following the manufacturers' protocols. First strand cDNA was reverse-transcribed using SuperScript IV (Invitrogen, 18091050). qPCR was run on Bio-Rad CFX96 Touch Real-Time PCR Detection System with iQ SYBR Supermix (Bio-Rad, 170-8882). Data were analyzed using CFX manager (Bio-Rad).

\section{Animal behavior tests}

Mouse behavioral analysis was scored in a genotype blind manner following the protocol described in (Guyenet et al., 2010). Briefly, ledge walking, hind limb clasping, gait, and kyphosis were scored with a scale of 0-3 in each category, resulting in total score of 0-12 points for all four measures at P30, P45, P60, P75, P90, P105 and P120. A score of 0 represents absence of the relevant phenotype and 3 represents the most severe phenotype. Each test was performed 3 times to ensure reproducibility. For data analysis, the score was calculated for each measure by taking the mean of the three measurements in each mouse.

\section{Statistics}

GraphPad Prism 6.0 (GraphPad Software, Inc) was used for all statistical analysis. After assessing for normal distribution, statistical analyses between two groups were calculated with the two-tailed t-test for normally distributed data. For comparison of more than two groups, normally distributed data was calculated with a one-way ANOVA. Asterisks indicate significance with (*) $\mathrm{P}<0.05,\left(_{(*)} \mathrm{P}<0.01,{ }_{(* *)} \mathrm{P}<0.001,\left({ }_{(* * *)} \mathrm{P}<0.0001\right.\right.$ for all data sets. Graphs show mean values \pm standard error of the mean (SEM). 


\section{Acknowledgements}

We are grateful to our lab members for valuable discussions. We thank Drs. A. D. Chisholm, S. L. Ackerman and G. Thomas for comments on the manuscript. We thank Dr. L. Holzman (U. Penn) for providing DI $k^{f l}$ mice, UCSD Transgenic and Knockout Mouse Core for generating $L z k^{K O}$ mice, and UCSD Neuroscience Microscopy Shared Facility (NS047101) for providing imaging support. We thank A. Moore, E. Xu, D. Arakelyan and R. Zarei for technical assistance. This work was partly supported by funds from Howard Hughes Medical Institute, the Craig H. Neilsen Foundation, the Junior Seau Foundation, and the UCSD Kavli Institute of Brain and Mind.

\section{Author contributions}

Y.L., Y.J. conceived of the study and wrote the manuscript. Y.L., E.R., C.S., C.Q., L.Z. performed the experiments and data analyses. All authors contributed to writing, reviewing, editing of the manuscript.

\section{DECLARIATION OF INTERESTS}

The authors declare no competing interests. 
Table 1: sgRNA sequences used to generate LZK CRISPR KO mice

\begin{tabular}{|l|l|l|}
\hline sgRNA\# & Sequence in the genome DNA & \multirow{2}{*}{ Location } \\
\cline { 1 - 2 } sgRNA2-Fw & CACCGTGGCACTACAGGTCACATAC & \multirow{2}{*}{ intron } \\
\cline { 1 - 2 } sgRNA2-Re & AAACGTATGTGACCTGTAGTGCCAC & \\
\cline { 1 - 2 } sgRNA5-Fw & CACCGGACCTCGTACAGCTGTCCGT & \multirow{2}{*}{ exon } \\
\cline { 1 - 2 } sgRNA5-Re & AAACACGGACAGCTGTACGAGGTCC & \multirow{2}{*}{ intron } \\
\cline { 1 - 2 } sgRNA12-Fw & CACCGACTCCAGTATAGCCTCGATG & \\
\cline { 1 - 2 } sgRNA12-Re & AAACCATCGAGGCTATACTGGAGTC & \\
\cline { 1 - 2 } & &
\end{tabular}


Table 2: Primers used in this study

\begin{tabular}{|c|c|c|c|}
\hline Designation & 5'-3' & PCR Products (bp) & Purpose \\
\hline YJ12516 & CGACCTCAACTTGGATATCAGCC & \multirow{2}{*}{$\begin{array}{l}148 \text { (Mkk7-L isoform) } \\
100 \text { (Mkk7-S isoform) }\end{array}$} & \multirow[t]{2}{*}{ RT-PCR } \\
\hline YJ12517 & GGAGCTCTCTGAGGATGGTGAGC & & \\
\hline YJ12518 & GCTTCTTTGCAGCTCCTTCGT & \multirow[t]{2}{*}{201 (Actin) } & \multirow[t]{2}{*}{ RT-PCR } \\
\hline YJ12519 & CCTTCTGACCCATTCCCACC & & \\
\hline YJ12520 & TGGAGGAGGACAAACTGGTCA & \multirow{3}{*}{$\begin{array}{l}323 \text { (Wild-type) } \\
\sim 500 \text { (DIk }{ }^{\text {iOE }} \text { mutant) } \\
\sim 600 \text { (Lzk }{ }^{\text {iOE }} \text { mutant) }\end{array}$} & \multirow[t]{3}{*}{ genotyping } \\
\hline YJ12521 & TTCCCTTTCTGCTTCATCTTGC & & \\
\hline YJ12522 & $\begin{array}{l}\text { CATATATGGGCTATGAACTAATGAC } \\
\text { CCCGT }\end{array}$ & & \\
\hline YJ12523 & $\begin{array}{l}\text { GATGATTGCTAGTCATGGAGTAGT } \\
\text { AGG }\end{array}$ & \multirow[t]{2}{*}{$\begin{array}{l}350 \text { (Wild-type) } \\
500\left(\text { DIk }{ }^{f l} \text { mutant }\right)\end{array}$} & \multirow[t]{2}{*}{ genotyping } \\
\hline YJ12524 & $\begin{array}{l}\text { GGTGGTGTTATCATAGTTCCATCAT } \\
\text { G }\end{array}$ & & \\
\hline YJ12525 & $\begin{array}{l}\text { ACATCTGGATCTGAAGACAGCCAG } \\
\text { G }\end{array}$ & \multirow[t]{2}{*}{$\begin{array}{l}\text { 〜500 (Wild-type) } \\
\sim 600 \text { (Lzkl mutant) }\end{array}$} & \multirow[t]{2}{*}{ genotyping } \\
\hline YJ12526 & $\begin{array}{l}\text { AGGTGCGTTTTCATTCTTCTGGAC } \\
\mathrm{C}\end{array}$ & & \\
\hline YJ12527 & GAGGTGTCTGCCGAACT & \multirow{2}{*}{$\begin{array}{l}370 \text { (Wild-type) } \\
470 \text { (Celf2 }{ }^{f l} \text { mutant) }\end{array}$} & \multirow[t]{2}{*}{ genotyping } \\
\hline YJ12528 & CACTCAGTCCCTGTTTGTAA & & \\
\hline YJ12529 & TGGCAGTGTGGAGACAGAAG & \multirow{3}{*}{$\begin{array}{l}720 \text { (Wild-type) } \\
420 \text { (Lzk }{ }^{K O} \text { mutant) }\end{array}$} & \multirow[t]{3}{*}{ genotyping } \\
\hline YJ12530 & CCTACCTGCCTTTCCCGTTG & & \\
\hline YJ12531 & TGCTCACCTGGGATCTGACTA & & \\
\hline YJ12532 & $\begin{array}{l}\text { TTAATACGACTCACTATAGGGTGG } \\
\text { CACTACAGGTCACATAC }\end{array}$ & \multirow[t]{2}{*}{121} & \multirow[t]{2}{*}{$\begin{array}{l}\text { sgRNA2 } \\
\text { PCR }\end{array}$} \\
\hline YJ12535 & AAAAGCACCGACTCGGTGCC & & \\
\hline
\end{tabular}




\begin{tabular}{|c|c|c|c|}
\hline YJ12533 & $\begin{array}{l}\text { TTAATACGACTCACTATAGGGGAC } \\
\text { CTCGTACAGCTGTCCGT }\end{array}$ & 121 & $\begin{array}{l}\text { sgRNA5 } \\
\text { PCR }\end{array}$ \\
\hline YJ12535 & AAAAGCACCGACTCGGTGCC & & \\
\hline YJ12534 & $\begin{array}{l}\text { TTAATACGACTCACTATAGGGACTC } \\
\text { CAGTATAGCCTCGATG }\end{array}$ & 121 & $\begin{array}{l}\text { sgRNA12 } \\
\text { PCR }\end{array}$ \\
\hline YJ12535 & AAAAGCACCGACTCGGTGCC & & \\
\hline YJ12536 & GGCCCAGGCCCATTATTGTG & 83 (Mkk7-L isoform) & qRT-PCR \\
\hline YJ12537 & GTTGGCCAGTGGGAGTTGCAG & & \\
\hline YJ12538 & GCCAAGCTGAAGCAGGAGAACC & 100 (Mkk7-S isoform) & qRT-PCR \\
\hline YJ12539 & CCAGTGGGAGTTGCAGGGTG & & \\
\hline
\end{tabular}


Table 3: Antibodies used in this study

\begin{tabular}{|c|c|c|c|c|}
\hline Antibodies & Company & $\begin{array}{l}\text { Catalogue } \\
\text { Number }\end{array}$ & Usage & Figure Panels \\
\hline \multirow[t]{2}{*}{ Rabbit Anti-Map3k12 } & Sigma-Aldrich & SAB2700169 & $1: 2000$ & $\begin{array}{l}\text { 1-S1H; 2-S1E; } \\
\text { 5-S1I }\end{array}$ \\
\hline & & & $1: 250$ & $3-S 2$ \\
\hline \multirow[t]{2}{*}{ Rabbit Anti-MAP3K13 } & Sigma-Aldrich & HPA016497 & $1: 300$ & $\begin{array}{l}\text { 1-S1C; 2-S1G; } \\
\text { 6-S1A }\end{array}$ \\
\hline & & & $1: 200$ & $4-S 1 D$ \\
\hline $\begin{array}{l}\text { Mouse Anti-Actin } \\
\text { (Clone C4) monoclonal } \\
\text { antibody }\end{array}$ & $\begin{array}{l}\text { MP } \\
\text { Biomedicals }\end{array}$ & 691001 & $1: 10,000$ & $\begin{array}{l}\text { 1-S1C,H; } \\
\text { 2-S1E,G; } \\
\text { 5-S1I; 6-S1A }\end{array}$ \\
\hline $\begin{array}{l}\text { Rabbit Anti-Bcl-xL } \\
(54 \mathrm{H} 6) \mathrm{mAb}\end{array}$ & Cell signaling & 2764 & $1: 2000$ & $6-S 1 A$ \\
\hline Rabbit Anti-FLAG & Millipore & F7425 & $1: 500$ & 2-S1G; 6-S1A \\
\hline $\begin{array}{l}\text { Sheep Anti-Mouse IgG, } \\
\text { HRP-linked whole Ab }\end{array}$ & GE healthcare & NXA931V & $1: 5000$ & $\begin{array}{l}\text { 1-S1C,H; } \\
\text { 2-S1E,G; } \\
\text { 5-S1I; 6-S1A }\end{array}$ \\
\hline $\begin{array}{l}\text { Donkey Anti-Rabbit } \\
\text { IgG, HRP-linked whole } \\
\text { Ab }\end{array}$ & GE healthcare & NA934V & $1: 5000$ & $\begin{array}{l}\text { 1-S1C,H; } \\
\text { 2-S1E,G; } \\
\text { 5-S1I; 6-S1A }\end{array}$ \\
\hline Rabbit Anti-Iba1 & Wako & 01919741 & $1: 1000$ & 2-S2C; 5-S2C \\
\hline $\begin{array}{l}\text { Mouse Anti- } \\
\text { Neurofilament } 200\end{array}$ & Sigma-Aldrich & N0142 & $1: 200$ & $3 \mathrm{H} ; 5-\mathrm{S} 3 \mathrm{~B}$ \\
\hline
\end{tabular}




\begin{tabular}{|c|c|c|c|c|}
\hline $\begin{array}{l}\text { (Phos. and Non-Phos.) } \\
\text { monoclonal antibody }\end{array}$ & & & & \\
\hline $\begin{array}{l}\text { Rabbit Anti-Phospho-c- } \\
\text { Jun (Ser73) (D47G9) } \\
\text { XP mAb }\end{array}$ & Cell signaling & 3270 & $1: 200$ & $\begin{array}{l}\text { 3A; 6A; 5-S1J; } \\
\text { 7-S1A,D }\end{array}$ \\
\hline $\begin{array}{l}\text { Rabbit Anti-Cleaved } \\
\text { Caspase-3 (Asp175) }\end{array}$ & Cell signaling & 9661 & $1: 200$ & $3 C ; 6 C$ \\
\hline $\begin{array}{l}\text { Rabbit Anti-Calbindin } \\
\text { (D1/4Q) XP mAb }\end{array}$ & Cell signaling & 13176 & $1: 500$ & $\begin{array}{l}\text { 1B; 2D; 3G,H; } \\
\text { 4A,E; 5G; 7A,F; } \\
\text { 4-S2C; 5-S1D; } \\
\text { 5-S3A,B }\end{array}$ \\
\hline $\begin{array}{l}\text { Mouse Anti-Calbindin } \\
\text { D-28k monoclonal } \\
\text { antibody }\end{array}$ & Swant & 300 & $1: 500$ & $\begin{array}{l}\text { 3A,C; 4F,G; } \\
\text { 6A,C; 5-S1J; } \\
\text { 5-S2C; 7-S1A,D }\end{array}$ \\
\hline $\begin{array}{l}\text { Rat Anti-GFAP } \\
(2.2 B 10) \text { monoclonal } \\
\text { antibody }\end{array}$ & $\begin{array}{l}\text { Thermo Fisher } \\
\text { Scientific }\end{array}$ & $13-0300$ & $1: 500$ & $\begin{array}{l}\text { 7A,F; 1-S1I; } \\
\text { 2-S2D; } \\
\text { 4-S2A,C; 5-S2A }\end{array}$ \\
\hline Chicken Anti-MAP2 & Abcam & ab5392 & $1: 500$ & 3G; 4E; 5-S3A \\
\hline $\begin{array}{l}\text { Guinea pig Anti- } \\
\text { Parvalbumin antiserum }\end{array}$ & $\begin{array}{l}\text { Synaptic } \\
\text { systems }\end{array}$ & 195004 & $1: 500$ & 2-S1D; 5-S3C \\
\hline $\begin{array}{l}\text { Goat Anti-Mouse IgG } \\
(\mathrm{H}+\mathrm{L}) \text { secondary } \\
\text { antibody Alexa Fluor } \\
647\end{array}$ & Invitrogen & A21236 & $1: 500$ & $\begin{array}{l}\text { 3A,C; 4F,G; } \\
\text { 6A,C; 5-S1J; } \\
\text { 7-S1A,D }\end{array}$ \\
\hline $\begin{array}{l}\text { Goat Anti-Guinea Pig } \\
\text { lgG }(\mathrm{H}+\mathrm{L}) \text { secondary } \\
\text { antibody Alexa Fluor } \\
488\end{array}$ & Invitrogen & A11073 & $1: 500$ & 2-S1D; 5-S3C \\
\hline
\end{tabular}




\begin{tabular}{|c|c|c|c|c|}
\hline $\begin{array}{l}\text { Goat Anti-Rabbit IgG } \\
(\mathrm{H}+\mathrm{L}) \text { secondary } \\
\text { antibody Alexa Fluor } \\
488\end{array}$ & Invitrogen & A11008 & $1: 500$ & $\begin{array}{l}\text { 1B; 2D; 3A,C,G; } \\
\text { 4A,E,F,G; 5G; } \\
\text { 6A,C; 2-S2C; } \\
\text { 3-S2; 4-S1D; } \\
\text { 5-S1D,J; 5-S3A; } \\
\text { 7-S1A,D }\end{array}$ \\
\hline $\begin{array}{l}\text { Goat Anti-Rabbit IgG } \\
(\mathrm{H}+\mathrm{L}) \text { secondary } \\
\text { antibody Alexa Fluor } \\
647\end{array}$ & Invitrogen & A21245 & $1: 500$ & $\begin{array}{l}\text { 3H; 7A,F; 4-S2C; } \\
5-S 2 C ; 5-S 3 B\end{array}$ \\
\hline $\begin{array}{l}\text { Goat Anti-Mouse IgG } \\
(\mathrm{H}+\mathrm{L}) \text { secondary } \\
\text { antibody Alexa Fluor } \\
488\end{array}$ & Invitrogen & A11001 & $1: 500$ & $\begin{array}{l}3 \mathrm{H} ; 5-\mathrm{S} 2 \mathrm{C} ; \\
5-\mathrm{S} 3 \mathrm{~B}\end{array}$ \\
\hline $\begin{array}{l}\text { Goat Anti-Rat IgG } \\
(\mathrm{H}+\mathrm{L}) \text { secondary } \\
\text { antibody Alexa Fluor } \\
488\end{array}$ & Invitrogen & A11006 & $1: 500$ & $\begin{array}{l}\text { 7A,F; 1-S1I; } \\
\text { 2-S2D; 4-S2A,C; } \\
\text { 5-S2A }\end{array}$ \\
\hline $\begin{array}{l}\text { Goat Anti-Chicken IgG } \\
(\mathrm{H}+\mathrm{L}) \text { secondary } \\
\text { antibody Alexa Fluor } \\
647\end{array}$ & Invitrogen & A21449 & $1: 500$ & 3G; 4E; 5-S3A \\
\hline
\end{tabular}




\section{References}

Adib EA, Smithson LJ, Collins CA. 2018. An axonal stress response pathway: degenerative and regenerative signaling by DLK. Current opinion in neurobiology no. 53:110-119. DOI: https://doi.org/10.1016/j.conb.2018.07.002, PMID: 30053694

Ajith S, Gazzara MR, Cole BS, Shankarling G, Martinez NM, Mallory MJ, et al. 2016. Position- dependent activity of CELF2 in the regulation of splicing and implications for signalresponsive regulation in T cells. RNA Biol no. 13 (6):569-81. DOI: https://doi.org/10. 1080/15476286.2016. 1176663, PMID: 27096301

Asrican B, Augustine GJ, Berglund K, Chen S, Chow N, Deisseroth K, et al. 2013. Nextgeneration transgenic mice for optogenetic analysis of neural circuits. Frontiers in neural circuits no. 7:160. DOI: https://doi.org/10.3389/fncir.2013.00160, PMID: 24324405

Björkblom B, Östman N, Hongisto V, Komarovski V, Filén J-J, Nyman TA, et al. 2005. Constitutively active cytoplasmic c-Jun $\mathrm{N}$-terminal kinase 1 is a dominant regulator of dendritic architecture: role of microtubule-associated protein 2 as an effector. Journal of Neuroscience no. 25 (27):6350-6361. DOI: https://doi.org/10.1523/JNEUROSCI.1517-05.2005, PMID: 16000625

Chang L, Jones Y, Ellisman MH, Goldstein LS, Karin M. 2003. JNK1 is required for maintenance of neuronal microtubules and controls phosphorylation of microtubuleassociated proteins. Developmental cell no. 4 (4):521-533. DOI: https://doi.org/10.1016/ s1534-5807(03)00094-7, PMID: 12689591

Chen L, Liu Z, Zhou B, Wei C, Zhou Y, Rosenfeld MG, et al. 2016. CELF RNA binding proteins promote axon regeneration in $\mathrm{C}$. elegans and mammals through alternative splicing of Syntaxins. Elife no. 5. DOI: https://doi.org/10.7554/eLife.16072, PMID: 27253061

Chen M, Geoffroy CG, Wong HN, Tress O, Nguyen MT, Holzman LB, et al. 2016. Leucine Zipper-bearing Kinase promotes axon growth in mammalian central nervous system neurons. Sci Rep no. 6:31482. DOI: https://doi.org/10.1038/srep31482, PMID: 27511108

Chen M, Geoffroy CG, Meves JM, Narang A, Li Y, Nguyen MT, et al. 2018. Leucine zipper-bearing kinase is a critical regulator of astrocyte reactivity in the adult mammalian CNS. Cell reports no. 22 (13):3587-3597. DOI: https://doi.org/10.1016/j.celrep.2018.02.102, PMID: 29590625

Chen X, Rzhetskaya M, Kareva T, Bland R, During MJ, Tank AW, et al. 2008. Antiapoptotic and trophic effects of dominant-negative forms of dual leucine zipper kinase in dopamine neurons of the substantia nigra in vivo. Journal of Neuroscience no. 28 (3):672-680. DOI: https://doi.org/10.1523/JNEUROSCI.2132-07.2008, PMID: 18199767

Cheng XS, Li MS, Du J, Jiang QY, Wang L, Yan SY, et al. 2011. Neuronal apoptosis in the developing cerebellum. Anat Histol Embryol no. 40 (1):21-7. DOI: https://doi.org/10.1111/j. 1439-0264.2010.01033.x, PMID: 21231956

Collins CA, Wairkar YP, Johnson SL, DiAntonio A. 2006. Highwire restrains synaptic growth by attenuating a MAP kinase signal. Neuron no. 51 (1):57-69. DOI: https://doi.org/10.1016/j. neuron.2006.05.026, PMID: 16815332

Cupolillo D, Hoxha E, Faralli A, De Luca A, Rossi F, Tempia F, et al. 2016. Autistic-like traits and cerebellar dysfunction in Purkinje cell PTEN knock-out mice. Neuropsychopharmacology 
no. 41 (6):1457-1466. DOI: https://doi.org/10.1038/npp.2015.339, PMID: 26538449

Cvetanovic M, Ingram M, Orr H, Opal P. 2015. Early activation of microglia and astrocytes in mouse models of spinocerebellar ataxia type 1. Neuroscience no. 289:289-299. DOI: https:// doi.org/10.1016/j.neuroscience.2015.01.003 PMID: 25595967

Dehmelt L, Halpain S. 2005. The MAP2/Tau family of microtubule-associated proteins. Genome biology no. 6 (1):1-10. DOI: https://doi.org/10.1186/gb-2004-6-1-204, PMID: 15642108

Elmore S. 2007. Apoptosis: a review of programmed cell death. Toxicologic pathology no. 35 (4):495-516. DOI: https://doi.org/10.1080/01926230701320337, PMID: 17562483

Ertürk A, Wang Y, Sheng M. 2014. Local pruning of dendrites and spines by caspase-3dependent and proteasome-limited mechanisms. Journal of Neuroscience no. 34 (5): 1672-1688. DOI: https://doi.org/10.1523/JNEUROSCI.3121-13.2014 13.2014, PMID: 24478350

Farley MM, Watkins TA. 2018. Intrinsic neuronal stress response pathways in injury and disease. Annual Review of Pathology: Mechanisms of Disease no. 13:93-116. DOI: https:// doi.org/10.1146/annurev-pathol-012414-040354, PMID: 29414247

Gdalyahu A, Ghosh I, Levy T, Sapir T, Sapoznik S, Fishler Y, et al. 2004. DCX, a new mediator of the JNK pathway. The EMBO journal no. 23 (4):823-832.

DOI: https://doi.org/10.1038/sj. emboj.7600079, PMID: 14765123

Goodwani S, Fernandez C, Acton PJ, Buggia-Prevot V, McReynolds ML, Ma J, et al. 2020. Dual Leucine Zipper Kinase Is Constitutively Active in the Adult Mouse Brain and Has Both Stress-Induced and Homeostatic Functions. International Journal of Molecular Sciences no. 21 (14):4849. DOI: https://doi.org/10.3390/ijms21144849, PMID: 32659913

Grill B, Murphey RK, Borgen MA. 2016. The PHR proteins: intracellular signaling hubs in neuronal development and axon degeneration. Neural development no. 11 (1):1-18. DOI: https://doi.org/10.1186/s13064-016-0063-0, PMID: 27008623

Gross A, McDonnell JM, Korsmeyer SJ. 1999. BCL-2 family members and the mitochondria in apoptosis. Genes \& development no. 13 (15):1899-1911.

DOI: https://doi.org/10.1101/gad.13. 15.1899, PMID: 10444588

Guyenet SJ, Furrer SA, Damian VM, Baughan TD, La Spada AR, Garden GA. 2010. A simple composite phenotype scoring system for evaluating mouse models of cerebellar ataxia. J Vis Exp (39). DOI: https://doi.org/10.3791/1787, PMID: 20495529

Hansen ST, Meera P, Otis TS, Pulst SM. 2013. Changes in Purkinje cell firing and gene expression precede behavioral pathology in a mouse model of SCA2. Human molecular genetics no. 22 (2):271-283. DOI: https://doi.org/10.1093/hmg/dds427, PMID: 23087021

Hippenmeyer S, Vrieseling E, Sigrist M, Portmann T, Laengle C, Ladle DR, et al. 2005. A developmental switch in the response of DRG neurons to ETS transcription factor signaling. PLoS Biol no. 3 (5):e159. DOI: https://doi.org/10.1371/journal.pbio.0030159, PMID:15836427

Hirai S, Kawaguchi A, Suenaga J, Ono M, Cui DF, Ohno S. 2005. Expression of MUK/DLK/ ZPK, an activator of the JNK pathway, in the nervous systems of the developing mouse 
embryo. Gene Expr Patterns no. 5 (4):517-23. DOI:

https://doi.org/10.1016/j.modgep.2004.12. 002, PMID: 15749080

Hirai S-i, Banba Y, Satake T, Ohno S. 2011. Axon Formation in Neocortical Neurons Depends on Stage-Specific Regulation of Microtubule Stability by the Dual Leucine Zipper Kinase- c-Jun N-Terminal Kinase Pathway. Journal of Neuroscience no. 31 (17):6468-6480. DOI: https://doi.org/1 0.1523/JNEUROSCI.5038-10.2011, PMID: 21525288

Hirai S-i, Miyata T, Ogawa M, Kiyonari H, Suda Y, Aizawa S, et al. 2006. The c-Jun Nterminal kinase activator dual leucine zipper kinase regulates axon growth and neuronal migration in the developing cerebral cortex. Journal of Neuroscience no. 26 (46):1199212002. DOI: https: //doi.org/10.1523/JNEUROSCI.2272-06.2006, PMID: 17108173

Holland SM, Collura KM, Ketschek A, Noma K, Ferguson TA, Jin Y, et al. 2016. Palmitoylation controls DLK localization, interactions and activity to ensure effective axonal injury signaling. Proceedings of the National Academy of Sciences no. 113 (3):763-768. DOI: https://doi.org/ 10.1073/pnas.1514123113, PMID: 26719418

Hollville E, Romero SE, Deshmukh M. 2019. Apoptotic cell death regulation in neurons. The FEBS journal no. 286 (17):3276-3298. DOI: https:// doi.org/10.1111/febs.14970, PMID: 31230407

Holzman LB, Merritt SE, Fan G. 1994. Identification, molecular cloning, and characterization of dual leucine zipper bearing kinase. A novel serine/threonine protein kinase that defines a second subfamily of mixed lineage kinases. Journal of Biological Chemistry no. 269 (49): 30808-30817. PMID: 7983011

Hoskison M, Yanagawa Y, Obata K, Shuttleworth CW. 2007. Calcium-dependent NMDAinduced dendritic injury and MAP2 loss in acute hippocampal slices. Neuroscience no. 145 (1):66-79. DOI: https://doi.org/10.1016/j.neuroscience.2006.11.034, PMID: 17239543

Hotamisligil GS, Davis RJ. 2016. Cell signaling and stress responses. Cold Spring Harbor Perspectives in Biology no. 8 (10):a006072. DOI: https://doi.org/10.1101/cshperspect.a0060 72, PMID: 27698029

Huang Y-WA, Zhou B, Wernig M, Südhof TC. 2017. ApoE2, ApoE3, and ApoE4 differentially stimulate APP transcription and A $\beta$ secretion. Cell no. 168 (3):427-441. e21. DOI: https://doi. org/10.1016/j.cell.2016.12.044, PMID: 28111074

Ikeda A, Hasegawa K, Masaki M, Moriguchi T, Nishida E, Kozutsumi Y, et al. 2001. Mixed lineage kinase LZK forms a functional signaling complex with JIP-1, a scaffold protein of the c-Jun NH(2)-terminal kinase pathway. J Biochem no. 130 (6):773-81. DOI: https://doi.org/10. 1093/oxfordjournals.jbchem.a00 3048, PMID: 11726277

Ikeda A, Masaki M, Kozutsumi Y, Oka S, Kawasaki T. 2001. Identification and characterization of functional domains in a mixed lineage kinase LZK. FEBS letters no. 488 (3):190-195. DOI: https://doi.org/10.1016/ s0014-5793(00)02432-7, PMID: 11163770

Jin Y, Zheng B. 2019. Multitasking: Dual Leucine Zipper-Bearing Kinases in Neuronal Development and Stress Management. Annual review of cell and developmental biology no. 35:501-521. DOI: https://doi.org/10.1146/annurev-cellbio- 100617-062644, PMID: 31590586

Joy MT, Assayag EB, Shabashov-Stone D, Liraz-Zaltsman S, Mazzitelli J, Arenas M, et al. 2019. CCR5 is a therapeutic target for recovery after stroke and traumatic brain injury. Cell no. 176 (5):1143-1157. e13. DOI: https://doi.org/10.1016/j.cell.2019. 01.044, PMID: 30794775 
Khatri N, Gilbert JP, Huo Y, Sharaflari R, Nee M, Qiao H, et al. 2018. The autism protein Ube3A/E6AP remodels neuronal dendritic arborization via caspase-dependent microtubule destabilization. Journal of Neuroscience no. 38 (2):363-378. DOI: https://doi.org/10.1523/ JNEUROSCI.1511- 17.2017, PMID: 29175955

Lattke M, Reichel SN, Magnutzki A, Abaei A, Rasche V, Walther P, et al. 2017. Transient IKK2 activation in astrocytes initiates selective non-cell- autonomous neurodegeneration. Molecular neurodegeneration no. 12 (1):16. DOI: https://doi.org/10.1186/s13024-017-01570, PMID: 28193238

Le Pichon CE, Meilandt WJ, Dominguez S, Solanoy H, Lin H, Ngu H, et al. 2017. Loss of dual leucine zipper kinase signaling is protective in animal models of neurodegenerative disease. Science translational medicine no. 9 (403).

DOI: https://doi.org/10.1126/scitransImed.aag039 4, PMID: 28814543

Lewcock JW, Genoud N, Lettieri K, Pfaff SL. 2007. The ubiquitin ligase Phr1 regulates axon outgrowth through modulation of microtubule dynamics. Neuron no. 56 (4):604-620. DOI: https://doi.org/10.1016/j.neuron.2007.09. 009, PMID: 18031680

Liu Y, Lee JW, Ackerman SL. 2015. Mutations in the microtubule-associated protein 1A (Map1a) gene cause Purkinje cell degeneration. Journal of Neuroscience no. 35 (11):45874598. DOI: https://doi.org/10.1523/ JNEUROSCI.2757-14.2015, PMID: 25788676

Lobsiger CS, Cleveland DW. 2007. Glial cells as intrinsic components of non-cellautonomous neurodegenerative disease. Nature neuroscience no. 10 (11):1355-1360. DOI: https://doi.org/10.1038/nn1988, PMID: 17965655

Love MI, Huber W, Anders S. 2014. Moderated estimation of fold change and dispersion for RNA-seq data with DESeq2. Genome biology no. 15 (12):550. DOI: https://doi.org/10.1186/ s13059-014-0550-8, PMID: 25516281

Martinez NM, Agosto L, Quu J, Mallory MJ, Gazzara MR, Barash Y, et al. 2015. Widespread JNK-dependent alternative splicing induces a positive feedback loop through CELF2mediated regulation of MKK7 during T-cell activation. Genes Dev no. 29 (19):2054-66. DOI: https://doi.org/10.1101/gad.267245. 115, PMID: 26443849

Merritt SE, Mata M, Nihalani D, Zhu C, Hu X, Holzman LB. 1999. The mixed lineage kinase DLK utilizes MKK7 and not MKK4 as substrate. Journal of Biological Chemistry no. 274 (15): 10195-10202. DOI: https://doi.org/10.1074/jbc.274.15.10195, PMID: 10187804

Nakata K, Abrams B, Grill B, Goncharov A, Huang X, Chisholm AD, et al. 2005. Regulation of a DLK-1 and p38 MAP kinase pathway by the ubiquitin ligase RPM-1 is required for presynaptic development. Cell no. 120 (3):407-420. DOI: https://doi.org/10.1016/j.cell.2004. 12.017, PMID: 15707898

Nihalani D, Merritt S, Holzman LB. 2000. Identification of structural and functional domains in mixed lineage kinase dual leucine zipper-bearing kinase required for complex formation and stress-activated protein kinase activation. Journal of Biological Chemistry no. 275 (10):72737279. DOI: https://doi.org/10.1074/ jbc.275.10.7273, PMID: 10702297

Pozniak CD, Sengupta Ghosh A, Gogineni A, Hanson JE, Lee SH, Larson JL, et al. 2013. Dual leucine zipper kinase is required for excitotoxicity-induced neuronal degeneration. $J$ Exp Med no. 210 (12):2553-67. DOI: https://doi.org/10.1084/jem.20122832,

PMID: 24166713 
Ran FA, Hsu PD, Wright J, Agarwala V, Scott DA, Zhang F. 2013. Genome engineering using the CRISPR-Cas9 system. Nature protocols no. 8 (11):2281.

DOI: https://doi.org/10.1038/ nprot.2013.143, PMID: 24157548

Sakuma H, Ikeda A, Oka S, Kozutsumi Y, Zanetta J-P, Kawasaki T. 1997. Molecular cloning and functional expression of a cDNA encoding a new member of mixed lineage protein kinase from human brain. Journal of Biological Chemistry no. 272 (45):28622-28629. DOI: https://doi. org/10.1074/jbc.272.45.28622, PMID: 9353328

Schaefer AM, Hadwiger GD, Nonet ML. 2000. rpm-1, a conserved neuronal gene that regulates targeting and synaptogenesis in C. elegans. Neuron no. 26 (2):345-356. DOI: https: //doi.org/10.1016/s0896-6273(00)81168-x, PMID: 10839354

Schellino R, Boido M, Vercelli A. 2019. JNK Signaling Pathway Involvement in Spinal Cord Neuron Development and Death. Cells no. 8 (12):1576. DOI: https://doi.org/10.3390/cells812 1576, PMID: 31817379

Shin JE, Cho Y, Beirowski B, Milbrandt J, Cavalli V, DiAntonio A. 2012. Dual leucine zipper kinase is required for retrograde injury signaling and axonal regeneration. Neuron no. 74 (6):1015-1022. DOI: https://doi.org/ 10.1016/j.neuron.2012.04.028, PMID: 22726832

Shin JE, Ha H, Kim YK, Cho Y, DiAntonio A. 2019. DLK regulates a distinctive transcriptional regeneration program after peripheral nerve injury. Neurobiology of disease no. 127:178192. DOI: https://doi.org/10.1016/j. nbd.2019.02.001, PMID: 30735704

Simard-Bisson C, Bidoggia J, Larouche D, Guerin SL, Blouin R, Hirai SI, et al. 2017. A Role for DLK in Microtubule Reorganization to the Cell Periphery and in the Maintenance of Desmosomal and Tight Junction Integrity. J Invest Dermatol no. 137 (1):132-141. DOI: https:// doi.org/10.1016/j.jid. 2016.07.035, PMID: 27519653

Siu M, Sengupta Ghosh A, Lewcock JW. 2018. Dual Leucine Zipper Kinase Inhibitors for the Treatment of Neurodegeneration. J Med Chem. DOI: https://doi.org/10.1021/acs.jmedchem. 8b00370, PMID: 29863360

Suenaga J, Yamamoto I, Ohno S, Hirai S-i. 2006. Developmental changes in the expression pattern of the JNK activator kinase MUK/DLK/ZPK and active JNK in the mouse cerebellum. Cell and tissue research no. 325 (1):189-195. DOI: https://doi.org/10.1007/s00441-006-0164 -x, PMID: 16520976

Summers DW, Frey E, Walker LJ, Milbrandt J, DiAntonio A. 2020. DLK activation synergizes with mitochondrial dysfunction to downregulate axon survival factors and promote SARM1dependent axon degeneration. Molecular Neurobiology no. 57 (2):1146-1158. DOI: https://doi. org/10.1007/s12035-019-01796-2, PMID: 31696428

Tararuk T, Östman N, Li W, Björkblom B, Padzik A, Zdrojewska J, et al. 2006. JNK1 phosphorylation of SCG10 determines microtubule dynamics and axodendritic length. The Journal of cell biology no. 173 (2):265-277. DOI: https:// doi.org/10.1083/jcb.200511055, PMID: 16618812

Tasic B, Hippenmeyer S, Wang C, Gamboa M, Zong H, Chen-Tsai Y, et al. 2011. Sitespecific integrase-mediated transgenesis in mice via pronuclear injection. Proc Natl Acad Sci U S A no. 108 (19):7902-7. DOI: https://doi.org/10.1073/pnas.1019 507108,

PMID: 21464299

Tedeschi A, Bradke F. 2013. The DLK signalling pathway-a double-edged sword in neural development and regeneration. EMBO reports no. 14 (7):605-614. DOI: https://doi.org/10. 1038/embor.2013.64, PMID: 23681442 
Thomas GM, Huganir RL. 2004. MAPK cascade signalling and synaptic plasticity. Nature Reviews Neuroscience no. 5 (3):173-183. DOI: https:// doi.org/10.1038/nrn1346, PMID: 14976517

Valakh V, Frey E, Babetto E, Walker LJ, DiAntonio A. 2015. Cytoskeletal disruption activates the DLK/JNK pathway, which promotes axonal regeneration and mimics a preconditioning injury. Neurobiol Dis no. 77:13-25. DOI: https://doi.org/10. 1016/j.nbd.2015.02.014, PMID: 25726747

Wan HI, DiAntonio A, Fetter RD, Bergstrom K, Strauss R, Goodman CS. 2000. Highwire regulates synaptic growth in Drosophila. Neuron no. 26 (2):313-329. DOI: https://doi.org/10. 1016/s0896-6273(00)81166-6, PMID: 10839352

Wang H, Wu M, Zhan C, Ma E, Yang M, Yang X, et al. 2012. Neurofilament proteins in axonal regeneration and neurodegenerative diseases. Neural regeneration research no. 7 (8):620. DOI: https:// doi.org/10.3969/j.issn.1673-5374.2012.08.010, PMID: 25745454

Watkins TA, Wang B, Huntwork-Rodriguez S, Yang J, Jiang Z, Eastham-Anderson J, et al. 2013. DLK initiates a transcriptional program that couples apoptotic and regenerative responses to axonal injury. Proc Natl Acad Sci U S A no. 110 (10):4039-44. DOI: https://doi. org/10.1073/pnas.1211074110, PMID: 23431164

Welsbie DS, Mitchell KL, Jaskula-Ranga V, Sluch VM, Yang Z, Kim J, et al. 2017. Enhanced functional genomic screening identifies novel mediators of dual leucine zipper kinasedependent injury signaling in neurons. Neuron no. 94 (6):1142-1154. e6. DOI: https://doi.org/ 10.1016/j.neuron.2017.06.008, PMID: 28641113

Welsbie DS, Yang Z, Ge Y, Mitchell KL, Zhou X, Martin SE, et al. 2013. Functional genomic screening identifies dual leucine zipper kinase as a key mediator of retinal ganglion cell death. Proceedings of the National Academy of Sciences no. 110 (10): 4045-4050.

DOI: https://doi. org/10.1073/pnas.1211284110, PMID: 23431148

White JJ, Arancillo M, King A, Lin T, Miterko LN, Gebre SA, et al. 2016. Pathogenesis of severe ataxia and tremor without the typical signs of neurodegeneration. Neurobiology of disease no. 86:86-98. DOI: https://doi.org/10.1016/j.nbd.2015.11.008, PMID: 26586559

White JJ, Arancillo M, Stay TL, George-Jones NA, Levy SL, Heck DH, et al. 2014. Cerebellar zonal patterning relies on Purkinje cell neurotransmission. Journal of Neuroscience no. 34 (24):8231-8245. DOI: https://doi.org/10.1523/JNEUROSCI.0122-14.2014, PMID: 24920627

White JJ, Sillitoe RV. 2017. Genetic silencing of olivocerebellar synapses causes dystonialike behaviour in mice. Nature communications no. 8 (1):1-16.

DOI: https://doi.org/10.1038/ncom ms14912, PMID: 28374839

Yang J, Wu Z, Renier N, Simon DJ, Uryu K, Park DS, et al. 2015. Pathological axonal death through a MAPK cascade that triggers a local energy deficit. Cell no. 160 (1-2):161-176. DOI: https://doi.org/10.1016/j.cell.2014.11.053, PMID: 25594179

Zhen M, Huang X, Bamber B, Jin Y. 2000. Regulation of presynaptic terminal organization by C. elegans RPM-1, a putative guanine nucleotide exchanger with a RING-H2 finger domain. Neuron no. 26 (2):331-343. (2):331-343. DOI: https://doi.org/10.1016/s08966273(00)81167- 8, PMID: 10839353 


\section{Figure Legends}

Figure 1. Morphology of cerebellar Purkinje cells is normal in the absence of LZK and DLK.

A. Representative images of hematoxylin and eosin staining of cerebellar sections from P60 mice of genotypes indicated. Scale bars: $500 \mu \mathrm{m}$.

B. Representative images of Calbindin staining of cerebellar sections from P60 mice of genotypes indicated. Scale bars: $100 \mu \mathrm{m}$.

C. Quantification of total number of Purkinje cells in all cerebellar lobules.

D. Quantification of cerebellum area, with perimeters measured by outlining the outer edge of midline sagittal sections of the cerebella.

E. Quantification of the molecular layer thickness in cerebellar lobules V-VI.

(C-E). $n \geq 3$ animals per genotype, and 3 sections/animal; data shown as means \pm SEM.

Statistics: One-way ANOVA; ns. no significant.

Figure 2. Induced expression of DLK using parvalbumin-cre ( $\left.P V^{\text {cre }}\right)$ causes animal growth defects and rapid degeneration of Purkinje cells.

A. Representative image of P21 pups of genotypes indicated, and pups with induced DLK expression in $\mathrm{PV}^{+}$neurons are smaller than siblings. Scale bar: $2 \mathrm{~cm}$.

B. Quantification of the body weight from P5 to P21. $n \geq 3$ per genotype for each time point.

C. Quantification of the cerebellum area from P5 to P21. $n \geq 3$ per genotype for each time point.

D. Representative images of Calbindin staining of cerebellar sections of littermates from mating parents $P V^{\mathrm{Cre} /+}$ to $D I k^{\mathrm{iOE} /+}$ (short for H11-LSL-DI ${ }^{\mathrm{iOE}}$ transgene) at indicated postnatal days. Red boxes are enlarged to show that induced expression of DLK causes a total loss of Purkinje cells by P21. Scale bars: $500 \mu \mathrm{m}$ (upper panels), $100 \mu \mathrm{m}$ (lower panels).

E. Quantification of total number of Purkinje cells in all cerebellar lobules.

F. Quantification of the molecular layer thickness in cerebellar lobules V-VI.

Color representation for genotypes in $\mathrm{C}, \mathrm{E}$, and $\mathrm{F}$ is the same as in $\mathrm{B}$.

$(E, F) . n \geq 3$ animals per genotype, 3 sections/animal; data shown as means $\pm S E M$.

Statistics for B-C, E-F: Student's unpaired t-test; ns, no significant; ${ }^{*}, p<0.05 ;{ }^{* *}, p<0.01$; ${ }^{* * * *}$, $p<0.0001$.

Figure 3. Induced expression of DLK activates JNK signaling and apoptosis, and disrupts dendritic cytoskeleton of Purkinje cells. 
A. Representative images of co-immunostaining of $p$-c-Jun and Calbindin in Purkinje cells in P6 mice of genotypes indicated. Arrows point to p-c-Jun immunostaining signals in nuclei of Purkinje cells. Scale bar: $100 \mu \mathrm{m}$.

B. Quantification of percentage of p-c-Jun+ signals per total Purkinje cells in P6 mice of $D I k^{\mathrm{iOE} /+}$ and $P V^{\mathrm{Cre} /+} ; D / k^{\mathrm{iOE} /+}$.

C. Representative images of cerebellar lobule III of P15 mice, co-immunostained for Calbindin and cleaved caspase-3, with arrows and enlarged blue boxes showing cleaved caspase $-3^{+}$signals in the swollen dendrites of Purkinje cells of $\mathrm{PV}^{\mathrm{Cre} /+} ; D I k^{\mathrm{iOE} /+}$ mice. Scale bars: $100 \mu \mathrm{m}$ for the left and middle columns, $50 \mu \mathrm{m}$ for the right.

D. Quantification of percentage of cleaved caspase $-3^{+}$cells in total Purkinje cells in P15 mice of $D I k^{\mathrm{iOE} /+}$ and $P V^{\mathrm{Cre} /+} ; D I k^{\mathrm{iOE} /+}$, and none detected in $D I k^{\mathrm{iOE} /+}$.

E. Quantification of percentage of Purkinje cells with swelling dendrites in mice of $D / k^{i O E /+}$ and $P V^{C r e /+} ; D I k^{i O E /+}$ from $\mathrm{P} 10$ to $\mathrm{P} 21 . \mathrm{n} \geq 3$ animals per genotype at each time point, none detected in $D / k^{\mathrm{iOE} /+}$.

F. Quantification of percentage of Purkinje cells containing cleaved caspase- $3^{+}$in swelling dendrites in total Purkinje cells in P15 mice of $D / k^{\mathrm{iOE} /+}$ and $\mathrm{PV}^{\mathrm{Cre} /+} ; \mathrm{Dl} \mathrm{k}^{\mathrm{iOE} /+}$.

G. Representative images of Purkinje cells of P15 mice co-immunostained for MAP2 and Calbindin. Swelling dendrites in Purkinje cells of $\mathrm{PV}^{\mathrm{Cre} /+} ; D \mathrm{~K}^{\mathrm{iOE} /+}$ mice have little expression of MAP2; arrows point to dendrites with intensity difference between the two genotypes. Scale bar: $50 \mu \mathrm{m}$.

$\mathrm{H}$. Representative images of Purkinje cells of P15 mice co-immunostained for NF-200 and Calbindin, showing that induced DLK expression reduces NF-200 staining in dendrites of Purkinje cells (arrows). Scale bar: $50 \mu \mathrm{m}$.

$(B, D, E, F) . n=3$ animals per genotype, minimal 3 sections/animal; data shown are means \pm SEM. Statistics: Student's unpaired t-test; ns, no significant; ${ }^{*}, p<0.05 ;{ }^{* * *}, p<0.001$; ${ }^{* * * *}$, $p<0.0001$.

\section{Figure 4. Increasing LZK expression using $P V^{\text {Cre }}$ causes progressive degeneration of} Purkinje cells.

A. Representative images of Calbindin staining of cerebellar sections of littermates from mating parents $P V^{\mathrm{Cre} /+}$ to $L z k^{\mathrm{iOE} /+}$ (short for H11-LSL-Lzk ${ }^{\mathrm{iOE}}$ transgene) at indicated postnatal days. Scale bars: $100 \mu \mathrm{m}$.

B. Quantification of total Purkinje cells in all cerebellar lobules.

C. Quantification of cerebellum area, perimeters measured by outlining the outer edge of cerebellum.

D. Quantification of the molecular layer thickness in cerebellar lobules V-VI.

Color representation for genotypes in C-D is the same as in B. 
E. Representative images of cerebellar sections of $P V^{C r e /+} ; L^{2} k^{i O E /+}$ mice at $\mathrm{P} 15$, coimmunostained for MAP2 and Calbindin. The dotted lines in top panels mark the boundary of anterior and posterior cerebellum, note higher tdTomato intensity in anterior cerebellum. Images in the bottom two rows show enlarged views of the anterior and posterior cerebellum, with arrows pointing to dendrites of Purkinje cells. Scale bars: $500 \mu \mathrm{m}$ (upper panel), $100 \mu \mathrm{m}$ (middle and lower panels).

F. Representative images of Purkinje cells of P90 mice co-immunostained for Calbindin and p-c-Jun. Scale bar: $50 \mu \mathrm{m}$.

G. Representative images of Purkinje cells of P90 mice co-immunostained for Calbindin and cleaved caspase-3. Note that $P V^{\mathrm{Cre} /+} ; L z k^{i \mathrm{OE} /+}$ mice have smaller cerebella, hence two rows of Purkinje cells are in view. Scale bar: $50 \mu \mathrm{m}$.

$\mathrm{H}$. Quantification of the percentage of cleaved caspase $-3^{+}$Purkinje cells in total Purkinje cells in $L z k^{\mathrm{iOE} /+}$ and $\mathrm{PV}^{\mathrm{Cre} /+} ; \mathrm{Lzk}^{\mathrm{iOE} /+}$ mice from $\mathrm{P} 10$ to $\mathrm{P} 120 . \mathrm{n}=3$ per genotype at each time point.

$(B-D, H) . n \geq 3$ per genotype; data shown are means \pm SEM. Statistics for $B, C, D, H$ : Student's unpaired t-test; ns, no significant; ${ }^{*}, p<0.05,{ }^{* *}, p<0.01,{ }^{* * *}, p<0.001,{ }^{* * * *}$, $p<0.0001$.

Figure 5. Conditional deletion of the RNA splicing factor Celf2 using $P V^{\text {Cre }}$ rescues degeneration of Purkinje cells induced by LZK activation.

A-E. Quantification of movement phenotypes of mice of indicated genotypes from P30 to

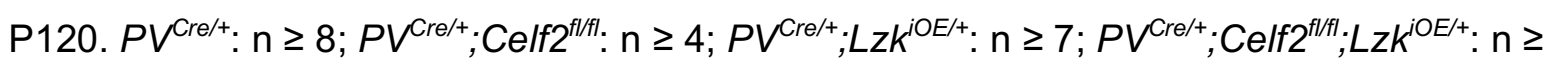
5 ; at each time point.

F. Quantification of the body weight of mice of indicated genotypes from P30 to P120. n $\geq 5$ per genotype at each time point.

Color representation for genotypes in $\mathrm{B}-\mathrm{F}$ is the same as in $\mathrm{A}$.

G. Representative images of Calbindin staining of cerebellar sections from P120 mice of genotypes indicated. Scale bars: $100 \mu \mathrm{m}$.

H. Quantification of total Purkinje cells in all cerebellar lobules at P120.

I. Quantification of cerebellum area at P120.

J. Quantification of the molecular layer thickness of P120 mice in cerebellar lobules V-VI.

$(\mathrm{H}-\mathrm{J}) . \mathrm{n}=3$ per genotype; data shown are means \pm SEM. Statistics for A-F, H, I, J: One-way ANOVA; ns, no significant; ${ }^{*}, p<0.05,{ }^{* *}, p<0.01,{ }^{* * *}, p<0.001,{ }^{* * *}, p<0.0001$.

Figure 6. Deletion of Celf2 in $P V^{\mathrm{Cre} /+} ; L z k^{i O E /+}$ mice reduces levels of $\mathrm{p}-\mathrm{c}-\mathrm{Jun}$ and apoptosis in Purkinje cells. 
A. Representative images of Purkinje cells, co-immunostained for p-c-Jun and Calbindin, in P120 mice of genotypes indicated. Arrows point to p-c-Jun immunostaining signals in Purkinje cells. ML: Molecular Layer; PCL: Purkinje Cell Layer; GCL: Granule Cell Layer. Scale bar: $100 \mu \mathrm{m}$.

B. Quantification of the p-c-Jun levels in Purkinje cells of P120 mice. MFI: mean of fluorescence intensity.

C. Representative images of Purkinje cells, co-immunostained for cleaved caspase-3 and Calbindin, in P120 mice of genotypes indicated, with enlarged boxes showing cleaved caspase $-3^{+}$signal in Calbindin labeled Purkinje cells. ML: Molecular Layer; PCL: Purkinje Cell Layer; GCL: Granule Cell Layer. Scale bars: $100 \mu \mathrm{m}$.

D. Quantification of the percentage of cleaved caspase $-3^{+}$Purkinje cells in total number of Purkinje cells of P120 mice of genotypes indicated.

$(B, D) . n=3$ per genotype; data shown are means \pm SEM. Statistics for $B, D$ : One-way ANOVA; ns, no significant; ${ }^{* *}, p<0.01,{ }^{* * *}, p<0.0001$.

Figure 7. DLK and LZK can induce Purkinje cell degeneration independent of each other.

A. Representative images of Purkinje cells of P21 mice of genotypes indicated, immunostained for Calbindin and GFAP. ML: Molecular Layer; PCL: Purkinje Cell Layer; GCL: Granule Cell Layer. Scale bars: $100 \mu \mathrm{m}$.

B. Quantification of total number of Purkinje cells in all cerebellar lobules at P21.

C. Quantification of the molecular layer thickness in cerebellar lobules V-VI of P21 mice.

D. Quantification of the cerebellum area of P21 mice.

E. Quantification of normalized GFAP levels in cerebellum of P21 mice. MFI: mean of fluorescence intensity.

F. Representative images of of Purkinje cells of P60 mice of genotypes indicated, immunostained for Calbindin and GFAP. ML: Molecular Layer; PCL: Purkinje Cell Layer; GCL: Granule Cell Layer. Scale bars: $100 \mu \mathrm{m}$.

G. Quantification of total number of Purkinje cells in all cerebellar lobules of P60 mice.

$\mathrm{H}$. Quantification of the molecular layer thickness in cerebellar lobules V-VI of P60 mice.

I. Quantification of the cerebellum area of P60 mice.

J. Quantification of normalized GFAP levels in cerebellum of P60 mice. MFI: mean of fluorescence intensity.

(B-E, G-J). $n=3$ per genotype; data shown are means \pm SEM. Statistics for B-E, G-J: Oneway ANOVA; ns, no significant; ${ }^{* * *}, p<0.001,{ }^{* * * *}, p<0.0001$.

\section{Supplementary figure legends}


Figure 1-figure supplement 1. Knockout mice lines and associated evidence.

A. Lzk KO mice were generated by CRISPR-Cas9 technology using 3 sgRNAs targeted to the kinase domain of LZK. Scale bar: $1 \mathrm{~kb}$.

$\mathrm{B}$. The homozygotes or heterozygotes of $L z k^{K O}$ were identified by PCR using primers YJ12529-12531.

C. The LZK protein levels in cerebellum of P60 mice of genotypes indicated were determined by immunoprecipitation and western blot.

D. DIk ${ }^{f / f l}$ mice have loxP sites flanking the exon 4 which contains the initiation ATG codon, and Cre-mediated excision results in a null allele. Scale bar: $1 \mathrm{~kb}$.

$\mathrm{E}$. The homozygotes or heterozygotes of $D I k^{f l}$ were identified by PCR using primers YJ12523 and YJ12524.

F. $L z k^{f l / f l}$ mice have loxP sites flanking exon 2 , and Cre-mediated excision results in frameshift, hence a null allele. Scale bar: $1 \mathrm{~kb}$.

G. The homozygotes or heterozygotes of $L z k^{f l}$ were identified by PCR using primers YJ12525 and YJ12526.

$\mathrm{H}$. The DLK protein levels in cerebellum of P60 mice of genotypes indicated were determined by western blot.

I. Representative images of GFAP staining of cerebellar astrocytes from P60 mice of genotypes indicated. Scale bars: $100 \mu \mathrm{m}$.

J. Quantification of normalized GFAP levels in cerebellum of P60 mice. $n=3$ per genotype. MFI: mean of fluorescence intensity.

K. Quantification of the body weight of mice of genotypes indicated at P60. $n \geq 3$ per genotype.

$(\mathrm{J}, \mathrm{K})$. Data shown are means \pm SEM. Statistics for J, K: One-way ANOVA; ns. no significant.

Figure 2-figure supplement 1. Cre-dependent DLK and LZK expression transgenic mice and associated evidence.

A. Illustration of Cre-dependent expression of $D I k^{i O E}$ and $L z k^{i O E}$ transgenic mice, generated following the protocol described previously (Tasic et al., 2011). 3 x Flag-Dlk or 1 x Flag-Lzk and tdTomato will be expressed after removal of the stop cassette by Cre recombinase.

$B$. The homozygotes or heterozygotes of $D I k^{i O E}$ and $L z k^{i O E}$ were identified by PCR using primers YJ12520-12522.

C. Graph shows mRNA levels of tdTomato obtained from RNA-sequencing of cerebellum from P15 mice of Vglut ${ }^{\mathrm{Cre} /+} ; D I k^{\mathrm{iOE} /+}$ and $\mathrm{Vglut}{ }^{\mathrm{Cre} /+} ; \mathrm{Lzk}^{\mathrm{iOE} /+}$. Transcript per million (TPM) values represent tdTomato transcript counts normalized by gene length and sequencing 
depth. Differences in the expression levels of tdTomato between $\mathrm{Vglut}^{\mathrm{Cre} / \mathrm{+}} ; \mathrm{DI} \mathrm{k}^{\mathrm{iOE} /+}$ and Vglut $^{\mathrm{Cre} /+} ; \mathrm{Lzk}^{\mathrm{iOE} / \mathrm{+}}$ is not statistically significant based on differential expression analysis using DESeq2 galaxy version 2.11.40.2 (Love et al., 2014).

D. Representative images of cerebellar sections of $P V^{C r e /+} ; D / k^{i O E /+}$ mice immunostained for parvalbumin at indicated postnatal days, along with tdTomato expression from $D I k^{i O E}$, showing the effect of Cre recombinase. Scale bars: $500 \mu \mathrm{m}$.

E. The DLK protein levels in cerebellar extracts from P10 mice of genotypes indicated were determined by western blot.

F. Quantification of the ratio of DLK relative to $\beta$-actin protein levels.

G. The LZK protein levels in cerebellar extracts from P21 mice of genotypes indicated were determined by immunoprecipitation and western blot.

$H$. Quantification of the ratio of LZK relative to $\beta$-actin protein levels.

$(\mathrm{C}, \mathrm{F}, \mathrm{H}) . \mathrm{n}=3$ per genotype; data shown are means \pm SEM. Statistics for $\mathrm{C}, \mathrm{F}, \mathrm{H}$ : Student's unpaired t-test; ns, no significant; ${ }^{*}, p<0.05,{ }^{* * * *}, p<0.0001$.

Figure 2-figure supplement 2. Additional evidence of Purkinje cell degeneration phenotypes caused by DLK activation.

A. Representative image of P21 brains of genotypes indicated. Cerebellum (arrowheads) is nearly absent in brain with induced DLK expression in $\mathrm{PV}^{+}$neurons. Scale bar: $5 \mathrm{~mm}$.

B. Representative images of hematoxylin and eosin staining of cerebellar sections from P21 mice of genotypes indicated. Scale bars: $500 \mu \mathrm{m}$.

C. Representative images of cerebellar sections from P21 mice of genotypes indicated, immunostained for IBA1; and tdTomato reporter expression marks Purkinje cells. The arrows show close association between microglia and Purkinje cells. ML: Molecular Layer; PCL: Purkinje Cell Layer; GCL: Granule Cell Layer. Scale bars: $100 \mu \mathrm{m}$.

D. Representative images of cerebellar sections from P21 mice of genotypes indicated, immunostained for GFAP.

E-F. Quantification of normalized IBA1 and GFAP levels in cerebellum of P21 mice. $n=3$ per genotype.

$(E, F)$. Data shown are means \pm SEM. Statistics for E, F: Student's unpaired t- test; ****, $p<0.0001$.

Figure 3-figure supplement 1. Additional evidence for apoptosis induced by DLK activation.

A. Representative images of cerebellar lobules of $D / k^{i O E /+}$ and $P V^{C r e /+} ; D I k^{i O E /+}$ mice from $P 5$ to P15, labeled with TUNEL fluorescence signal (fluorescein-12-dUTP). Scale bars: $100 \mu \mathrm{m}$.

B. Quantification of TUNEL ${ }^{+}$cells density in cerebellum. $n \geq 3$ per group at each time point. 
C. Representative image showed the co-localization of TUNEL signal with tdT $^{+}$Purkinje cells in P15 mice (arrows). ML: Molecular Layer; PCL: Purkinje Cell Layer; GCL: Granule Cell Layer. Scale bar: $50 \mu \mathrm{m}$.

(B). Data shown are means \pm SEM. Statistics for B: Student's unpaired t- test; ns, no significant; ${ }^{* *}, p<0.01,{ }^{* * *}, p<0.001$.

Figure 3-figure supplement 2. DLK protein localization in Purkinje cells.

Representative images of cerebellar section of P10 mice immunostained for DLK; arrows show DLK distribution in Purkinje cells (arrows). ML: Molecular Layer; PCL: Purkinje Cell Layer; GCL: Granule Cell Layer. Scale bar: $100 \mu \mathrm{m}$.

Figure 4-figure supplement 1. Additional evidence for elevating LZK expression in $\mathbf{P V}^{+}$ neurons causing animal growth and movement defects.

A. Representative image of P120 mice of genotypes indicated. Scale bar: $2 \mathrm{~cm}$.

B. Quantification of the body weight of mice of genotypes indicated from P15 to P120. $n \geq 4$ per group at each time point.

C. Representative images of hematoxylin and eosin staining of cerebellar sections from P120 mice of genotypes indicated. Scale bars: $500 \mu \mathrm{m}$.

D. Representative images of Purkinje cells of P21 mice immunostained for LZK. Enlarged blue boxed area show transgenic LZK strongly expressed in dendrites and soma of Purkinje cells in $P V^{C r e /+}$;Lzk ${ }^{\text {iOE/+ }}$ mice. ML: Molecular Layer; PCL: Purkinje Cell Layer; GCL: Granule Cell Layer. Scale bars: $500 \mu \mathrm{m}$ (whole sections), $100 \mu \mathrm{m}$ (enlarged views).

E. Quantification of relative LZK protein levels in PC soma of anterior and posterior of cerebellum in $P V^{\mathrm{Cre} /+} ; L z k^{\mathrm{iOE} /+}$ mice. $\mathrm{n}=3$.

$(B, E)$. Data shown are means \pm SEM. Statistics for B, E: Student's unpaired t-test; ns, no significant; ${ }^{* * * *}, p<0.0001$.

Figure 4-figure supplement 2. Additional evidence for progressive degeneration of Purkinje cells induced by LZK activation.

A. Representative images of GFAP staining of cerebellar astrocytes of the mice from P15 to P120. ML: Molecular Layer; PCL: Purkinje Cell Layer; GCL: Granule Cell Layer. Scale bar: $100 \mu \mathrm{m}$.

B. Quantification of normalized GFAP levels in cerebellum of the mice from P15 to P120. From P21, mice with induced LZK expression in $\mathrm{PV}^{+}$neurons have significantly higher GFAP levels in cerebellum than control $L z k^{\mathrm{iOE} /+}$ mice. $\mathrm{n}=3$ per genotype at each time point. MFI: 
mean of fluorescence intensity. Data shown are means \pm SEM. Statistics: Student's unpaired t-test; ns, no significant; ${ }^{*}, p<0.05,{ }^{* * * *}, p<0.0001$.

C. Representative images of Purkinje cells and Bergmann glia in cerebellum of P45 mice, co-immunostained for Calbindin and GFAP. The death of Purkinje cells induced increased reactivity of their adjacent Bergmann glia (arrows). ML: Molecular Layer; PCL: Purkinje Cell Layer; GCL: Granule Cell Layer. Scale bar: $100 \mu \mathrm{m}$.

\section{Figure 5-figure supplement 1. CELF2 is a regulator of Mkk7 in Purkinje cells.}

A. Schematic of $m k k 7$ locus on Chromosome 8 , along with primers for mRNA detection of Mkk7 isoforms. Scale bar: 1kb. CELF2 promotes exclusion of exon 2 of Mkk7. The gel image shows the RT-PCR analysis of the Mkk7 long isoform (Mkk7-L) and short isoform (Mkk7-S) as well as $\beta$-actin mRNA levels in cerebellum of $P V^{\text {Cre/+ }}$ mouse using primers YJ1251612519.

B. qRT-PCR analyses show the mRNA ratio of Mkk7-S / Mkk7-L in cerebellum from P21 mice of genotypes indicated. RNA samples are collected from $n=3$ mice / genotype. For qRT-PCR, $\mathrm{n}=5$ replicates / sample.

C. The Celf $2^{f / f l}$ mice have two loxP sites flanking exon 3 , and Cre-mediated excision results in an early stop codon within exon 4 , hence a null allele. The homozygotes or heterozygotes of Celf2 ${ }^{f l}$ were identified by PCR using primers YJ12527 and YJ12528.

D. Representative images of Calbindin staining of cerebellar sections from P21 mice of genotypes indicated. Scale bars: $500 \mu \mathrm{m}$.

E. Quantification of total number of PCs in all cerebellar lobules.

F. Quantification of the molecular layer thickness in cerebellar lobules V-VI.

G. Quantification of the cerebellum area of P21 mice.

$H$. Quantification of the body weight of P21 mice of genotypes indicated.

I. The DLK protein levels in cerebellum from P10 mice of genotypes indicated were determined by western blot. $\mathrm{n}=3$ per group.

J. Representative images of Purkinje cells of P15 mice of genotypes indicated, coimmunostained for Calbindin and $\mathrm{p}$-c-Jun. Celf2 deletion did not reduce the phosphorylation level of c-Jun induced by DLK overexpression in $\mathrm{PV}^{+}$neurons (arrows), nor rescued the dendrite swelling caused by DLK overexpression in $\mathrm{PV}^{+}$neurons (arrowheads). $\mathrm{ML}$ : Molecular Layer; PCL: Purkinje Cell Layer; GCL: Granule Cell Layer. Scale bar: $100 \mu \mathrm{m}$. K. Quantification of the p-c-Jun levels in Purkinje cells of P15 mice. MFI: mean of fluorescence intensity.

L. Quantification of normalized p-c-Jun area in Purkinje cells of P15 mice. DLK overexpression in $\mathrm{PV}^{+}$neurons induces a higher level of $\mathrm{p}$-c-Jun in Purkinje cells than LZK overexpression (arrows). 
(F-I, K-L). $\mathrm{n}=3$ per genotype; data shown are means \pm SEM. Statistics for B, F-I, K-L: Oneway ANOVA; ns, no significant; ${ }^{*}, p<0.05,{ }^{* *}, p<0.01,{ }^{* * * *}, p<0.0001$.

Figure 5-figure supplement 2. CELF2 deletion reduces astrogliosis and microgliosis associated with LZK activation in $\mathrm{PV}^{+}$neurons.

A. Representative images of GFAP staining of cerebellar astrocytes from P120 mice of genotypes indicated. ML: Molecular Layer; PCL: Purkinje Cell Layer; GCL: Granule Cell Layer. Scale bars: $100 \mu \mathrm{m}$.

B. Quantification of normalized GFAP levels in cerebellum of P120 mice. MFI: mean of fluorescence intensity.

C. Representative images of cerebellar sections from P120 mice of genotypes indicated, coimmunostained for IBA1 and Calbindin. Enlarged white boxed areas show dying Purkinje cells caused by LZK activation in $\mathrm{PV}^{+}$neurons were phagocytosed by microglia. Scale bar: 100 m. ML: Molecular Layer; PCL: Purkinje Cell Layer; GCL: Granule Cell Layer.

D. Quantification of normalized IBA1 levels in cerebellum. MFI: mean of fluorescence intensity.

(B, D). $n=3$ per group; data shown are means \pm SEM. Statistics for $B$, D: One-way ANOVA; ns, no significant; ${ }^{* *}, p<0.01,{ }^{* * *}, p<0.001,{ }^{* * *}, p<0.0001$.

\section{Figure 5-figure supplement 3. CELF2 deletion rescues reduced expression of MAP2} and NF-200 and pinceau disorganization induced by LZK activation.

A. Representative images of cerebellar sections from P120 mice of genotypes indicated, coimmunostained for Calbindin and MAP2. Arrows point MAP2 staining in dendrites of Purkinje cells.

B. Representative images of cerebellar sections from P120 mice of genotypes indicated, coimmunostained for NF-200 and Calbindin. LZK overexpression in $\mathrm{PV}^{+}$neurons changes the organization of basket cell pinceaux (arrows) at the initial segment of axons of Purkinje cells, which is suppressed by Celf2 deletion.

(A-B) ML: Molecular Layer; PCL: Purkinje Cell Layer; GCL: Granule Cell Layer. Scale bar: $50 \mu \mathrm{m}$.

C. Representative images of parvalbumin staining of cerebellar sections from P120 mice of genotypes indicated. Enlarged boxed areas in lower panel show suppression of pinceaux disorganization by Celf2 deletion. ML: Molecular Layer; PCL: Purkinje Cell Layer; GCL: Granule Cell Layer. Scale bars: $500 \mu \mathrm{m}$ (upper panel), $100 \mu \mathrm{m}$ (lower panel).

Figure 6-figure supplement 1. Additional evidence of apoptosis in Purkinje cell degeneration caused by LZK activation. 
A. Western blot showing LZK and Bcl-xL protein levels in cerebellar extracts from P21 mice of genotypes indicated. The LZK proteins were first immunoprecipitated and then analyzed by western blot.

B. Quantification of normalized LZK protein levels. $n=3$ per genotype. Data shown are means \pm SEM. Statistics: Student's unpaired t-test; ns, no significant.

C. Quantification of the ratio of cleaved Bcl-xL relative to $\beta$-actin protein levels. $n=3$ per group. Data shown are means \pm SEM. Statistics: One-way ANOVA; ns, no significant; ***, $\mathrm{p}<0.001$.

D. Representative images of TUNEL fluorescence signal (fluorescein-12-dUTP) in cerebellar lobules of P120 mice of genotypes indicated. Scale bars: $100 \mu \mathrm{m}$.

E. Quantification of the percentage of TUNEL ${ }^{+}$Purkinje cells in total Purkinje cells

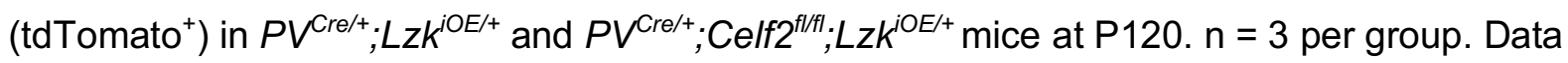
shown are means \pm SEM. Statistics: Student's unpaired t-test; ${ }^{* *}, p<0.01$.

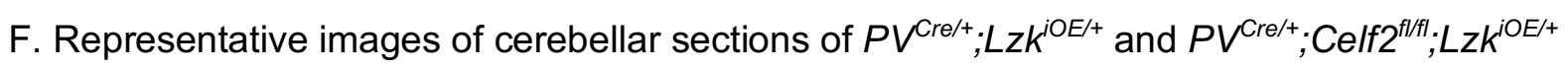
mice labeled with TUNEL fluorescence signal and reporter tdTomato. The TUNEL signal was co-localized with Purkinje cells in $\mathrm{PV}^{\mathrm{Cre} /+} ; \mathrm{Lzk}^{\mathrm{iOE/+}}$ mice (arrow), but not in $\mathrm{PV}^{\mathrm{Cre} /+}$;Celf2 ${ }^{\mathrm{fl} / \mathrm{fl} ; \mathrm{Lz}}{ }^{\mathrm{iOE} /+}$ mice. ML: Molecular Layer; PCL: Purkinje Cell Layer; GCL: Granule Cell Layer. Scale bars: $100 \mu \mathrm{m}$.

\section{Figure 7-figure supplement 1. Levels of $\mathrm{p}$-c-Jun induced by activation of DLK or LZK} is not affected by loss of Lzk or Dlk, respectively.

A. LZK deletion did not attenuate the phosphorylation of c-Jun induced by DLK overexpression in $\mathrm{PV}^{+}$neurons. Shown are representative images of cerebellar sections of P10 mice, co-immunostained for p-c-Jun and Calbindin. EGL: External Granule Layer; ML: Molecular Layer; PCL: Purkinje Cell Layer; IGL: Internal Granule Layer. Scale bar: $100 \mu \mathrm{m}$. B. Quantification of the p-c-Jun levels in Purkinje cells of P10 mice of genotype indicated. $\mathrm{MFI}$ : mean of fluorescence intensity. $n=3$ per genotype.

C. Quantification of the body weight of P60 mice of genotypes indicated. $n \geq 3$ per genotype.

D. DLK deletion did not attenuate the phosphorylation of c-Jun induced by LZK overexpression in $\mathrm{PV}^{+}$neurons. Shown are representative images of cerebellar lobules of P60 mice, co-immunostained for Calbindin and p-C-Jun. ML: Molecular Layer; PCL: Purkinje Cell Layer; GCL: Granule Cell Layer. Scale bar: $100 \mu \mathrm{m}$.

E. Quantification of the p-c-Jun levels in Purkinje cells of P60 mice. MFI: mean of fluorescence intensity. $n=3$ per group.

$(B, C, E)$. Data shown are means \pm SEM. Statistics for B, C, E: One-way ANOVA; ns, no significant; ${ }^{* * * *}, p<0.0001$. 


\section{Supplementary Videos}

Video 1. Locomotor deficits in $\mathrm{P} 15 \mathrm{PV}^{\mathrm{Cre} / \mathrm{+}} ; \mathrm{DI} \mathrm{k}^{\mathrm{OOE} /+}$ mice.

A representative $\mathrm{P} 15$ old $\mathrm{PV}^{\mathrm{Cre} /+} ; \mathrm{DI} \mathrm{k}^{\mathrm{iOE} /+}$ mouse exhibited difficulty moving forward and drags its abdomen along the ground, as well as tremors.

Video 2. Locomotor deficits in $\mathrm{P} 120 \mathrm{PV}^{\mathrm{Cre} /+} ; \mathrm{Lzk}^{\text {iOE/+ }}$ mice.

A representative $\mathrm{P} 120$ old $P V^{\mathrm{Cre} /+} ; \mathrm{Lz} \mathrm{K}^{\mathrm{iOE} /+}$ mouse exhibited severe limp while walking and tremors. 


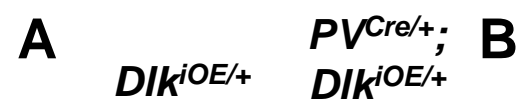

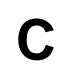

Fig.2

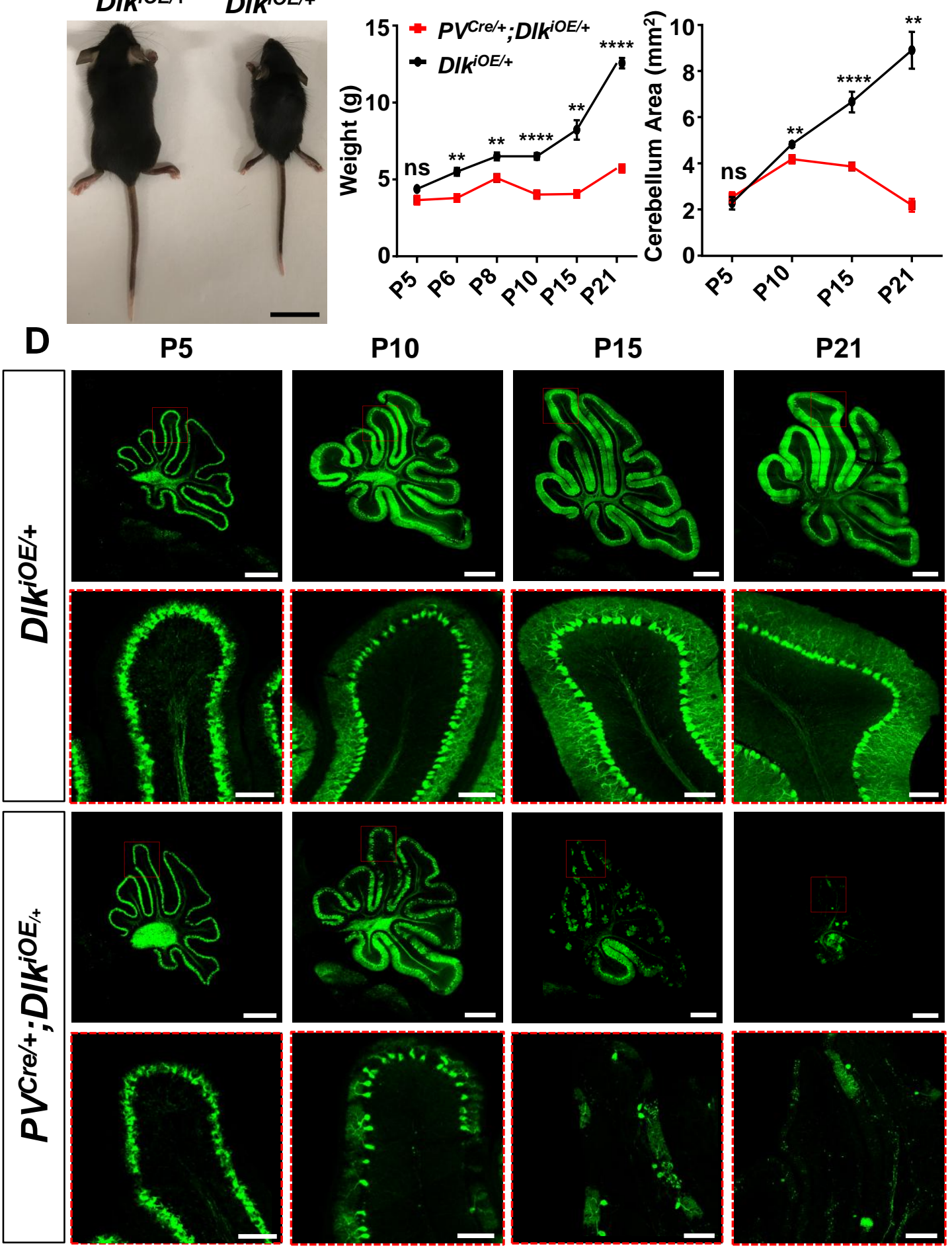

E

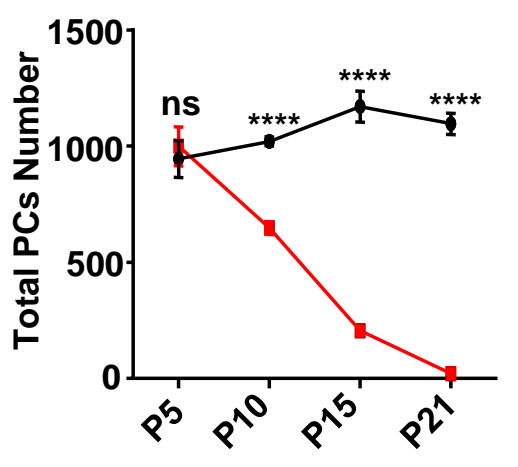

F

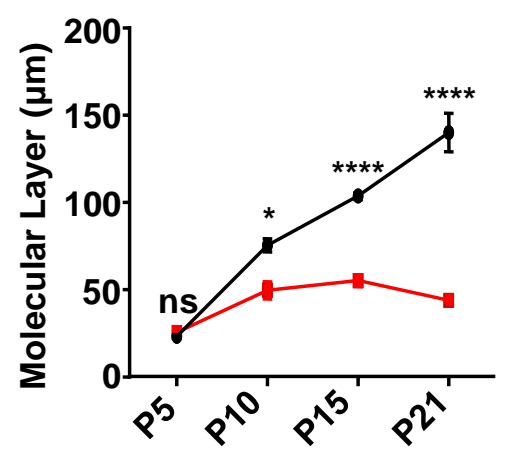


A $D I k^{i O E /+} \quad P V^{C r e /+} ; D l k^{i O E /+}$
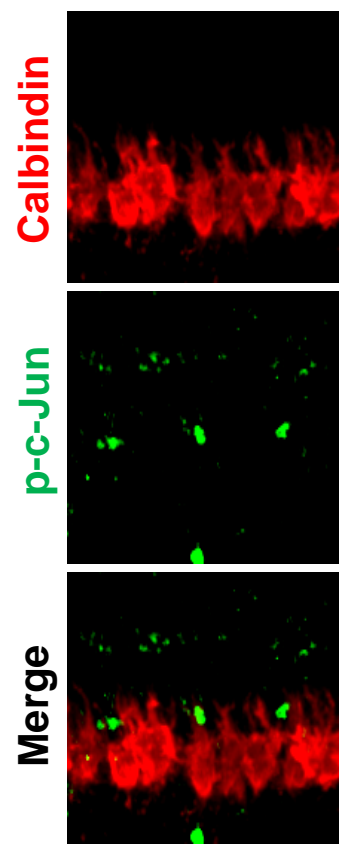

B
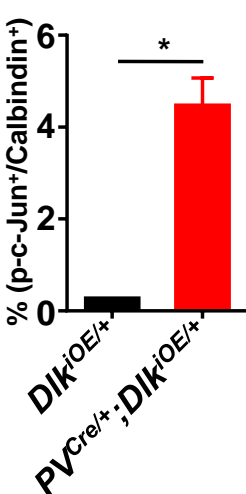

G MAP2

商

แั山
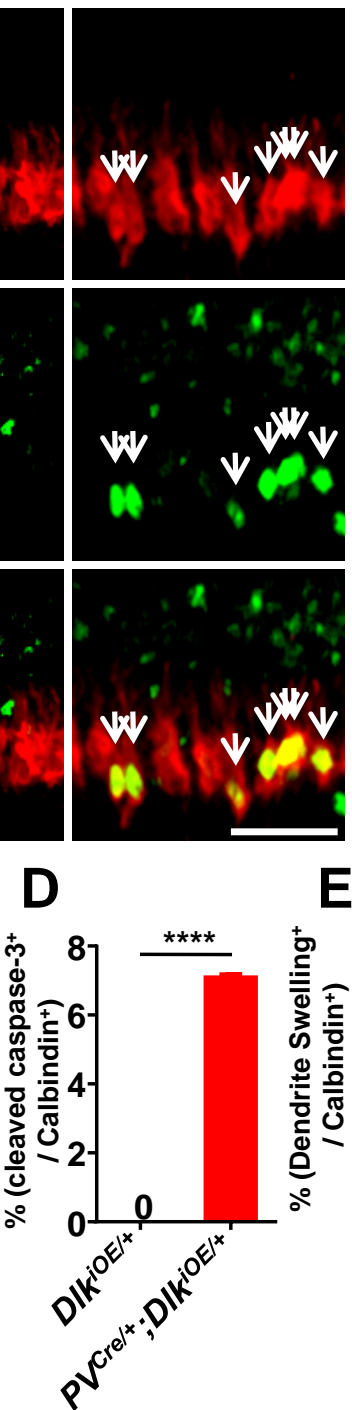

Calbindin

\section{E}
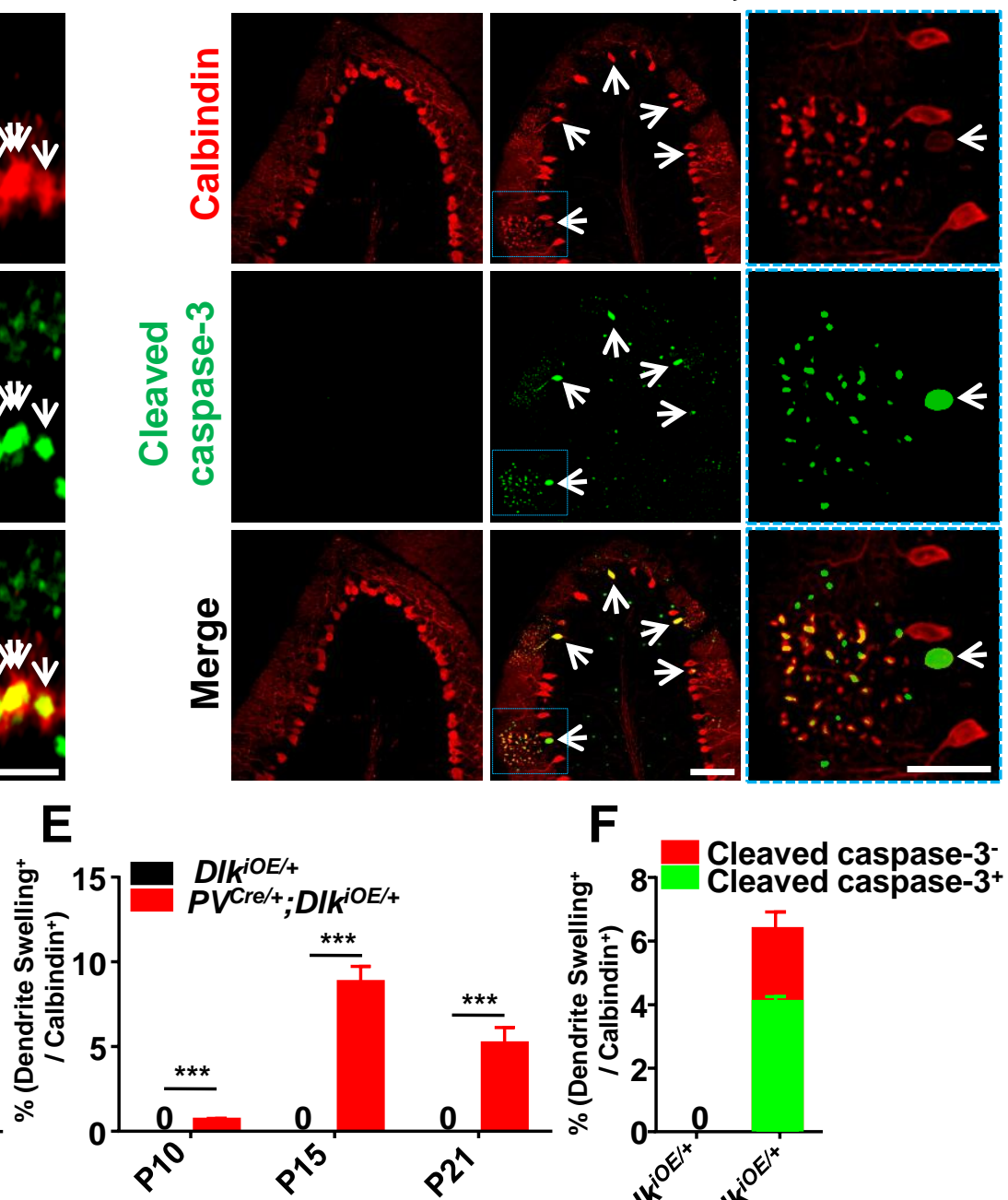

C $\mathrm{DIk}^{\mathrm{iOE} /+}$

PVCre/+;DIkiOE/+

F

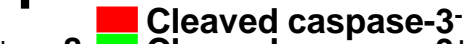

+50 Cleaved caspase- $3^{+}$

言
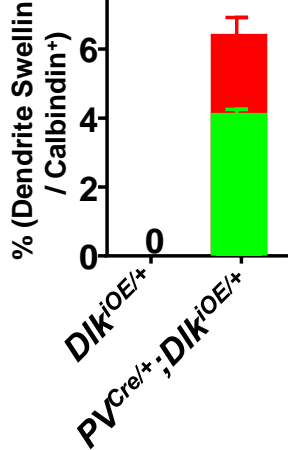

Merge
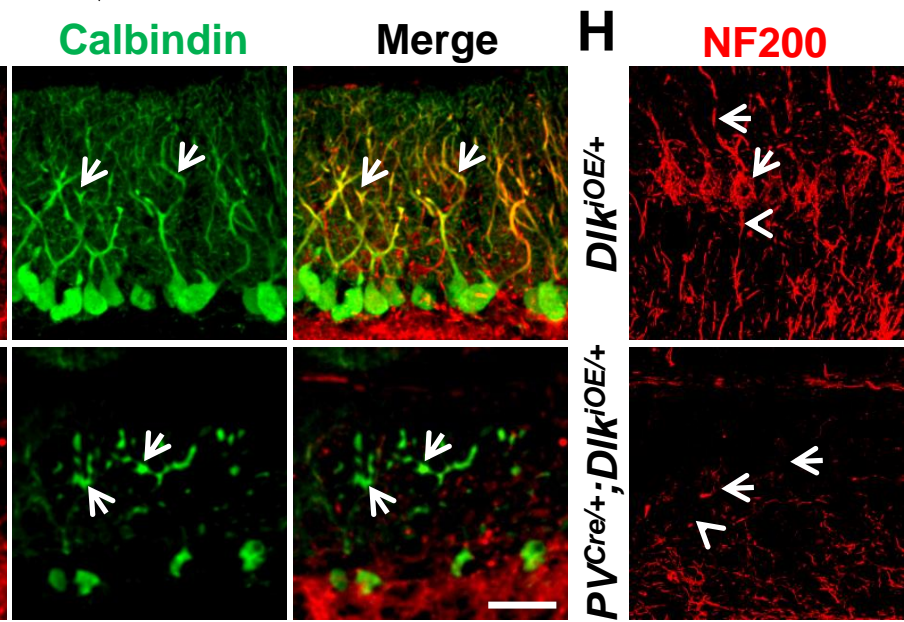

Merge

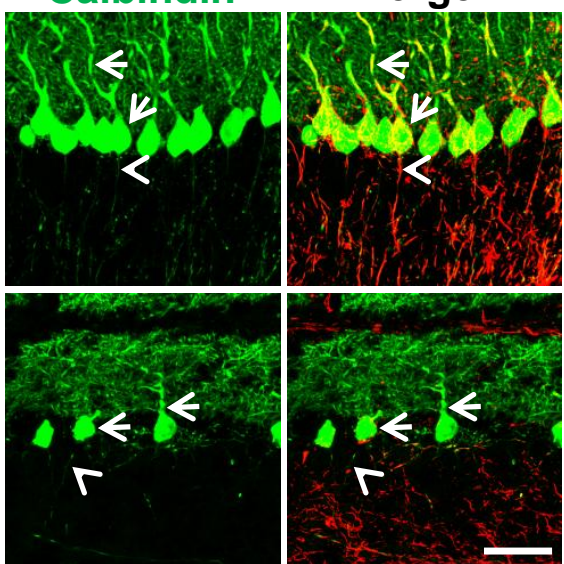


Fig.4

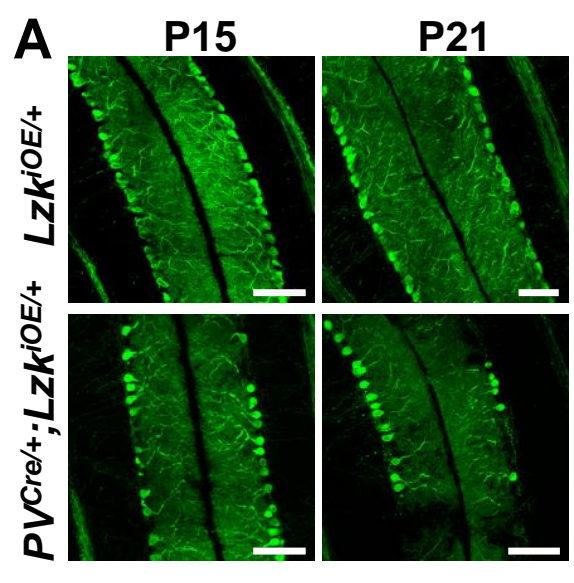

P30

P45

P60

P120

B
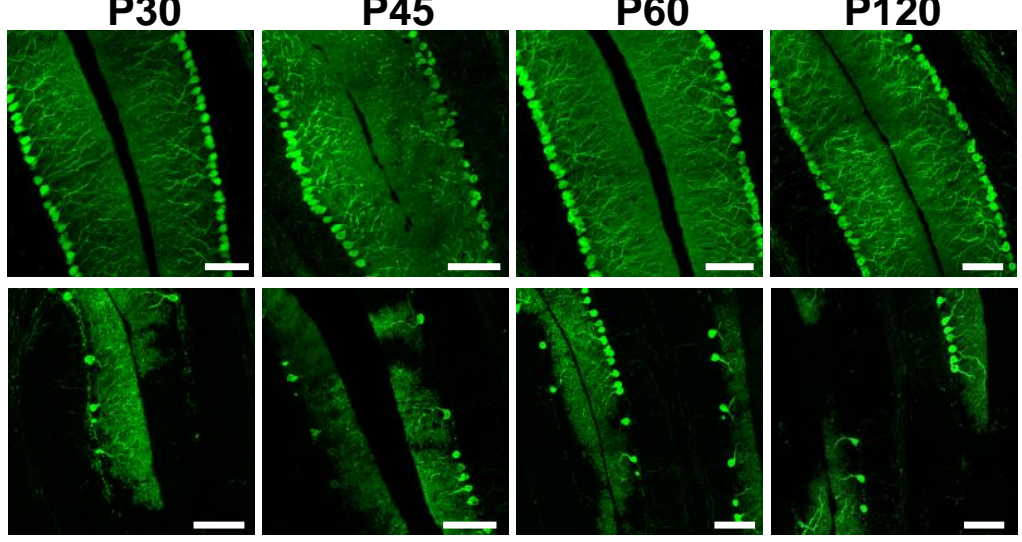

1500 - Lzk KOE/+ $^{\text {IO }}$

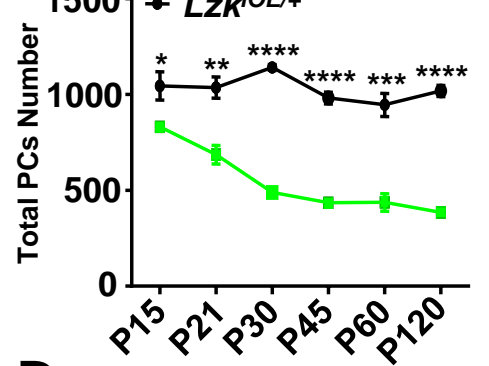

\section{D}

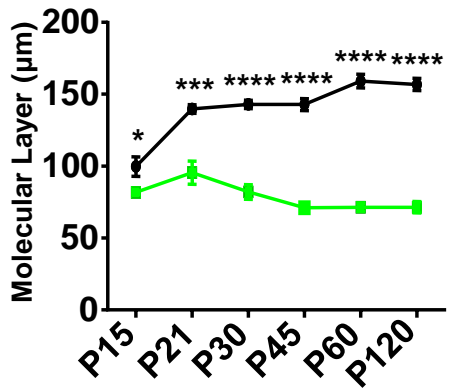

H
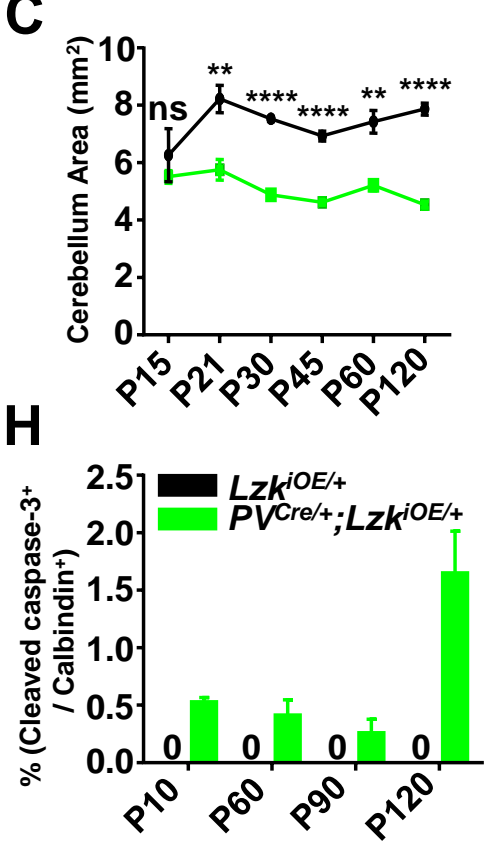

$\mathbf{F}$

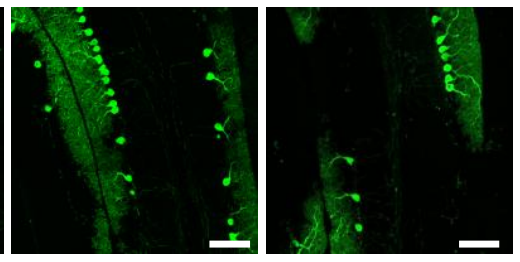

F $\quad$ Lzk $^{\mathrm{iOE} /+} \quad$ PVCre/+;Lzk ${ }^{\mathrm{iOE} /+}$

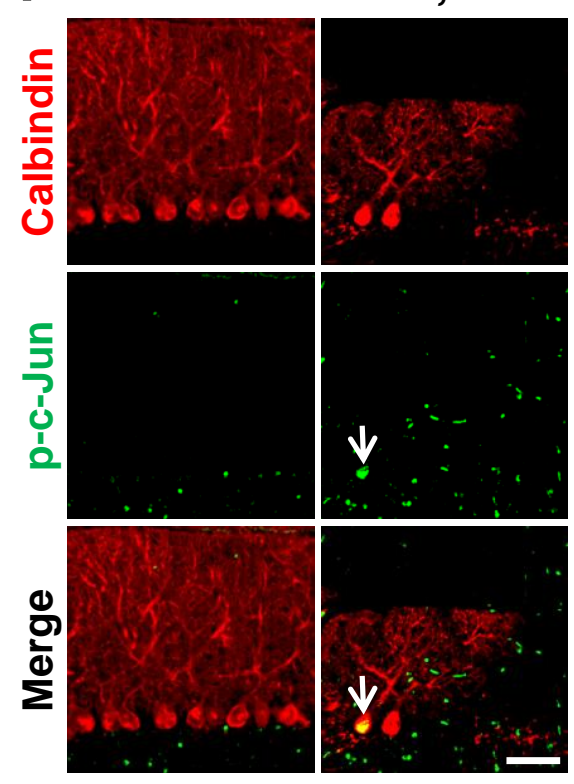

E

E MAP2

Calbindin Merge tdTomato

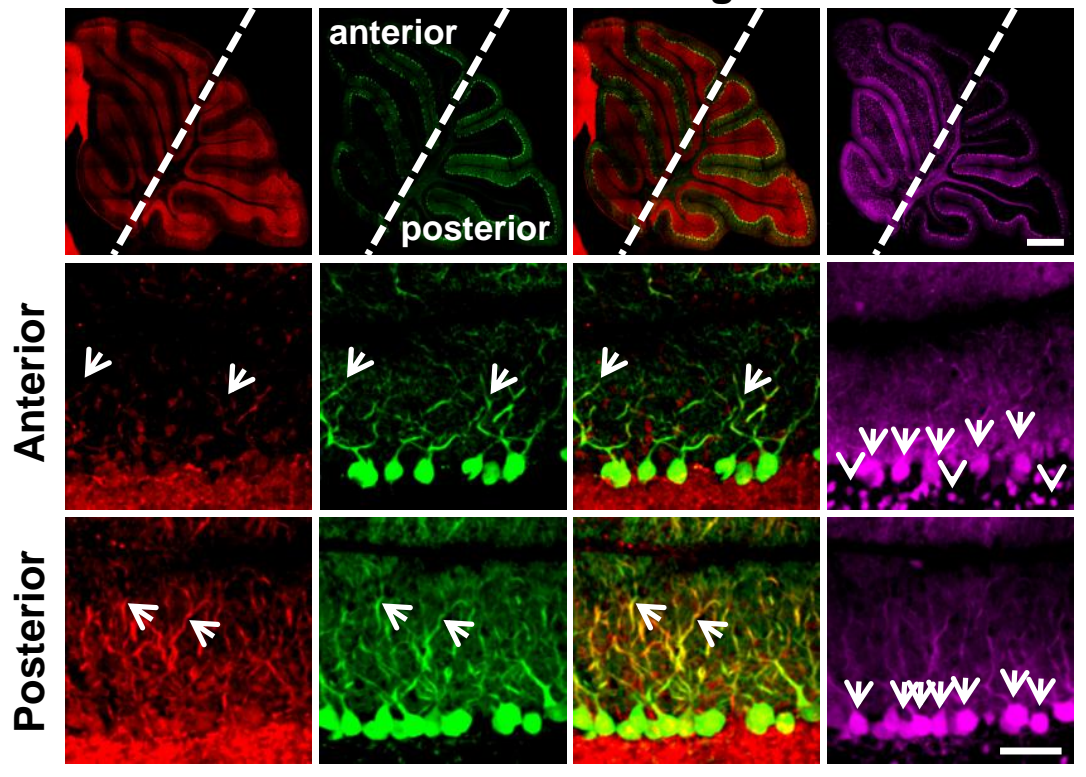

G $\quad \mathrm{Lzk}^{\mathrm{iOE} /+} \quad P V_{\mathrm{Cre} /+;} \mathrm{Lzk}^{\mathrm{iOE} /+}$

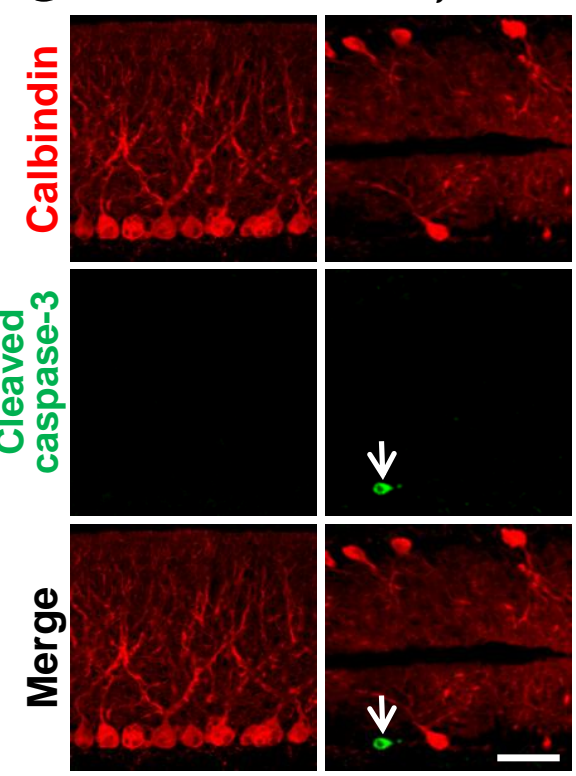


Fig.5
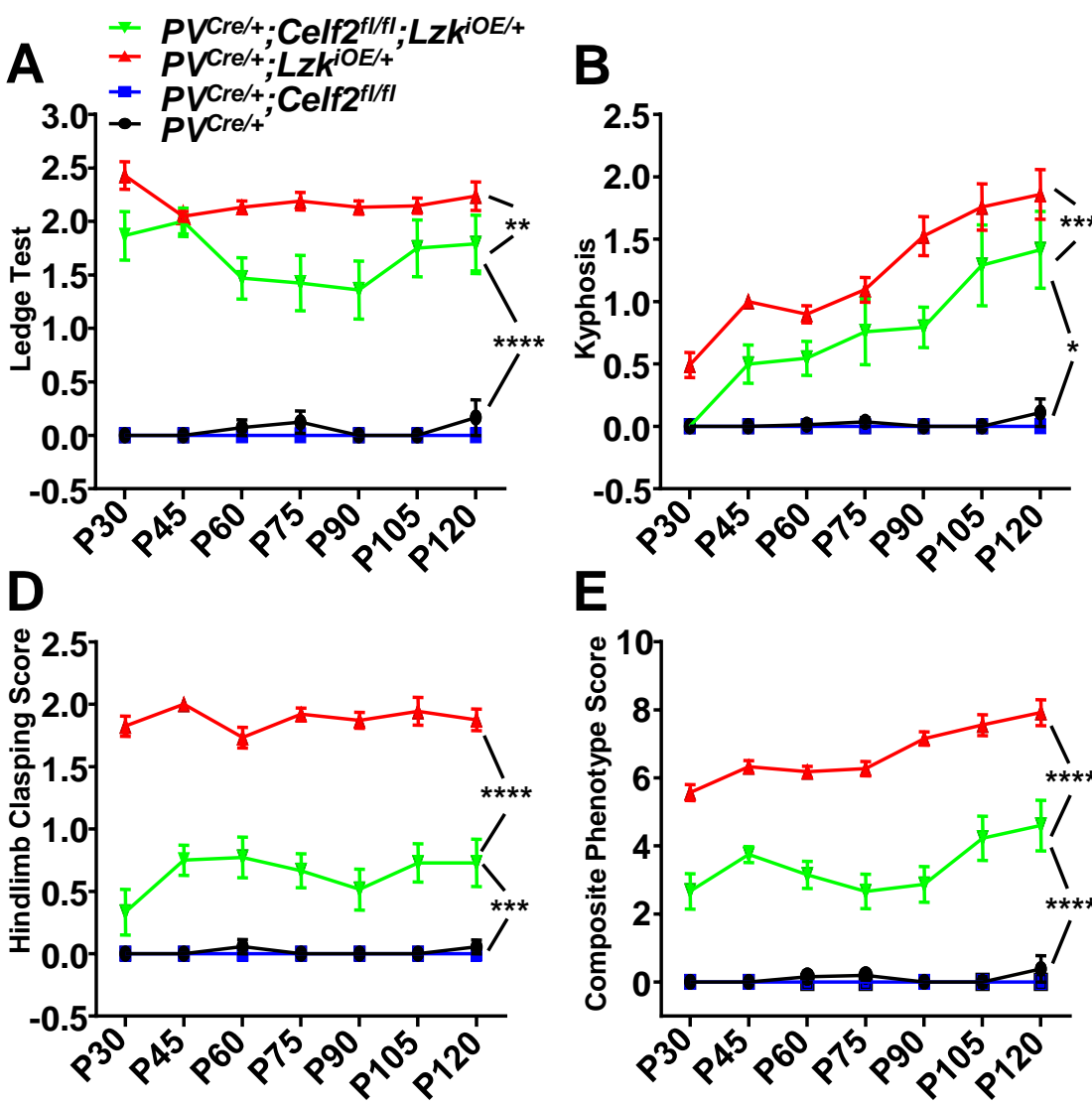

E
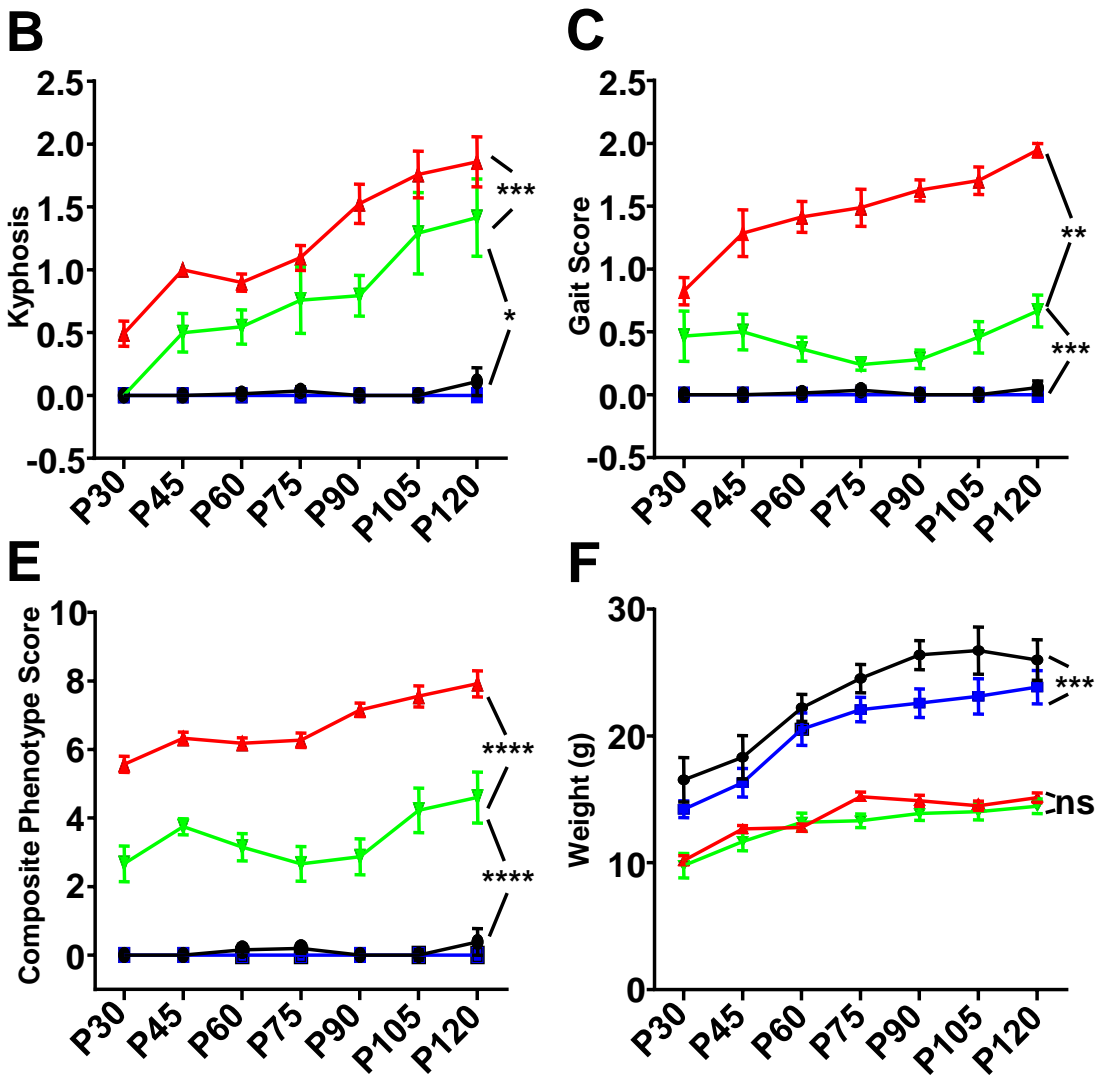

G

PVCre/+

PVCre/+$^{*}$ Celf2 ${ }^{f / f l}$
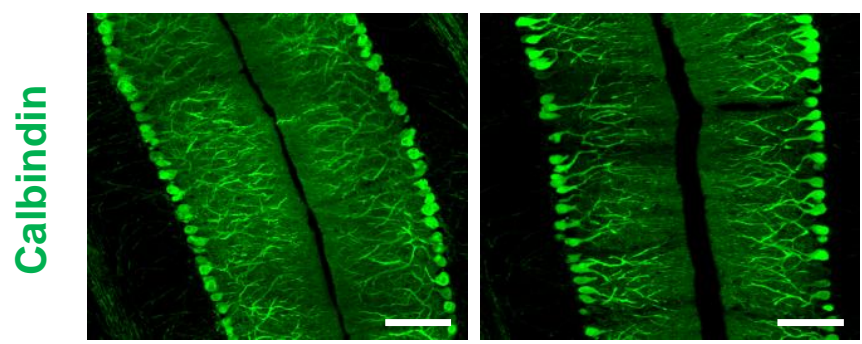

PVCre/t;

H

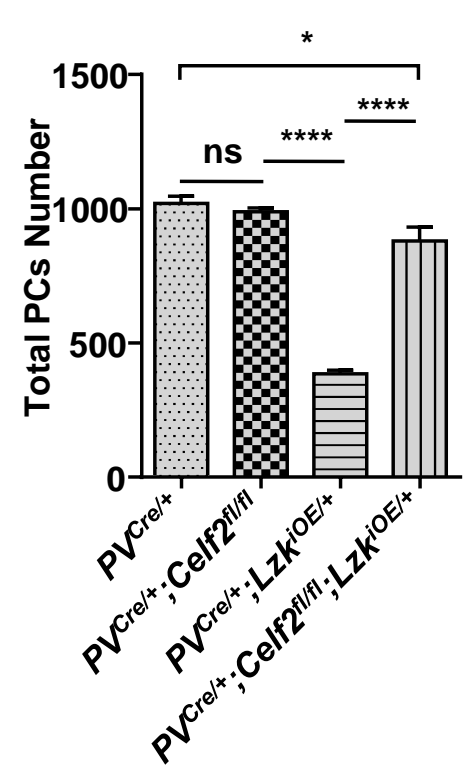

PVCre/+; ${ }_{\text {Lzk }}{ }^{\text {iOE} /+}$

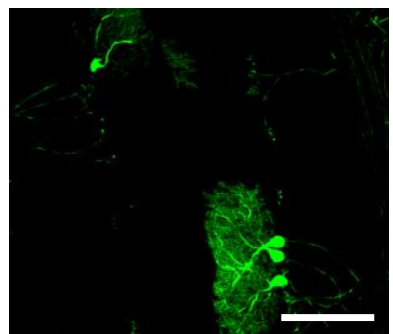

Celf2fl/fl; Lzk $^{\text {iOE } /+}$
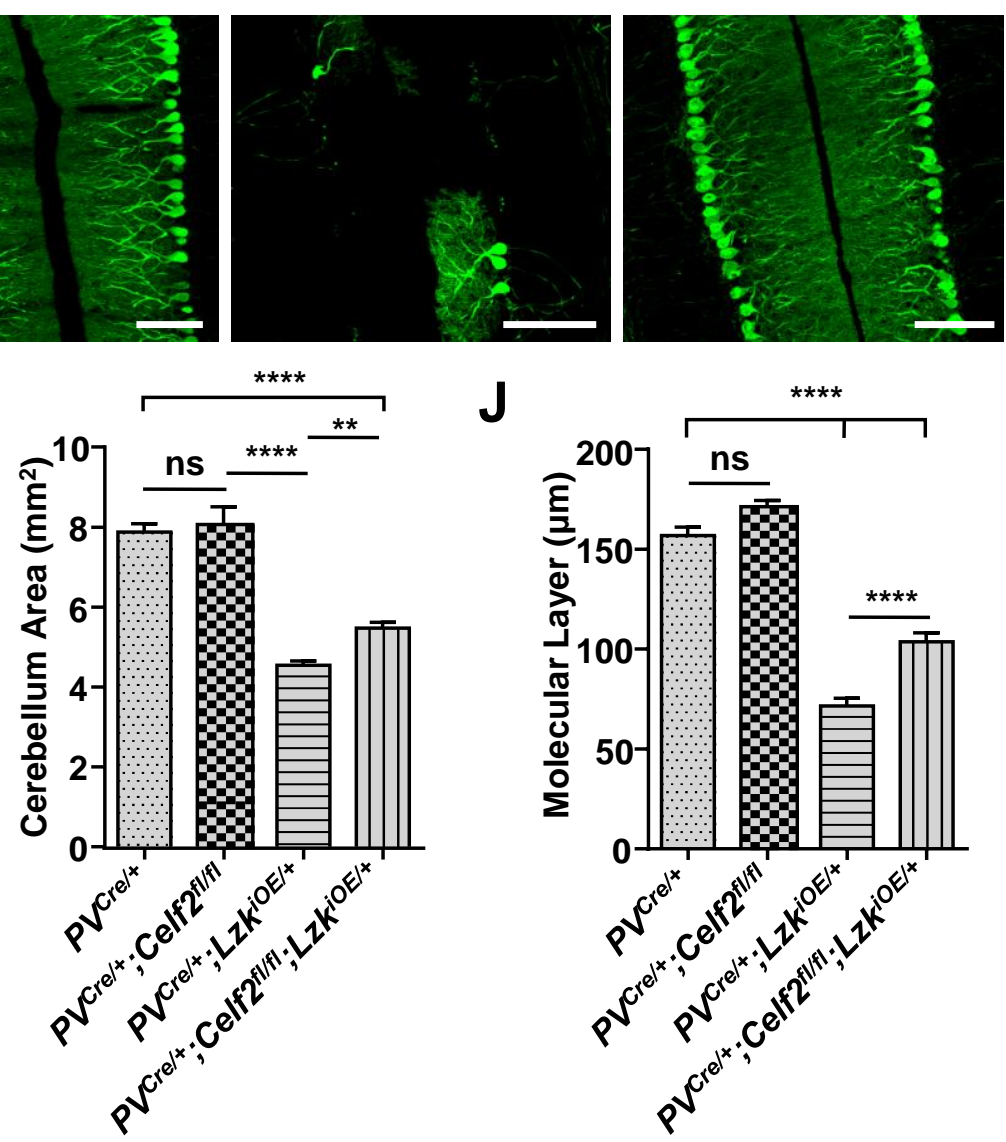
PVCre/t;

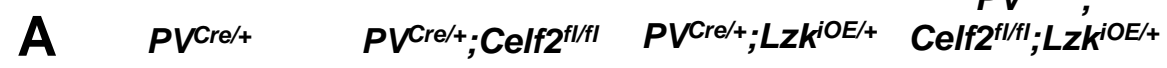

Fig.6

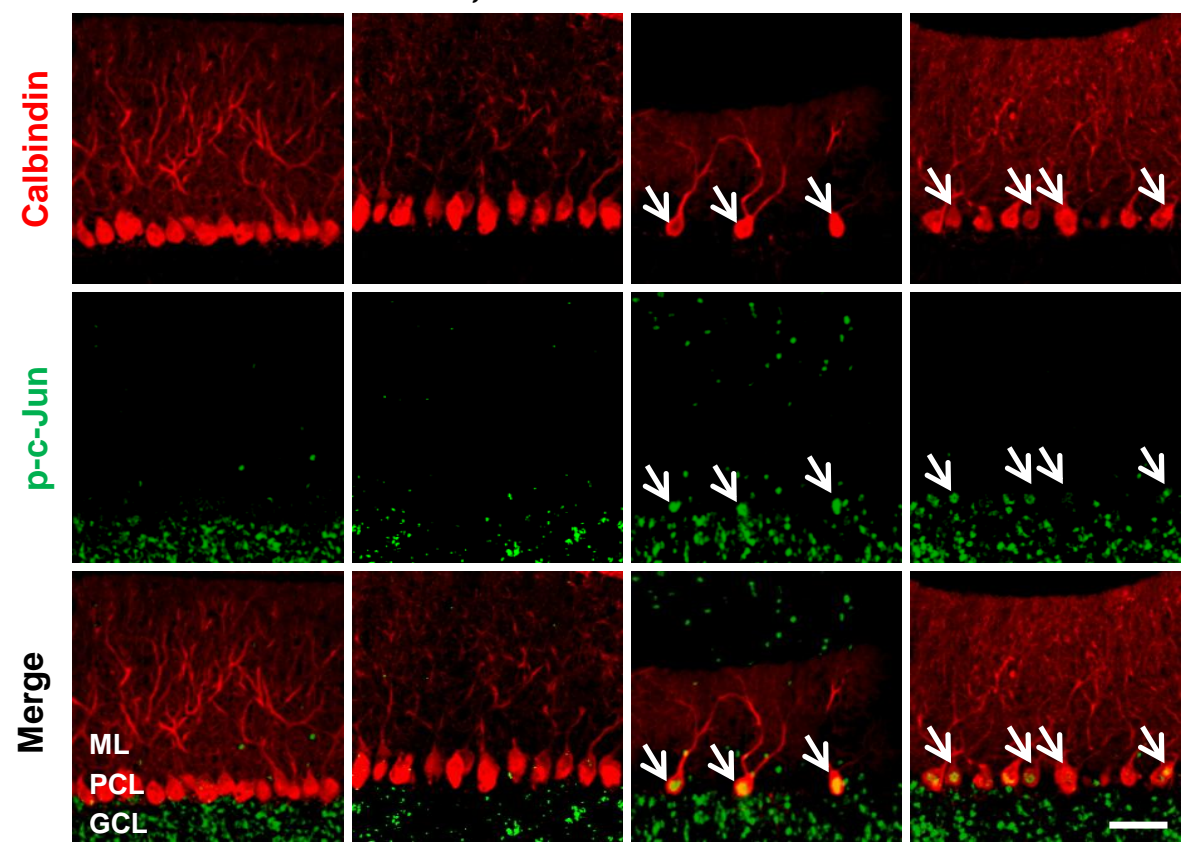

B

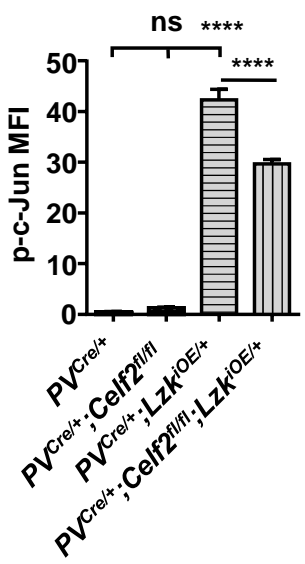

D

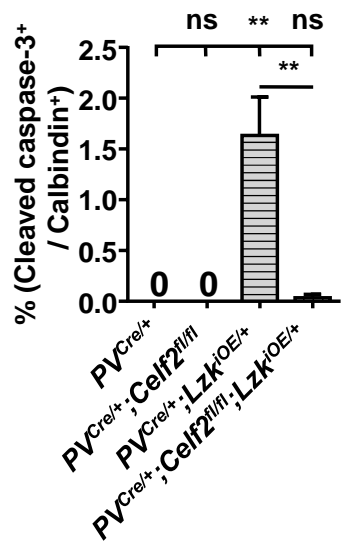

PVCre/+,

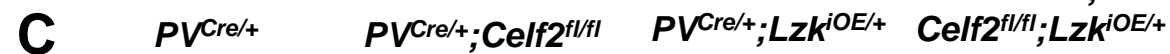

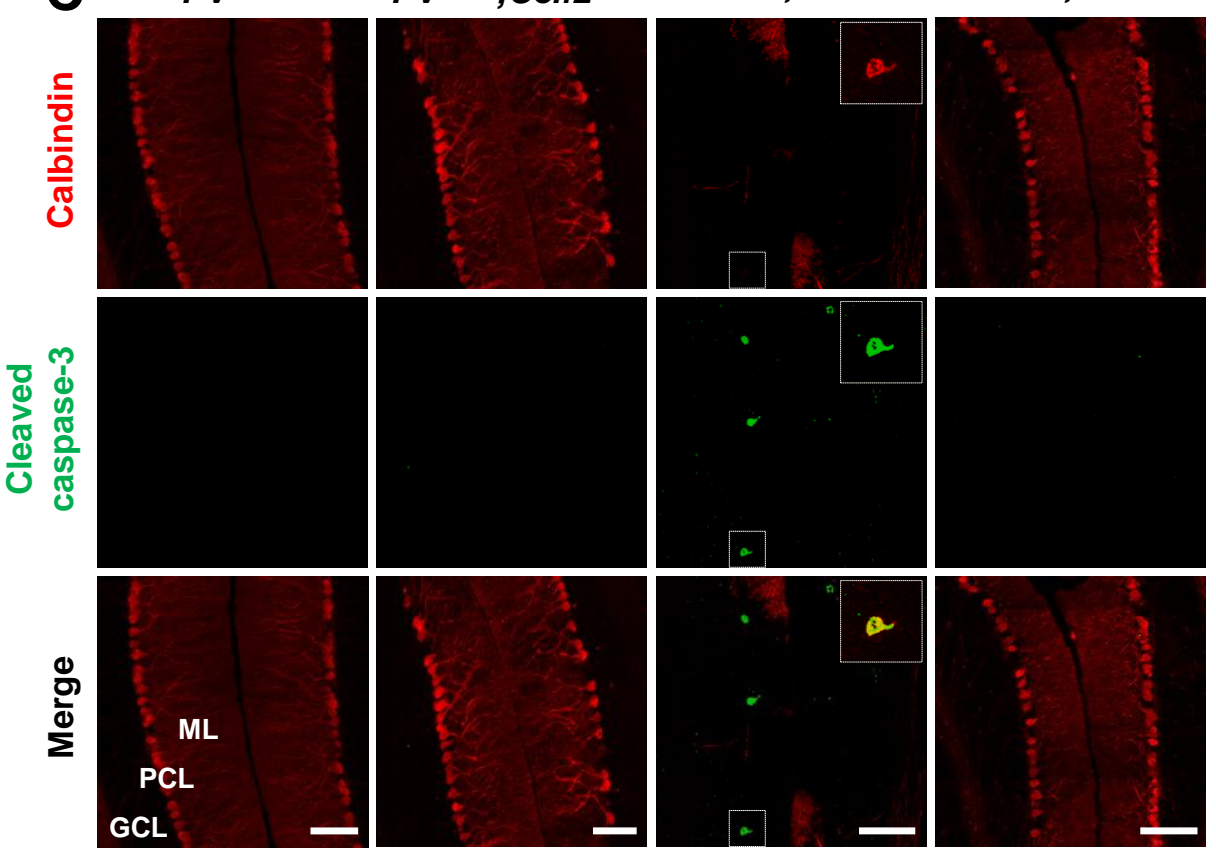


Fig.7
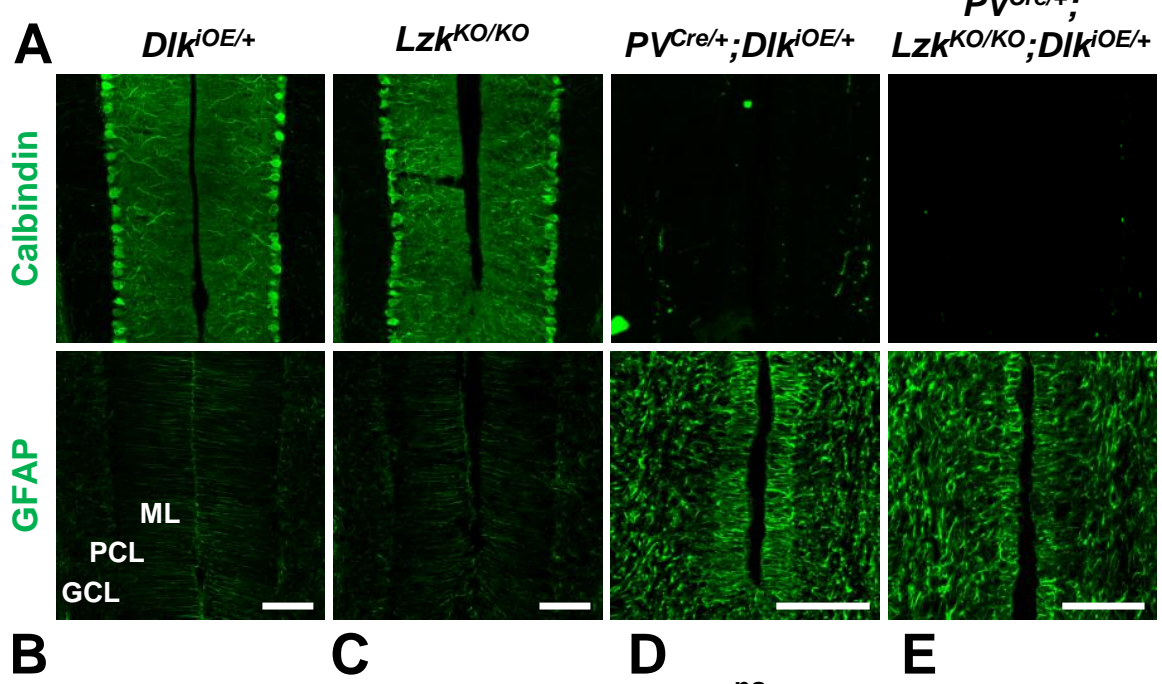

E
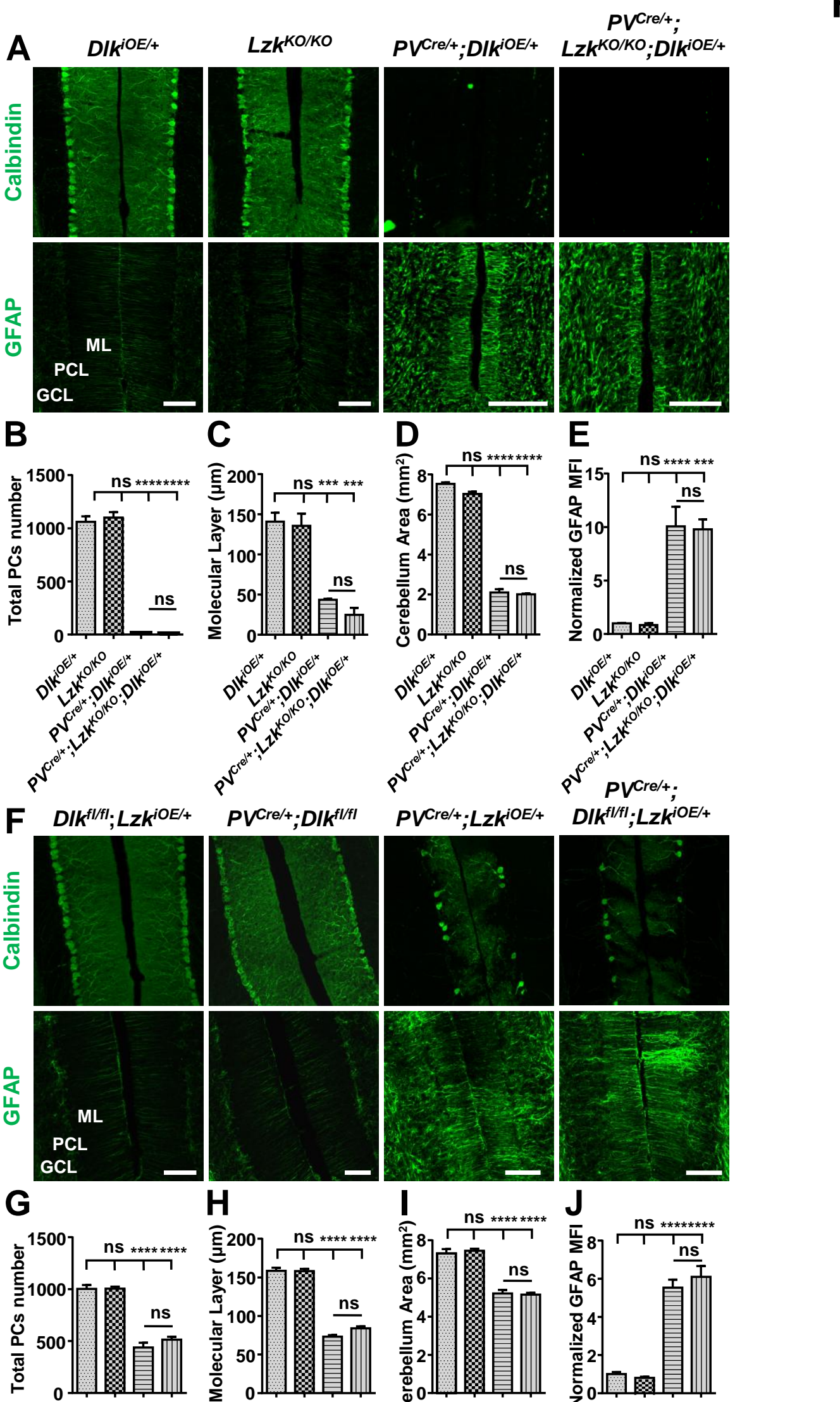

F $D I k^{f l / f l} ; L z k^{i O E /+}$

PVCre/+;DIkfl/fI
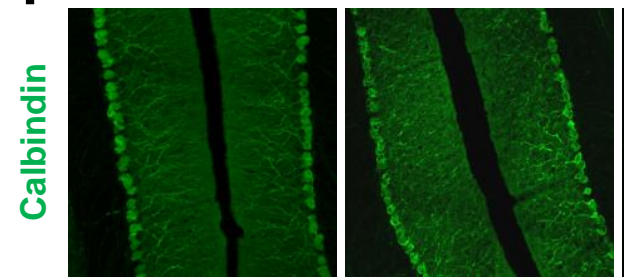

PVCre/+;LzkiOE/+
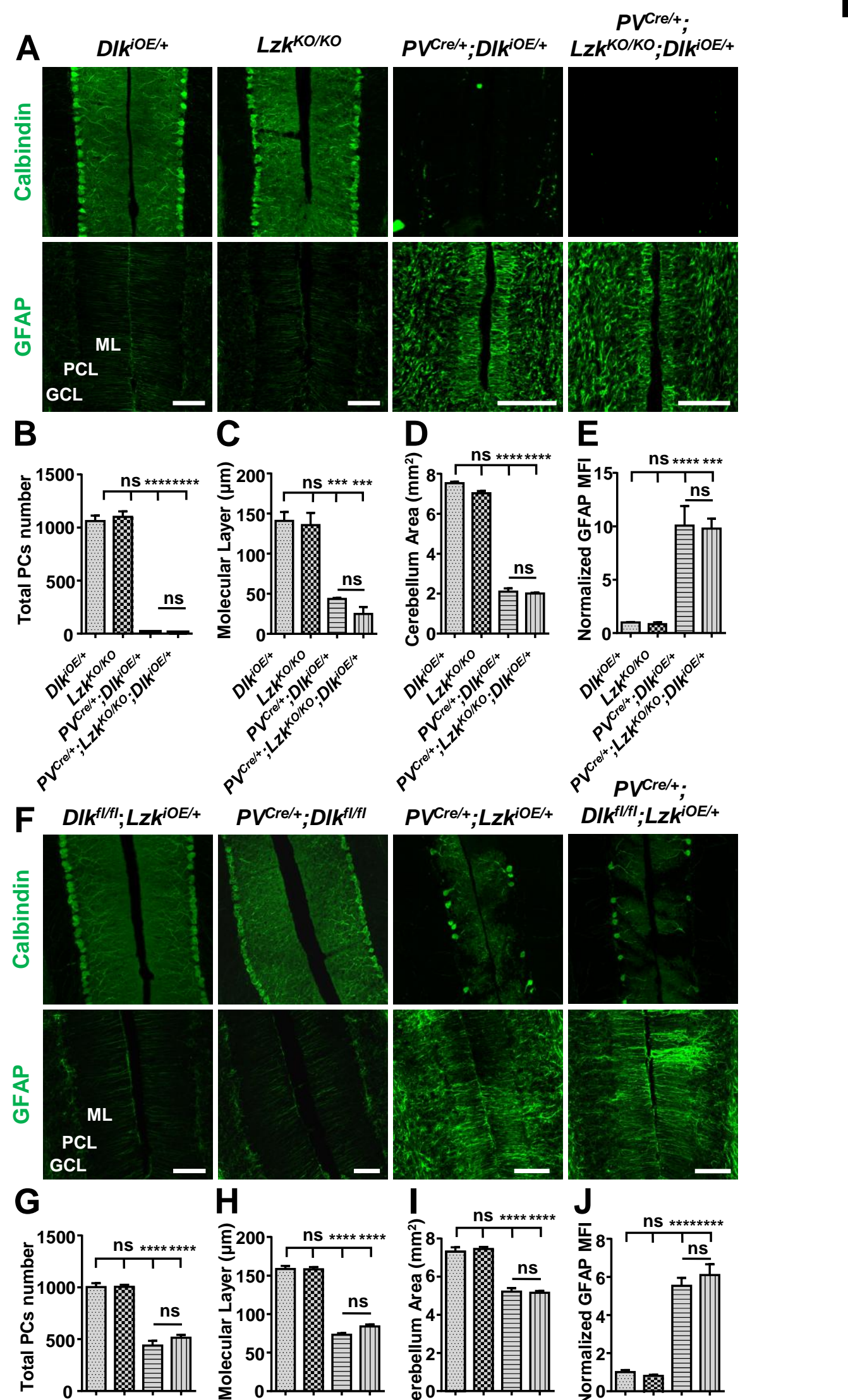

\section{G}
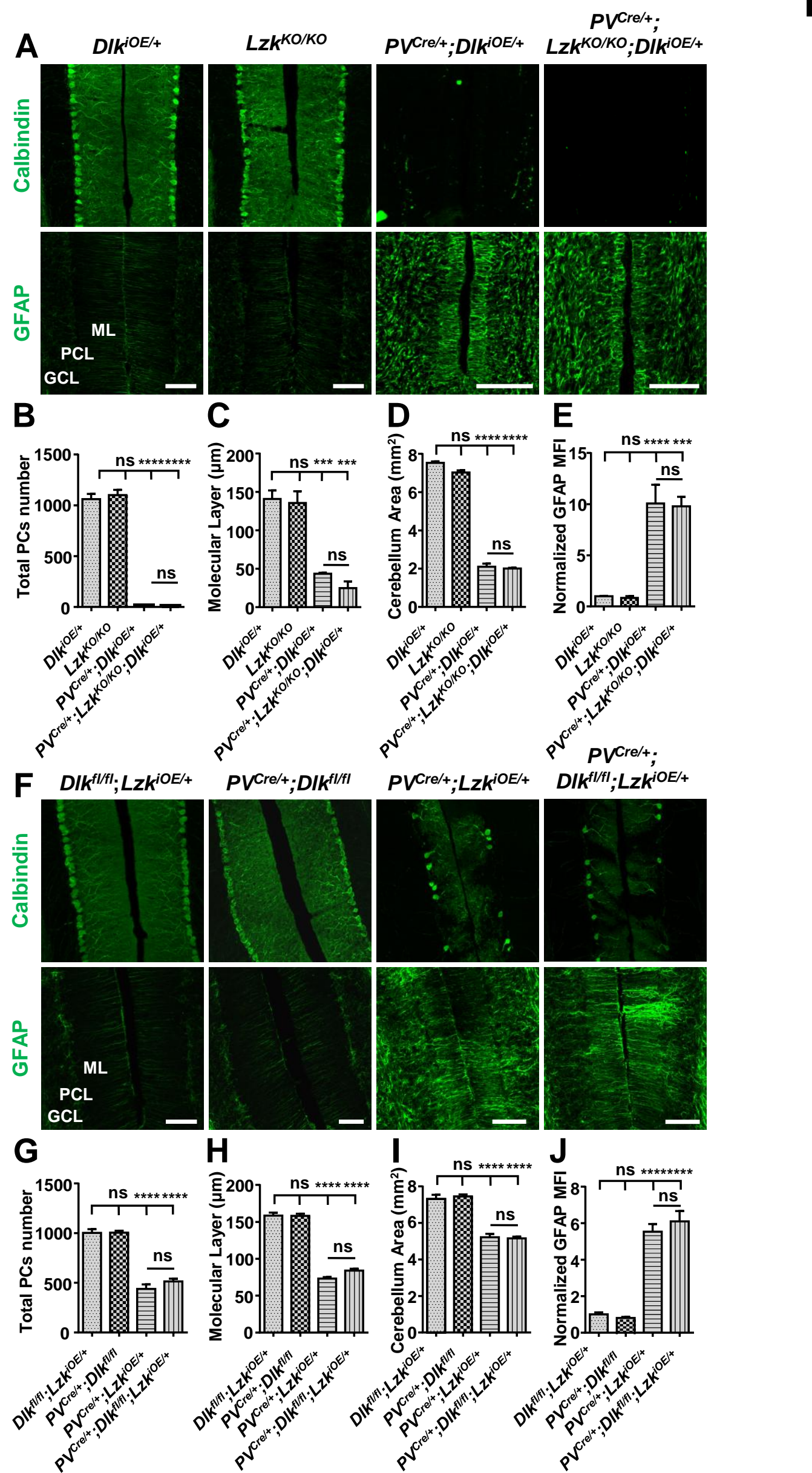


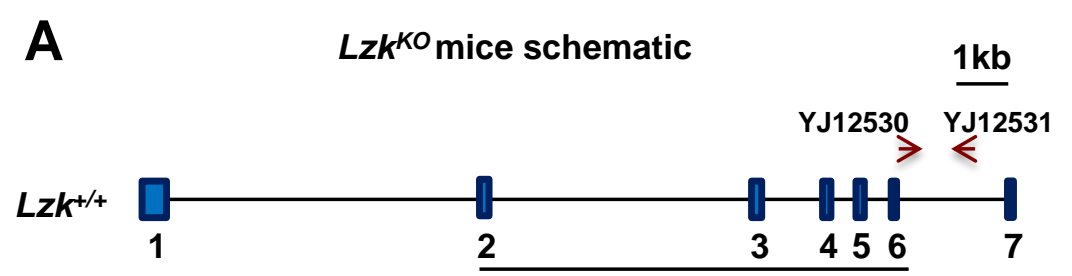

Exons coding kinase domain

LzkKO

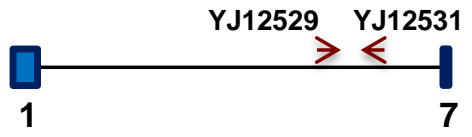

D
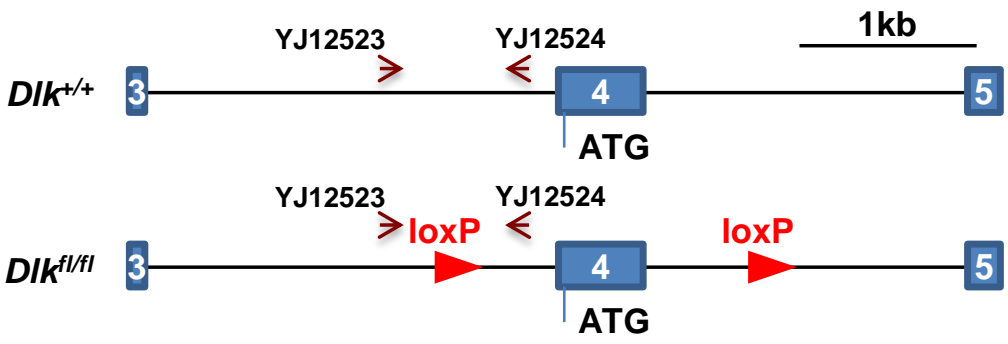

E

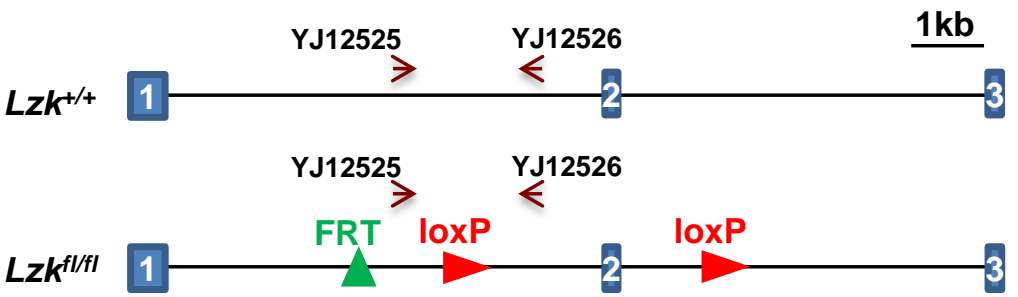

B

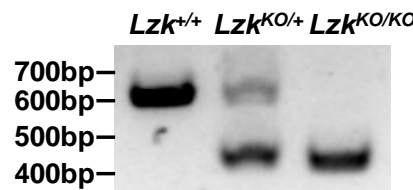

C

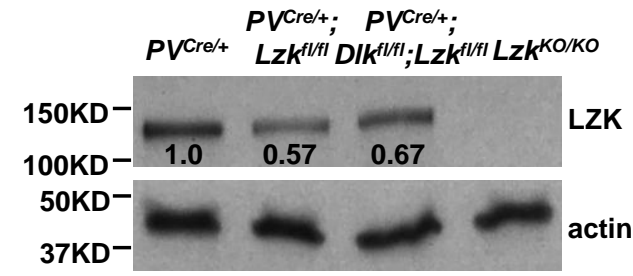

E

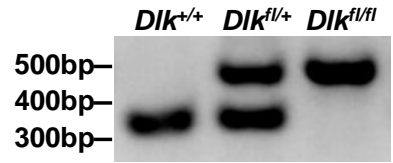

G

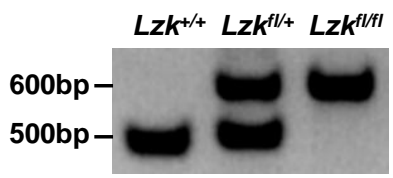

H

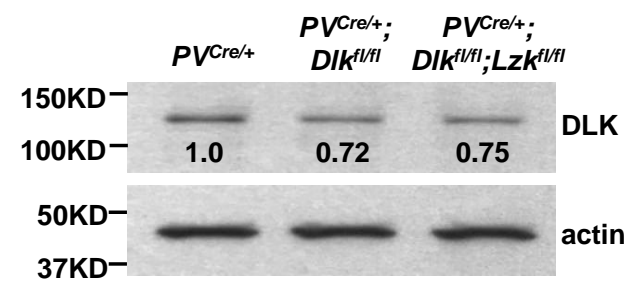

J
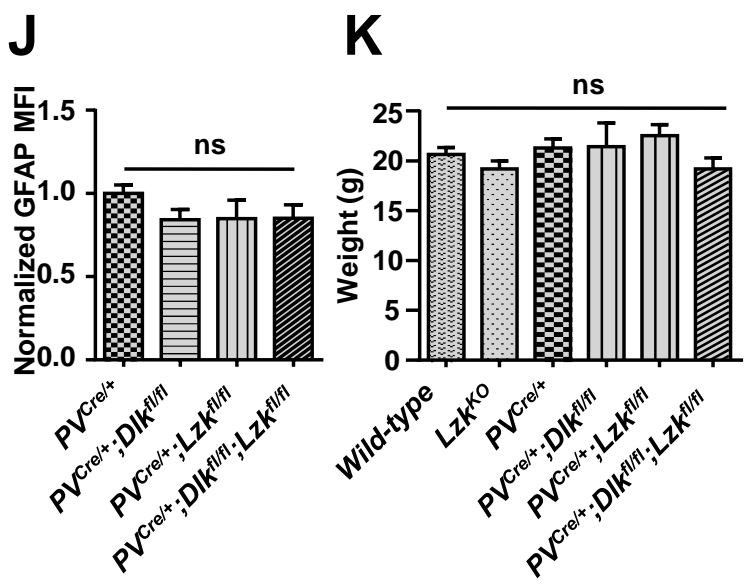
A

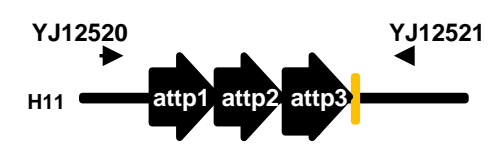

$\underset{\text { YJ12520 }}{\longrightarrow}$

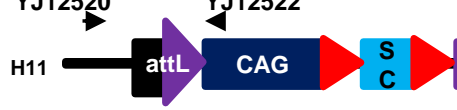

YJ12520

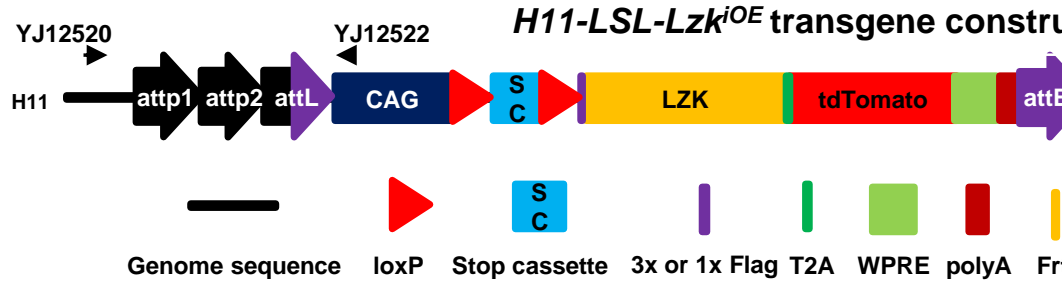

B

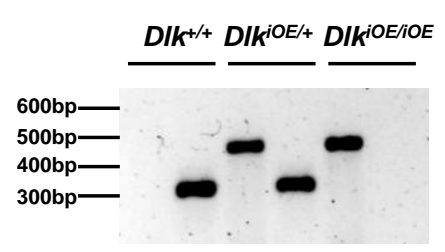

H11-LSL-DIk ${ }^{i O E}$ transgene construct

DLK tdTomato attB Bacterial

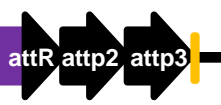

attR attp2 attp3
C

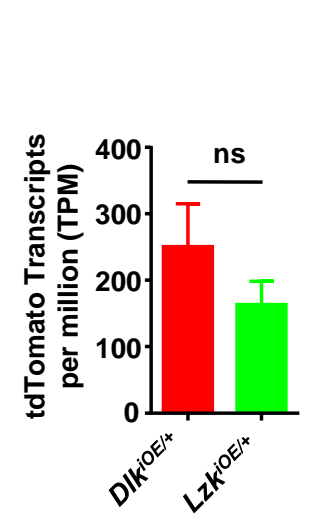

E

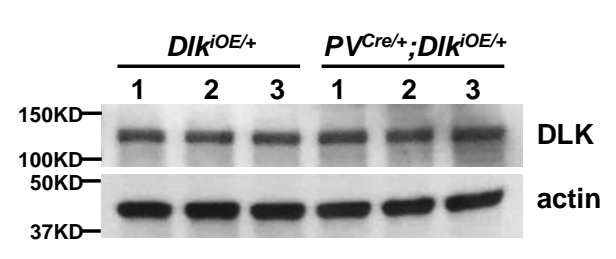

P5

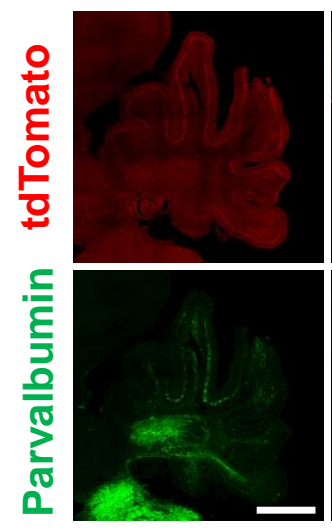

F

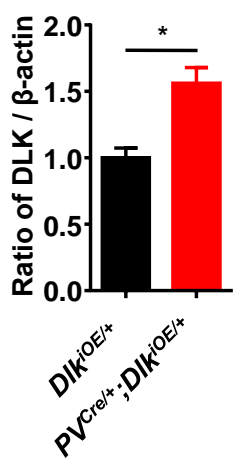

P6
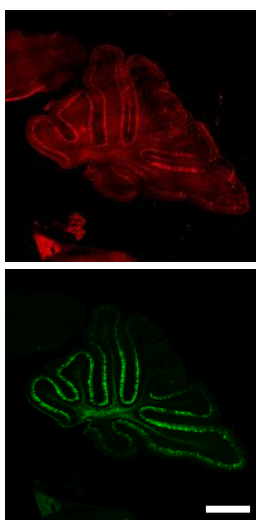

G
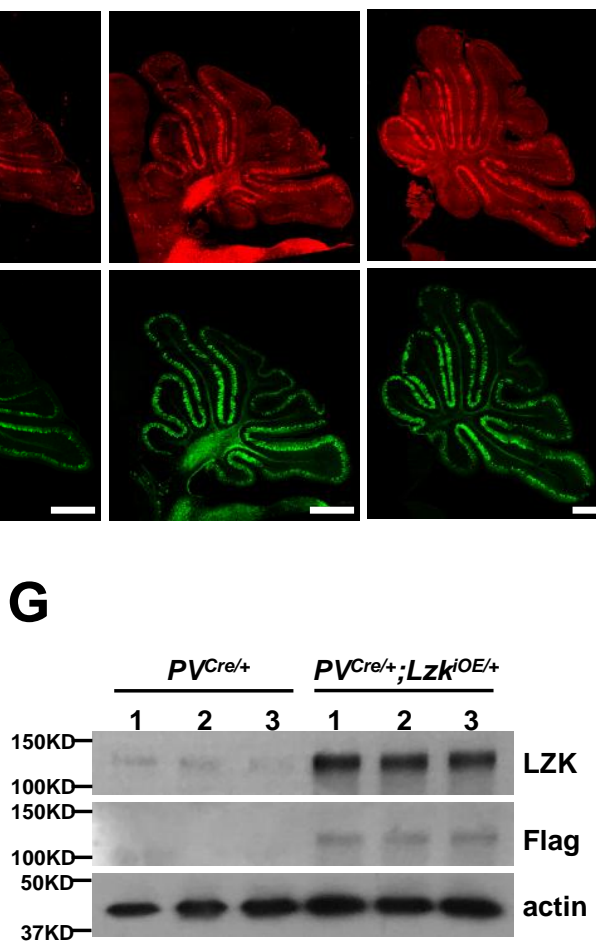

P15

H

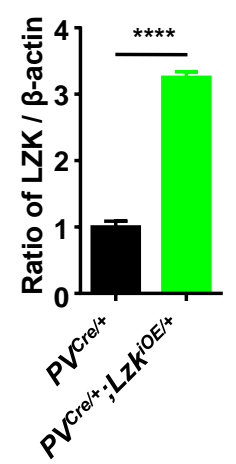

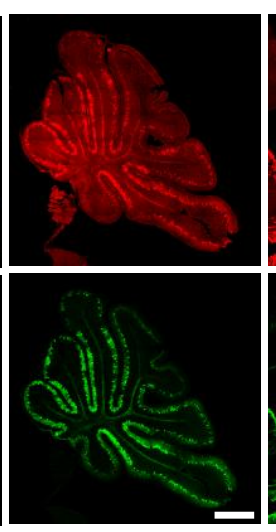

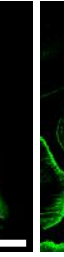

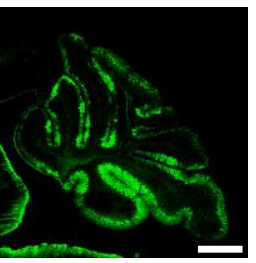


Figure 2-figure supplement 2

A DIk

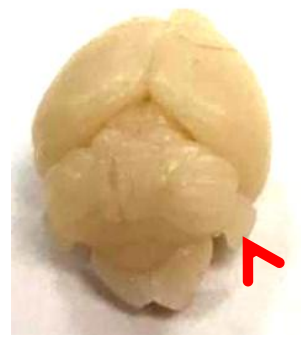

C
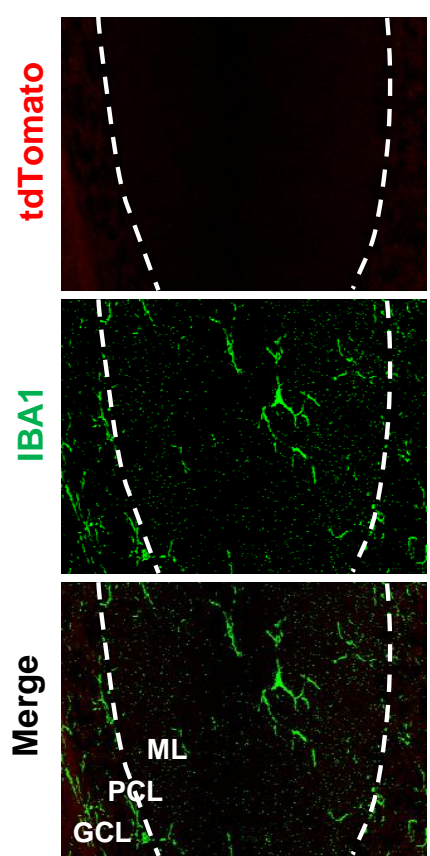

PV $^{\text {Cre/+; }}$ DI $k^{\mathrm{iOE} /+}$

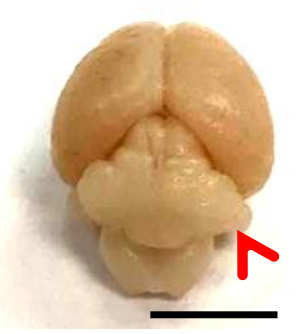

PVCre/+;DIk ${ }^{\text {iOE } /+}$
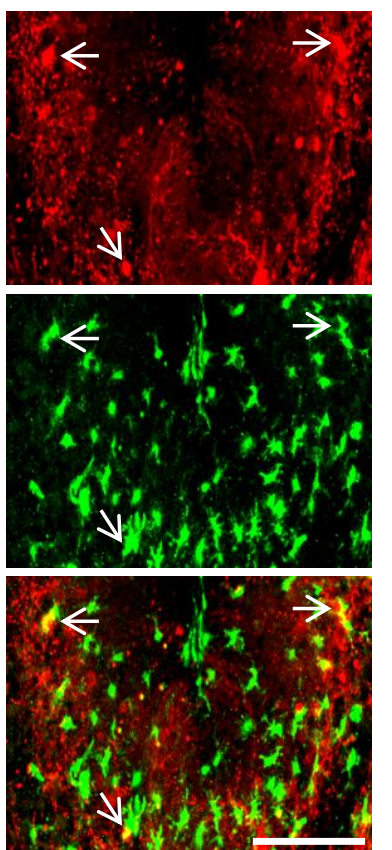

B $D I k^{i O E /+}$

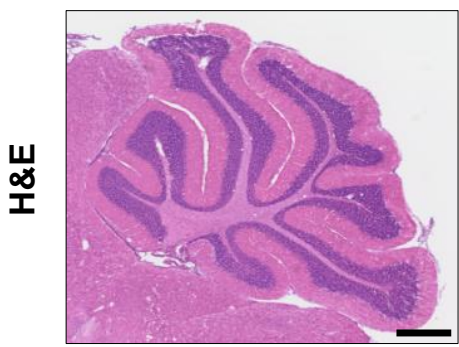

D

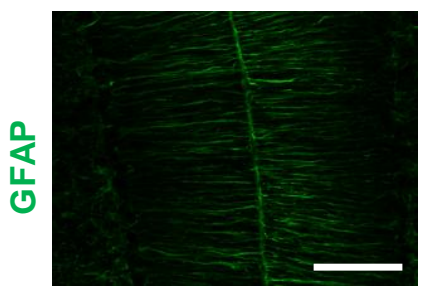

$D I k^{i O E /+}$

E

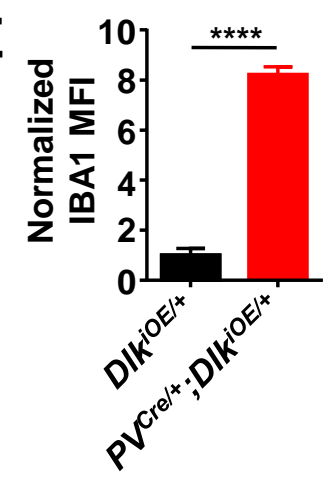

PVCrel/; $; \mathbf{l k}^{\mathrm{iOE} /+}$

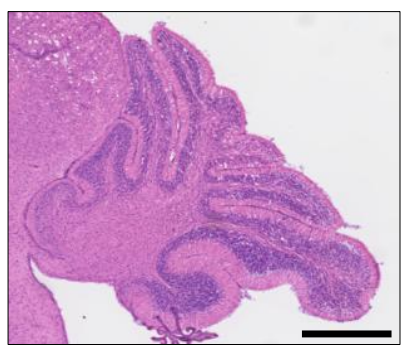

PVCre/+; $\mathrm{Dlk}^{\mathrm{iOE} /+}$

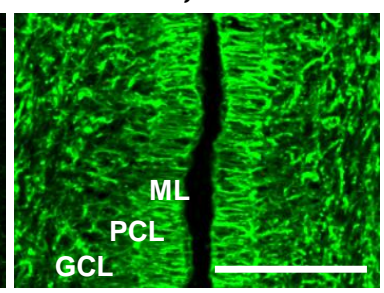

F

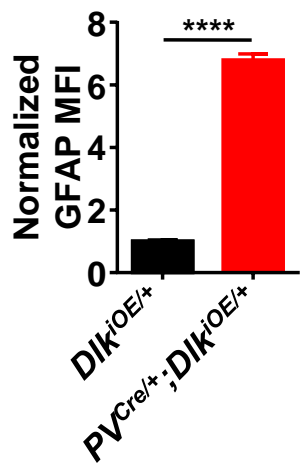


Figure 3-figure supplement 1

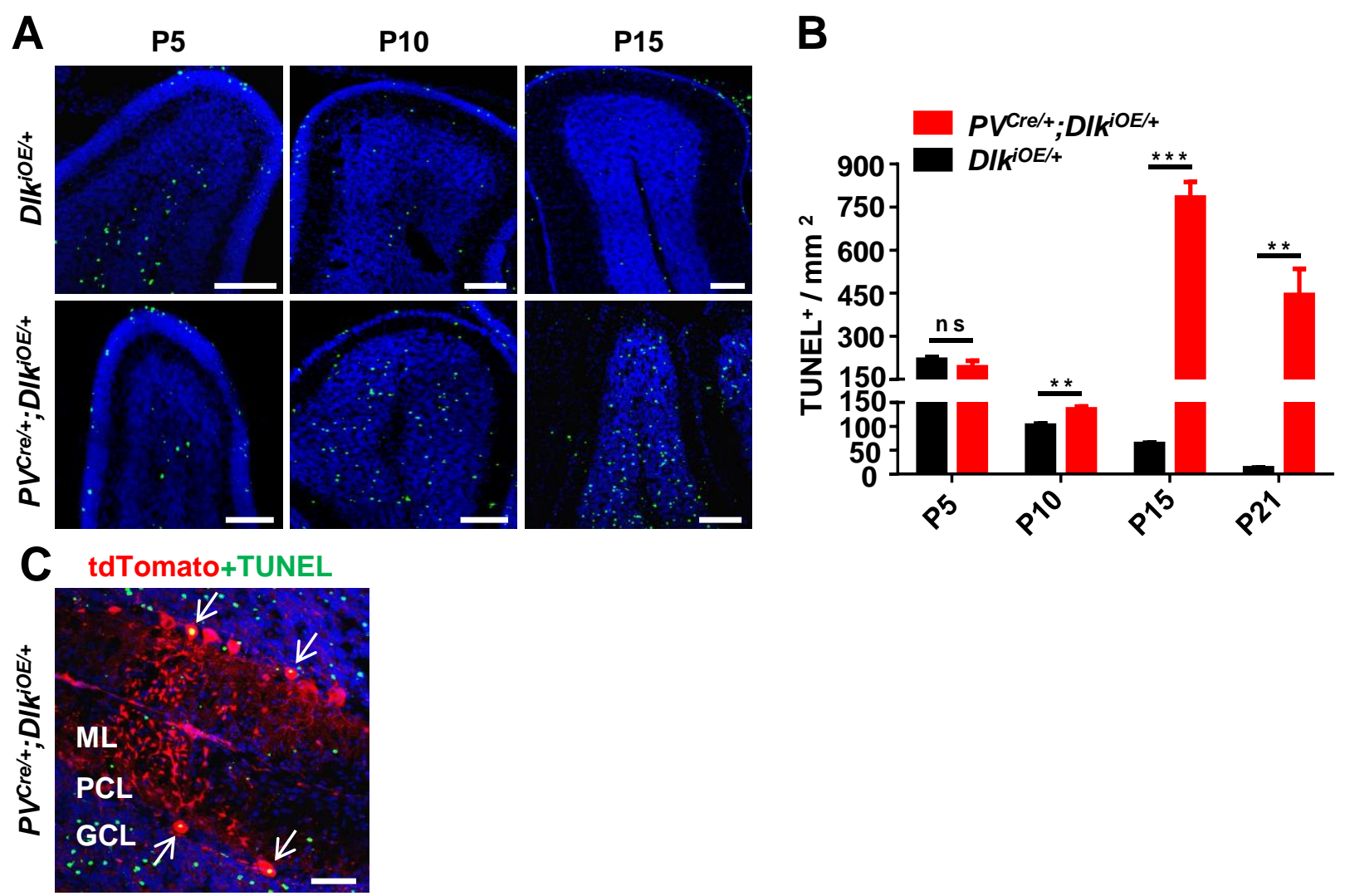


Figure 3-figure supplement 2

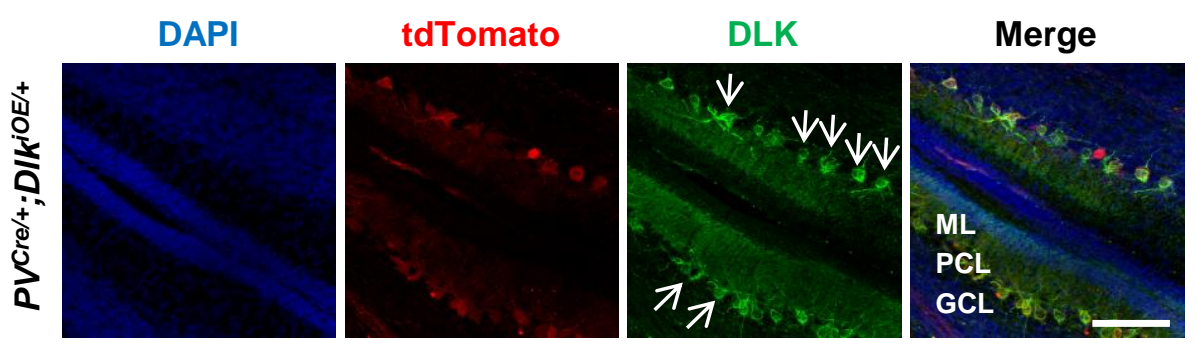




\section{Figure 4-figure supplement 1}

A

PVCre/-; D tdTomato

$L z k^{i O E /+}$

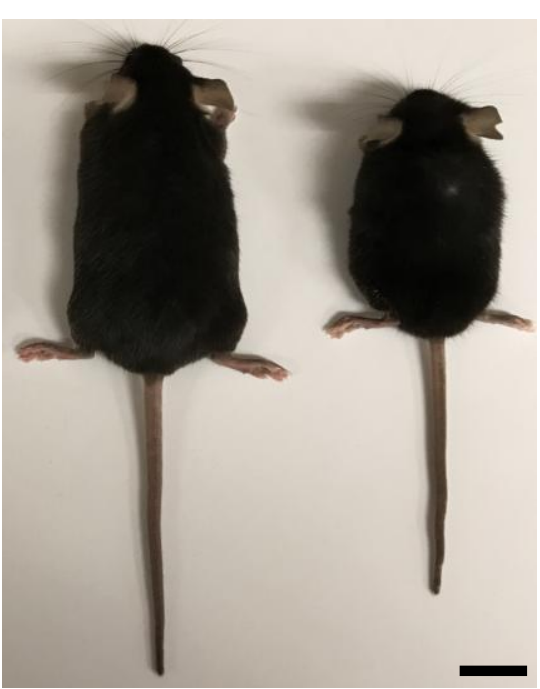

B

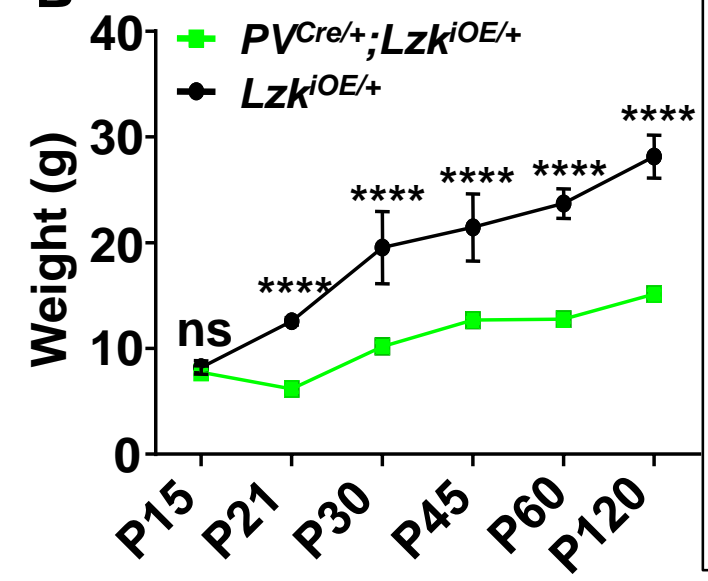

C

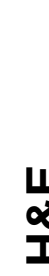

LzK $^{\mathrm{iOE} /+}$

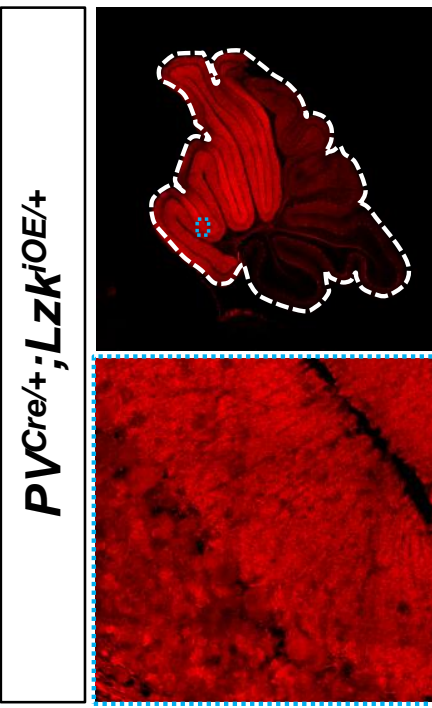

PVCre/+;Lzk KOE/+ $^{\text {iO }}$

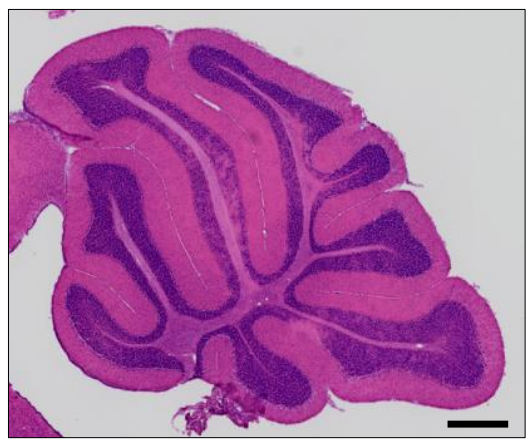

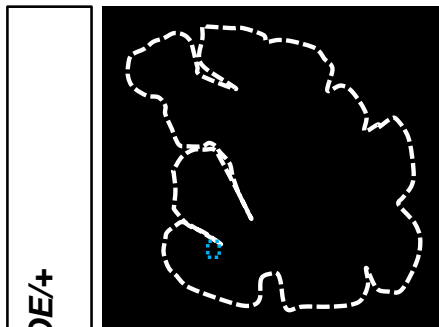

LZK
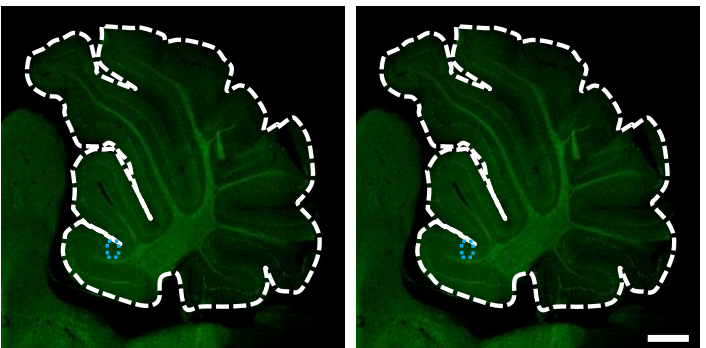
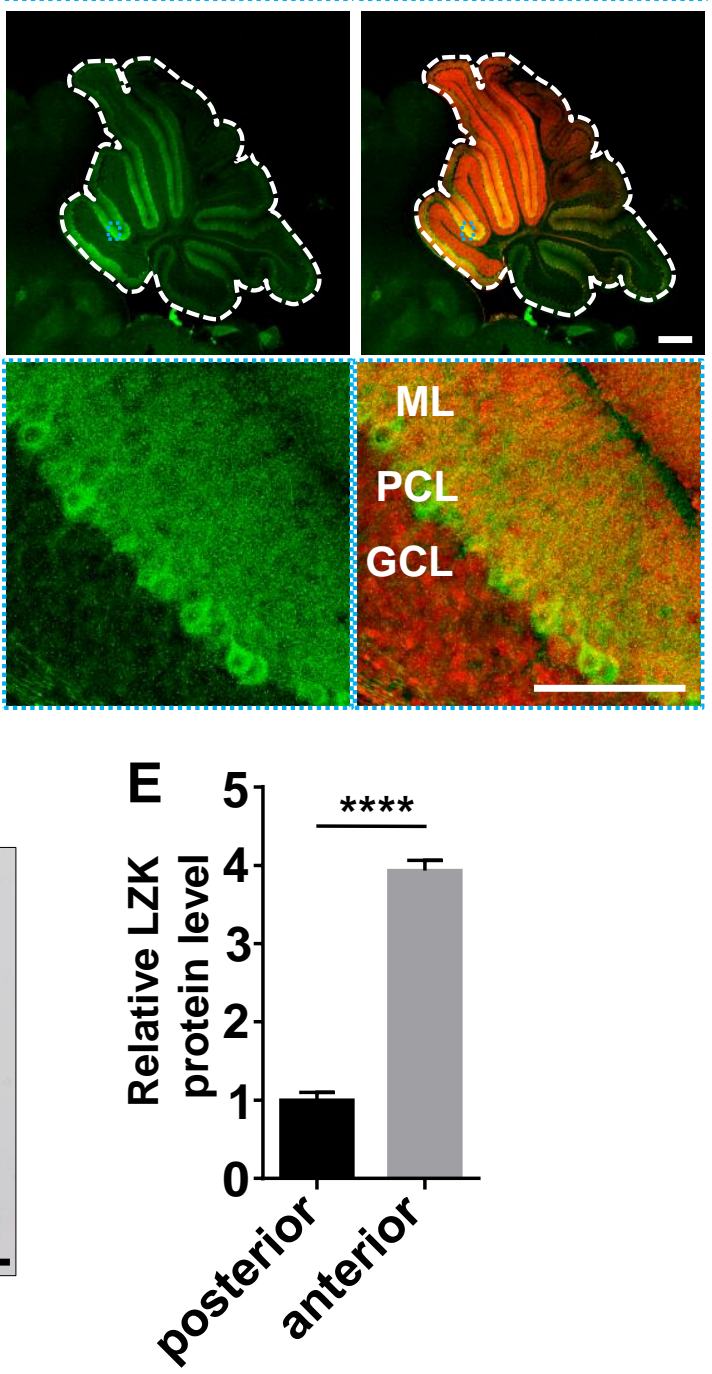
Figure 4-figure supplement 2

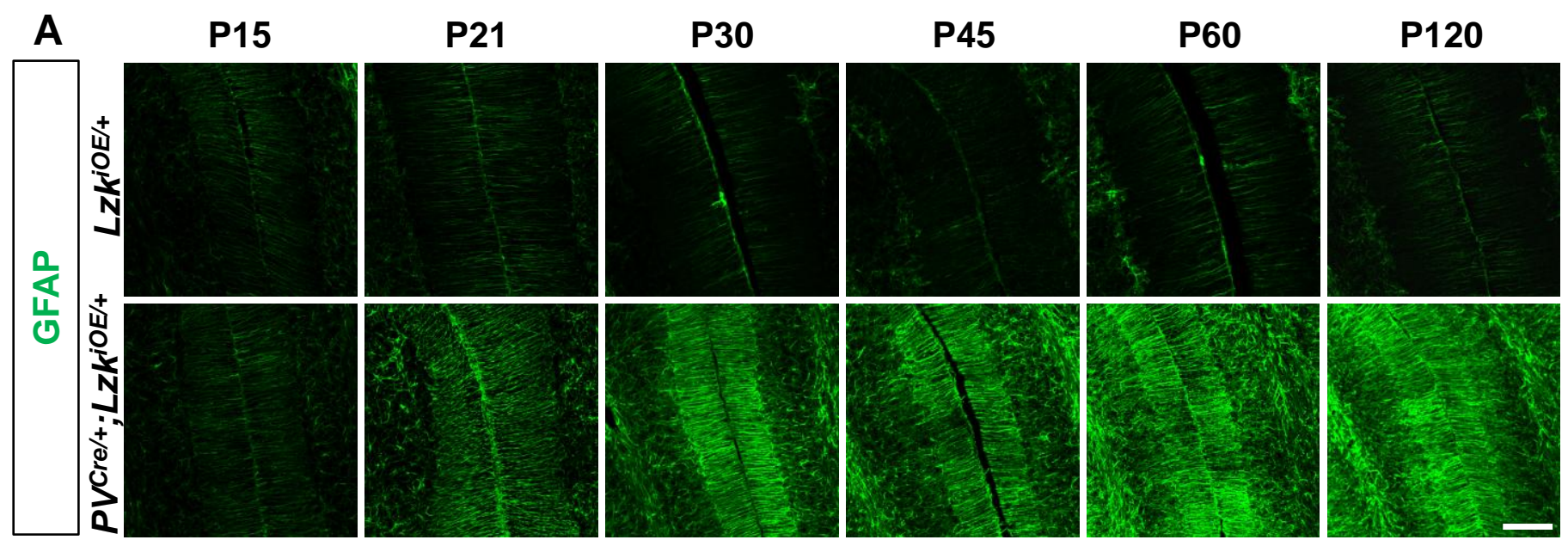

B

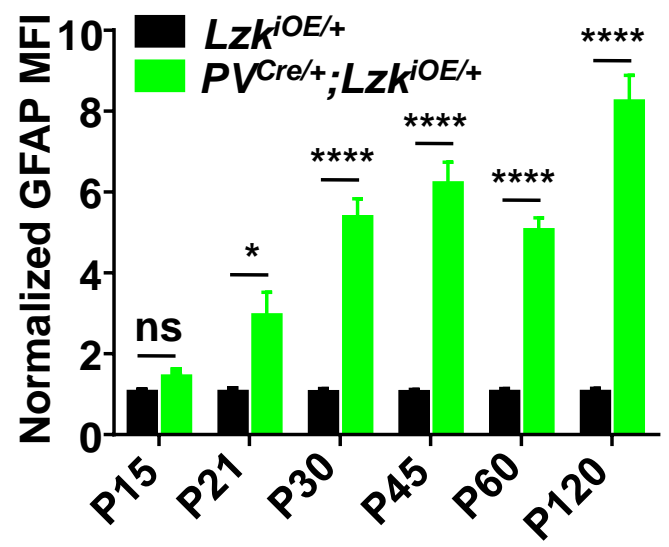

C

Calbindin

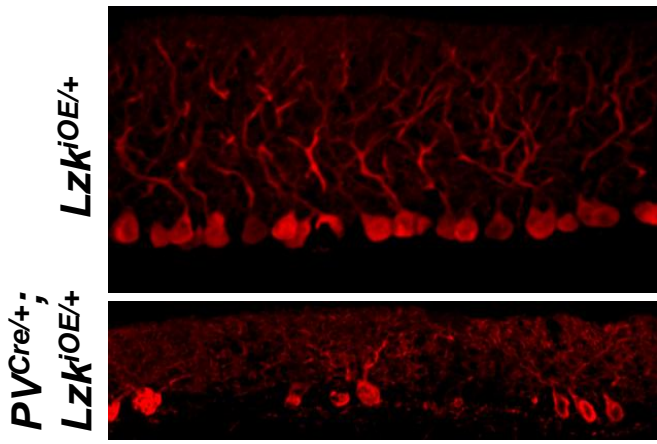

GFAP

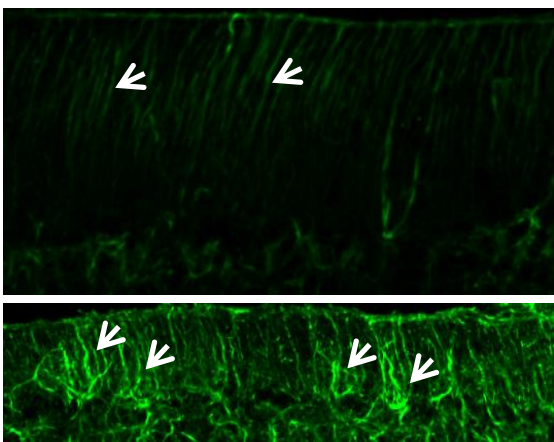

Merge

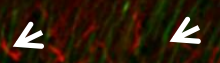

ML

PCL

GCL

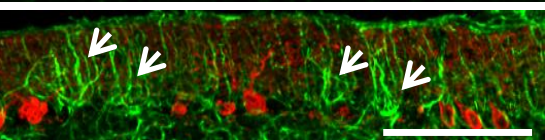


Figure 5-figure supplement 1
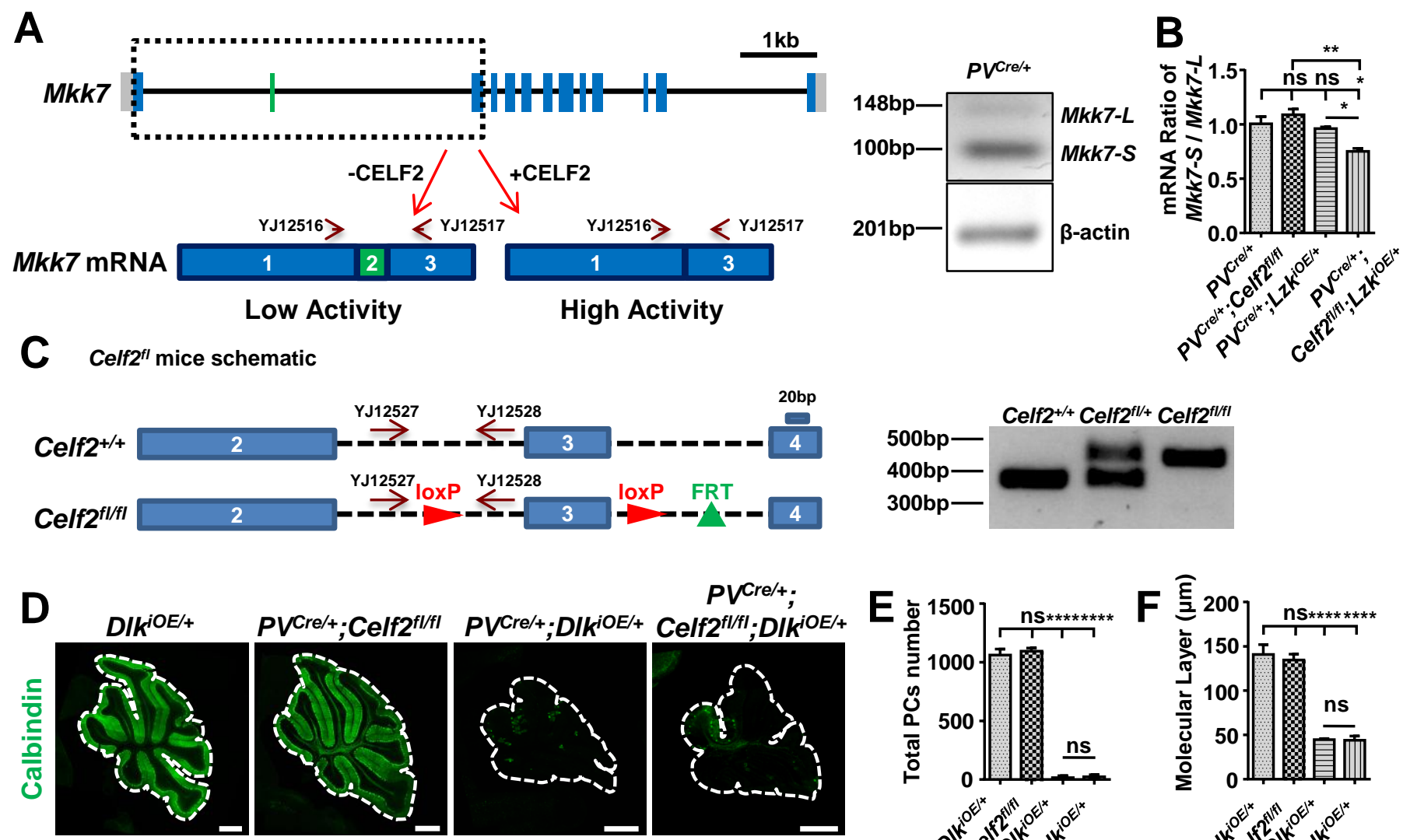

1

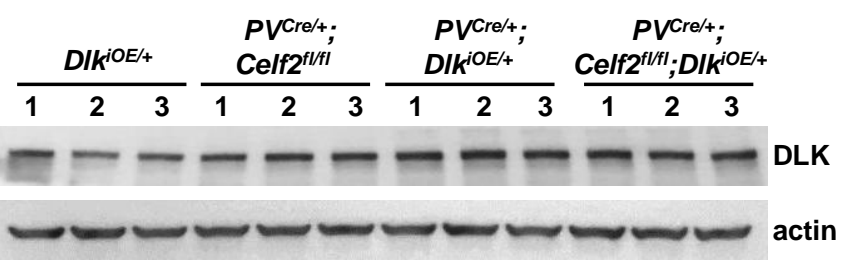

PVCre/+;
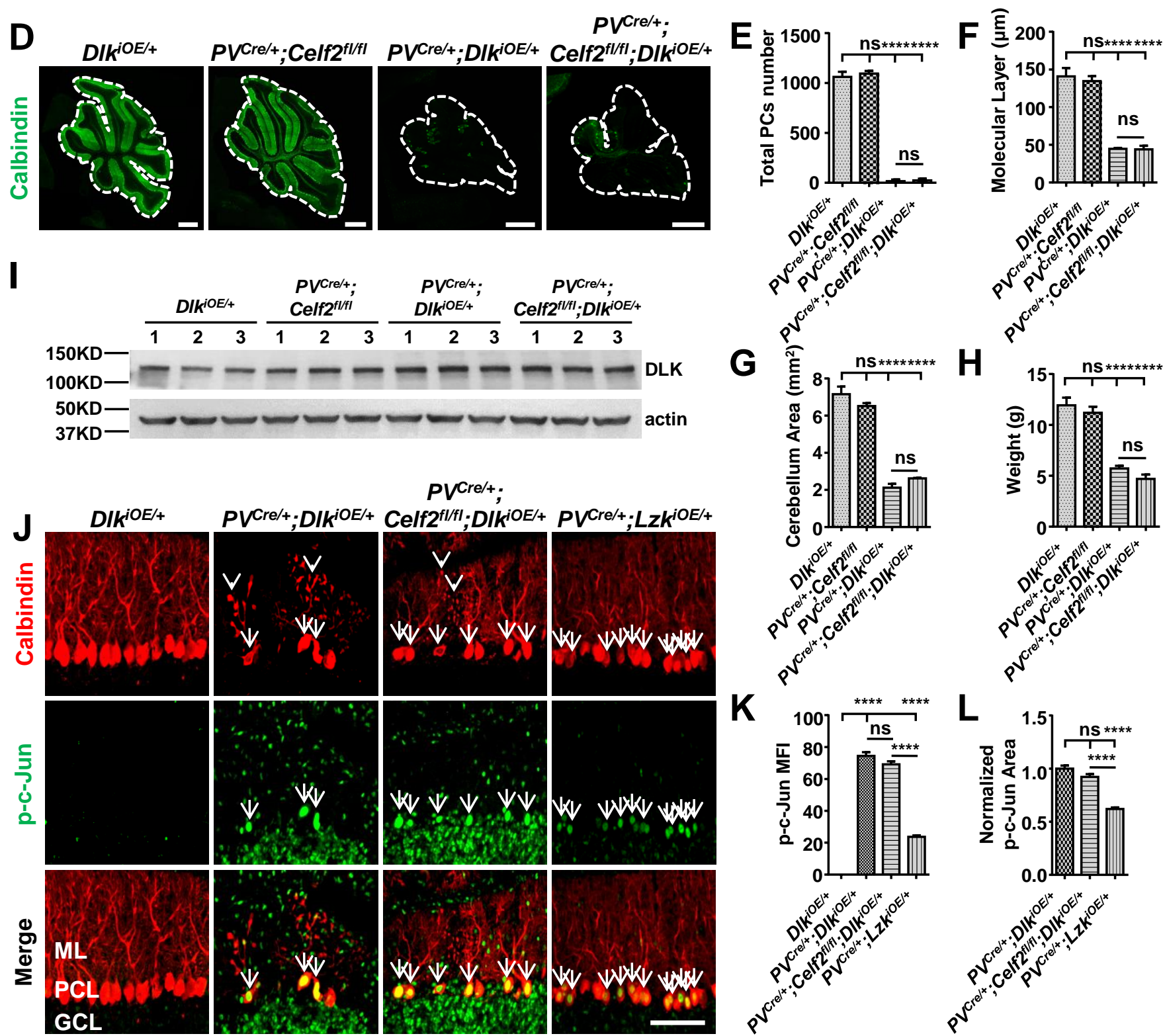

150KD-

$100 \mathrm{KD}$

50KD
37KD<smiles>[134IH]</smiles>

$\frac{\text { ลू }}{\beta^{5}}$

8 .

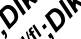
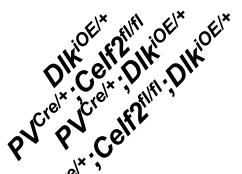

ลี

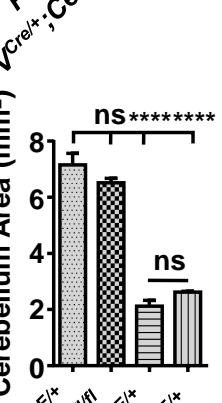

4
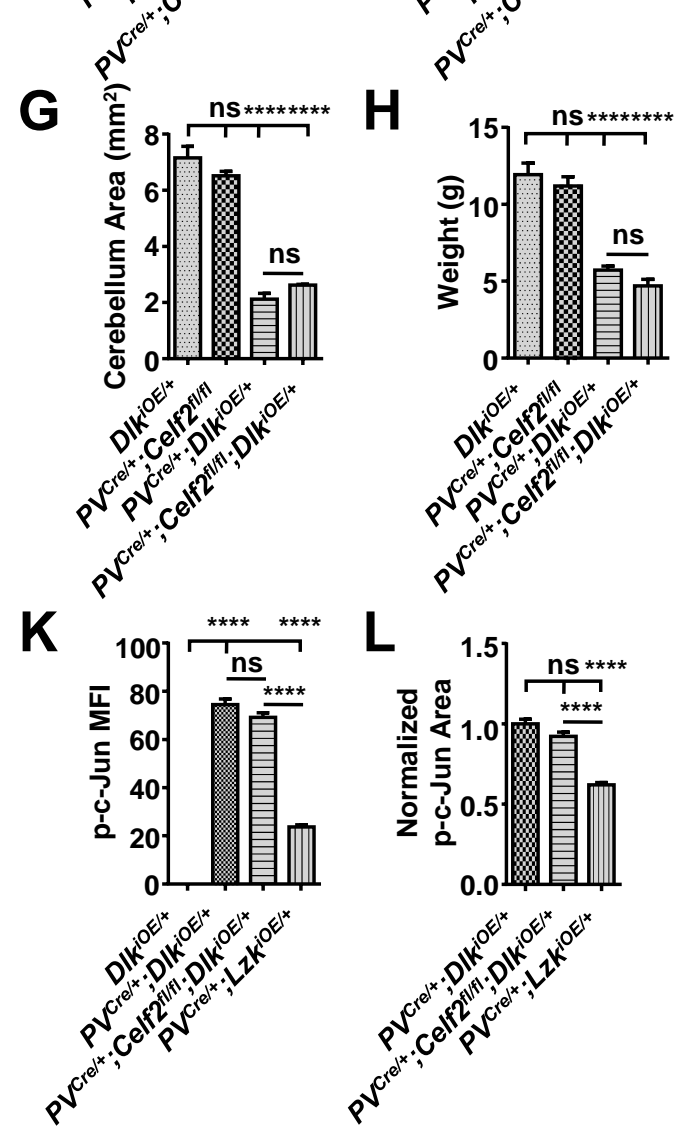


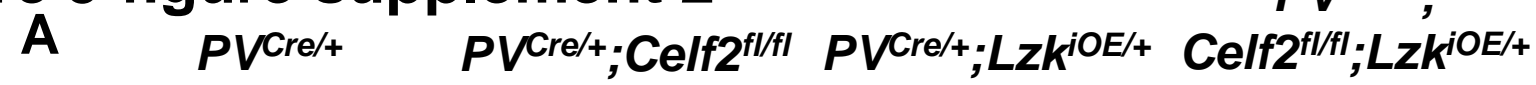

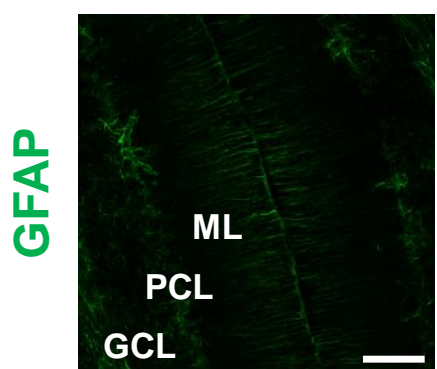

B

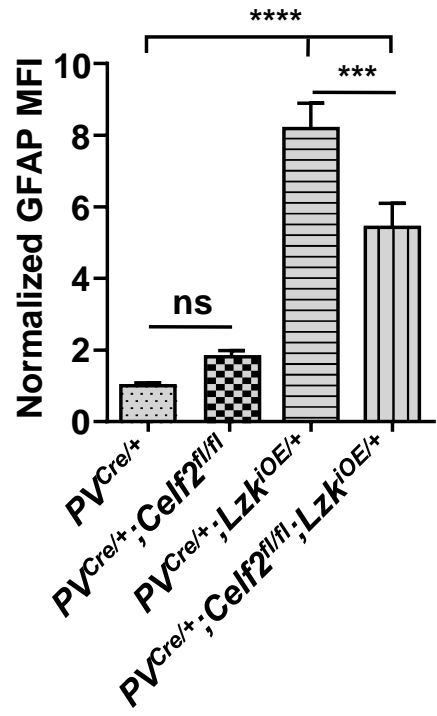

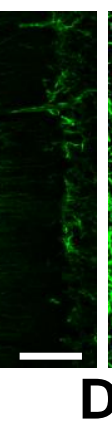

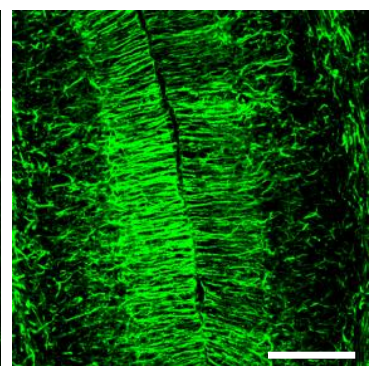

D

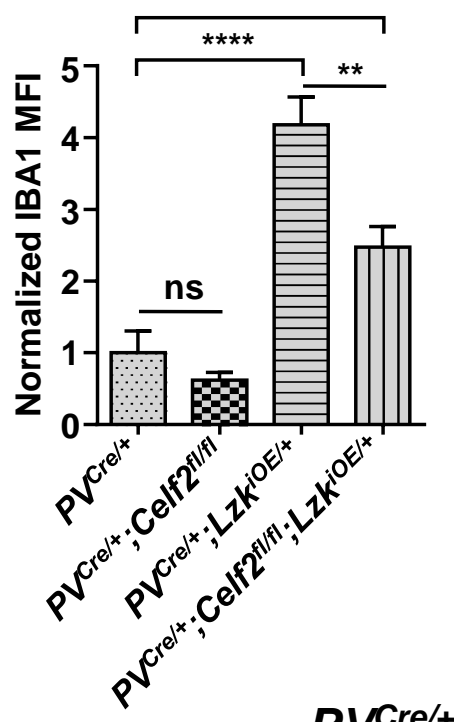

PVCre/+;
$\mathrm{PVCre}^{+} ;$Celf2 ${ }^{f / f l}$
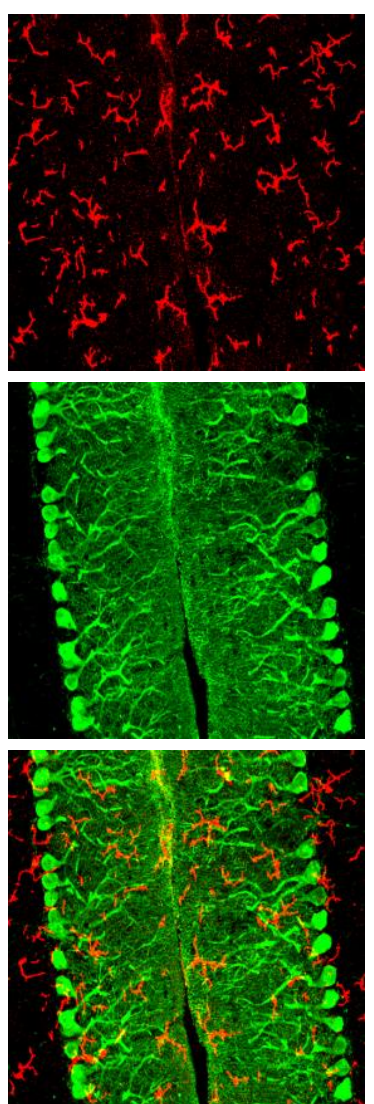

PVCre/+;LzkiOE/+ Celf2fl/fl ;LzKiOE/+
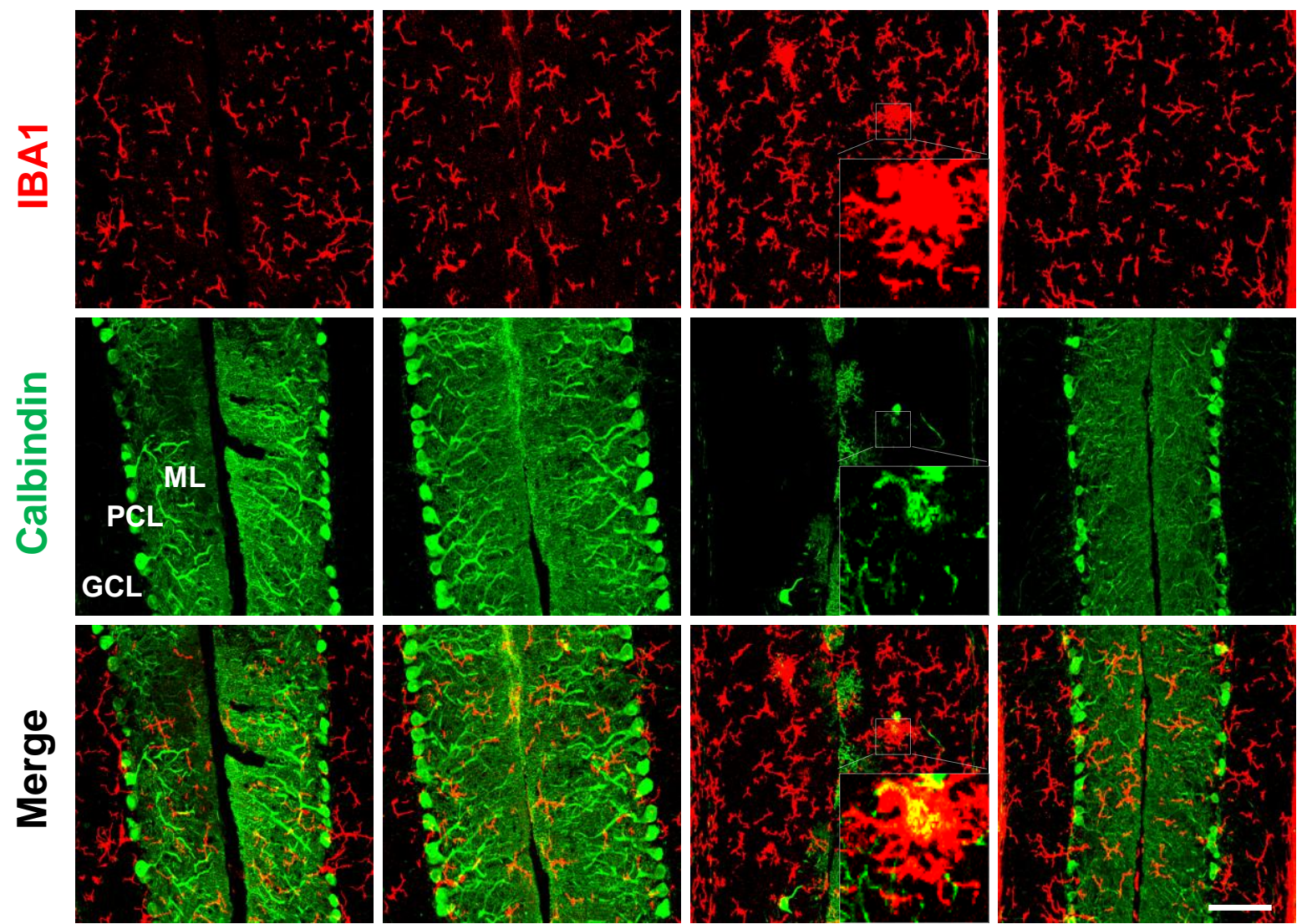
Figure 5-figure supplement 3

PVCre/+;

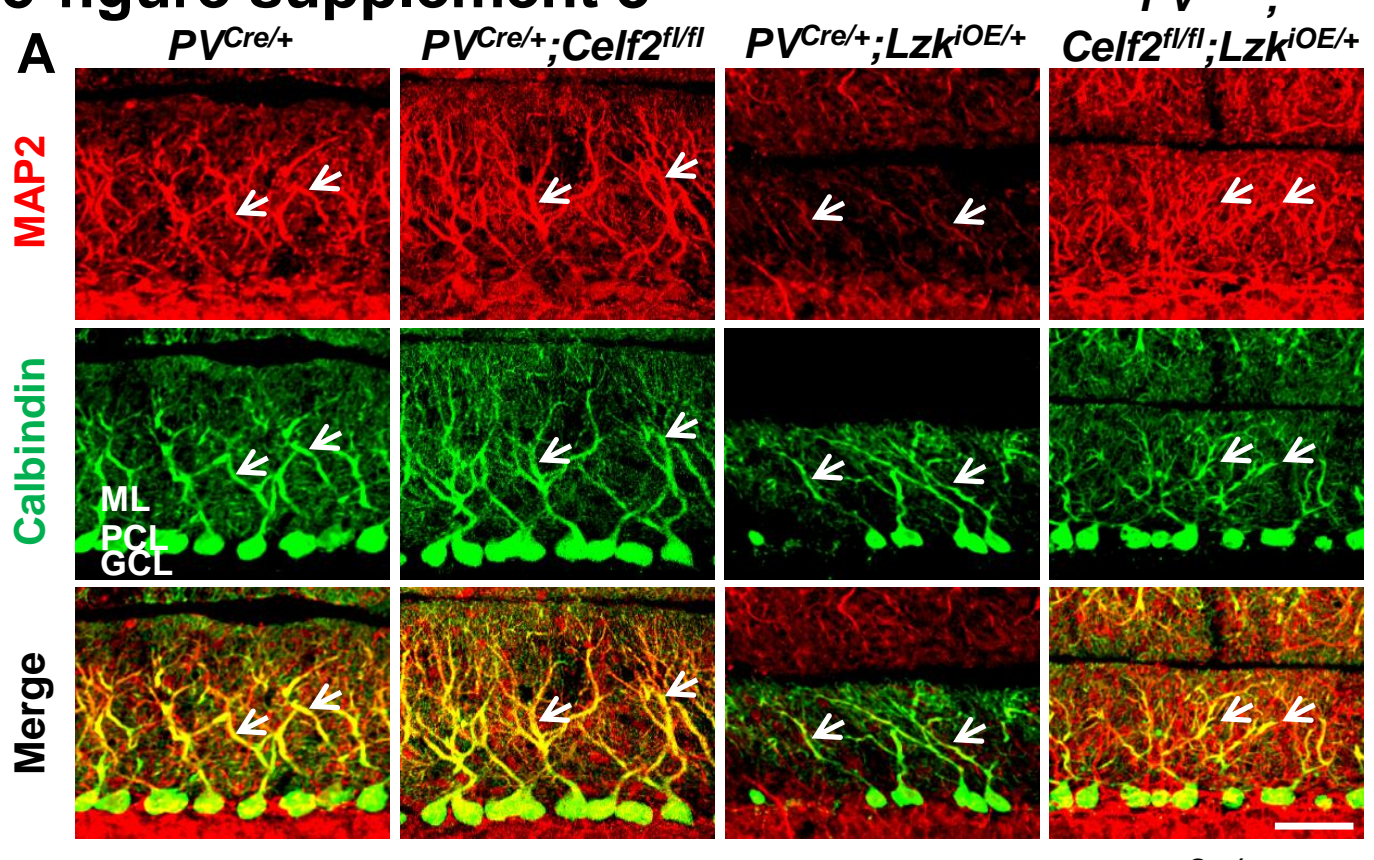

PVCre/+;

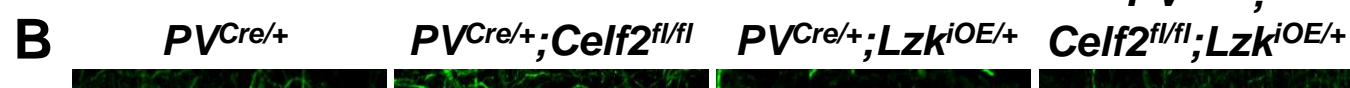

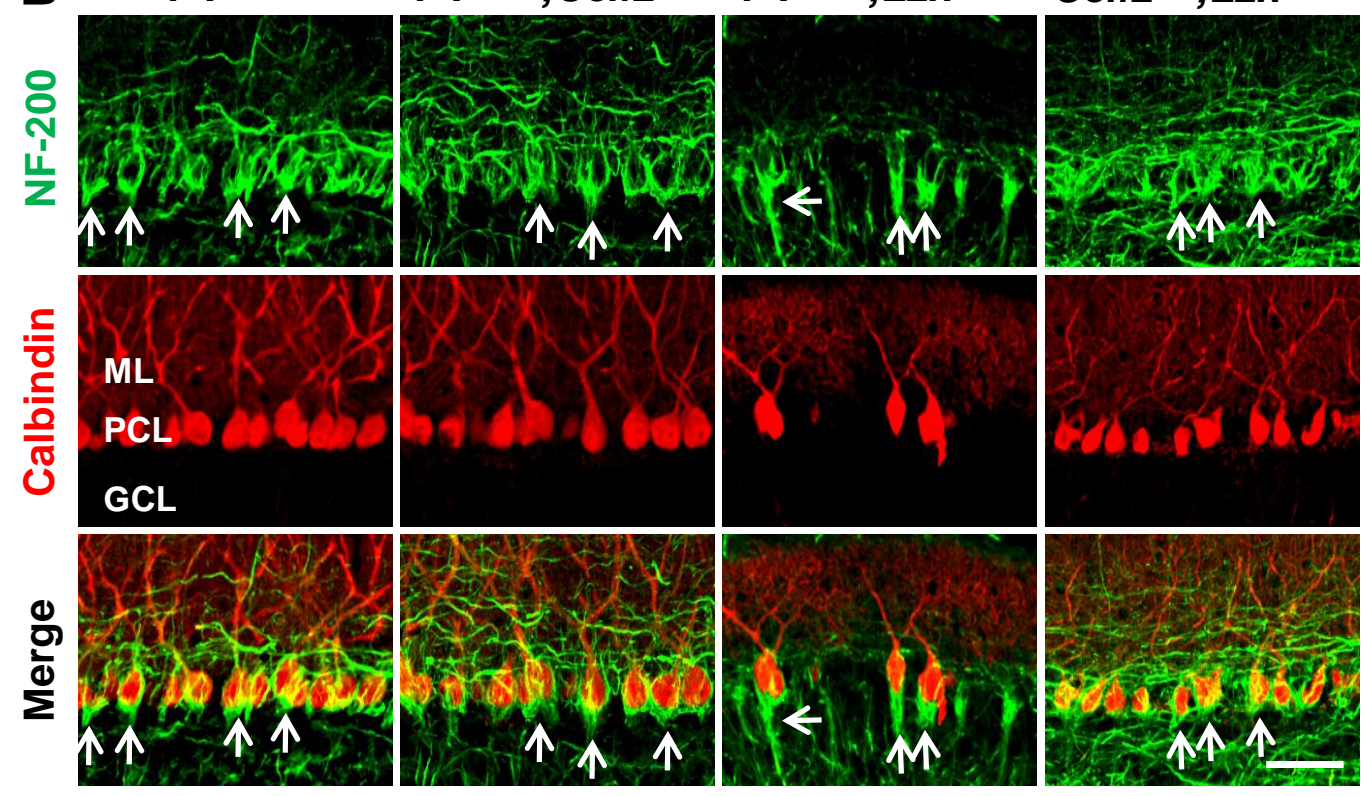

PVCre/+;

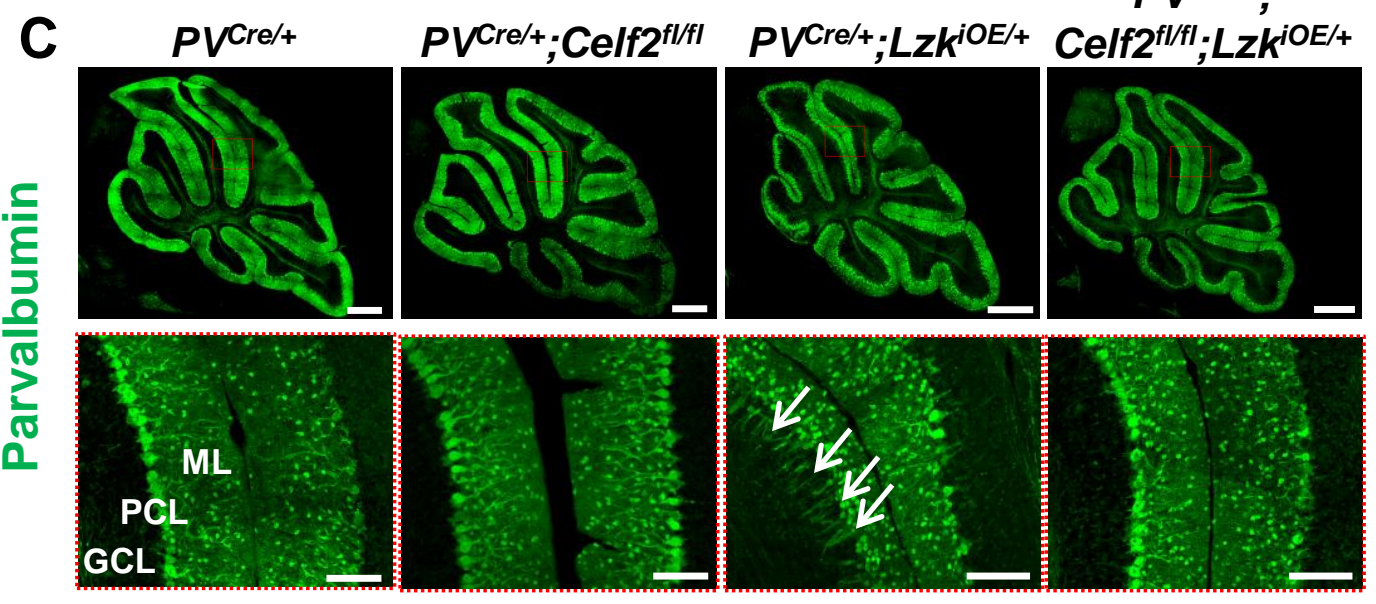


Figure 6-figure supplement 1
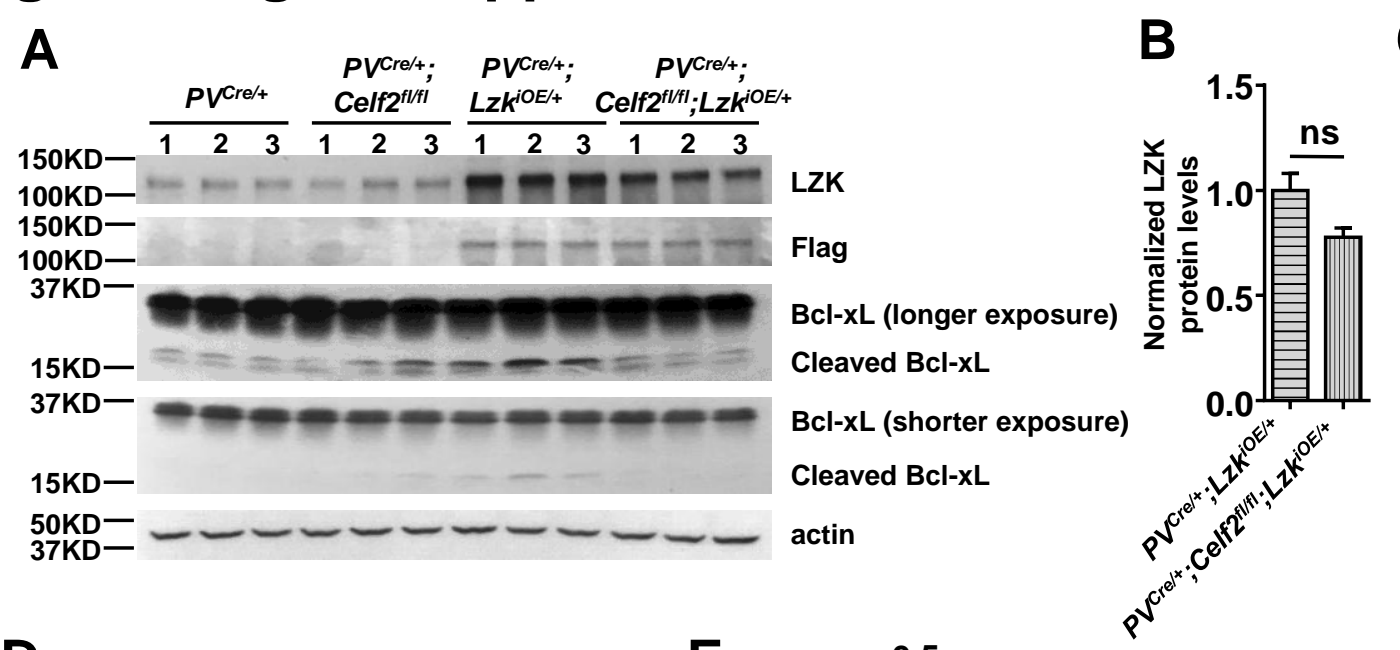

C

D

TUNEL
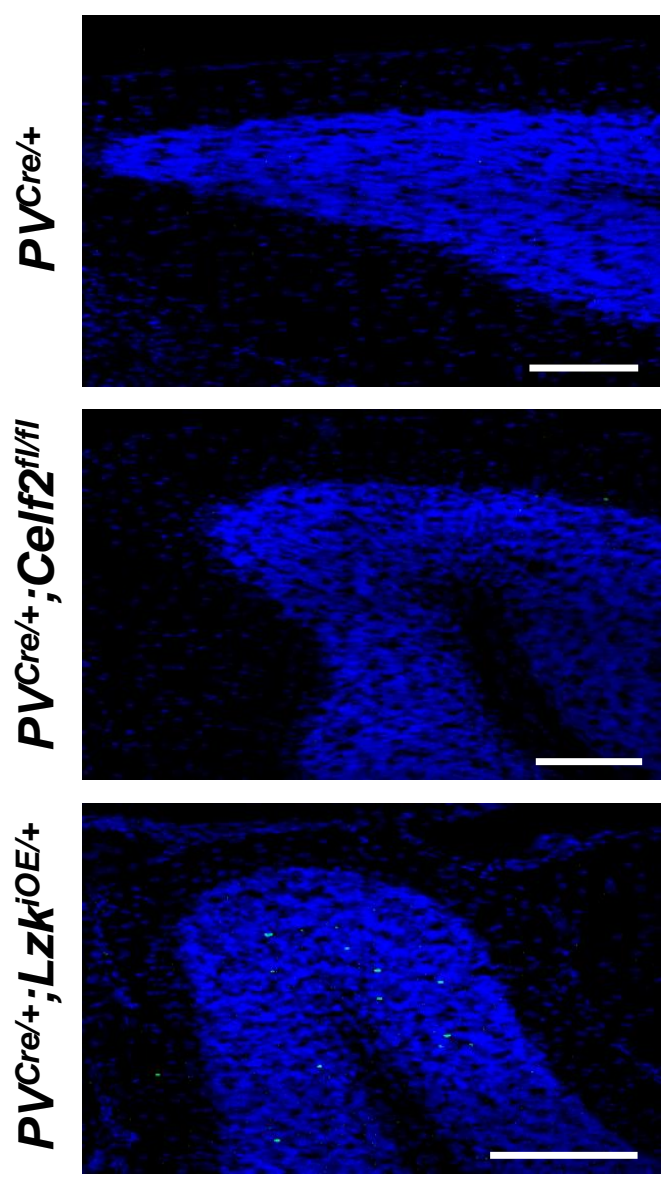

$\dot{\vdots}$
$\vdots$
$\vdots$
$\mathbf{a}$
E

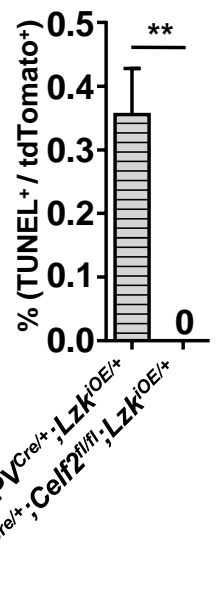

F

$\frac{1}{3}$
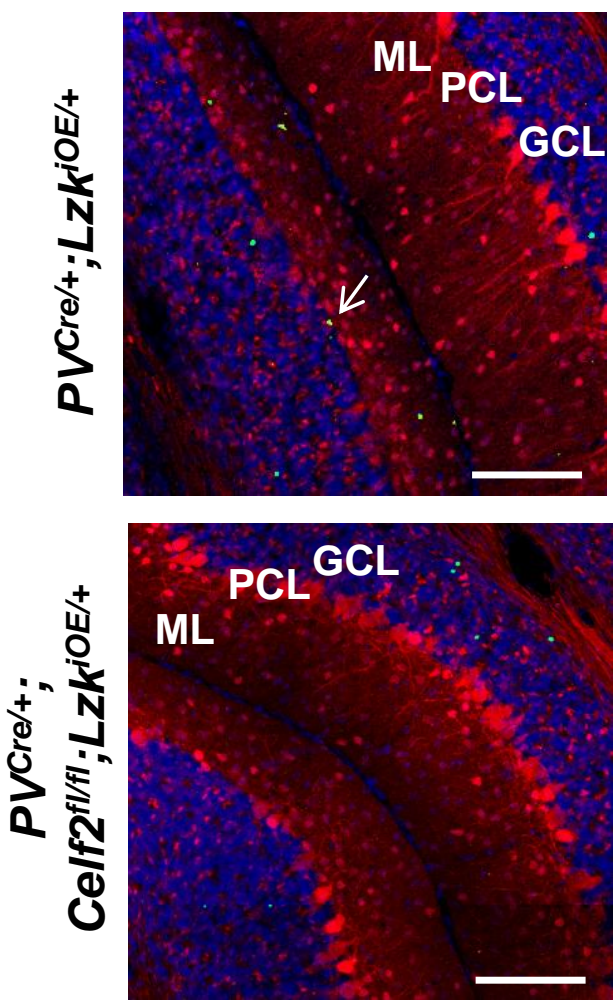


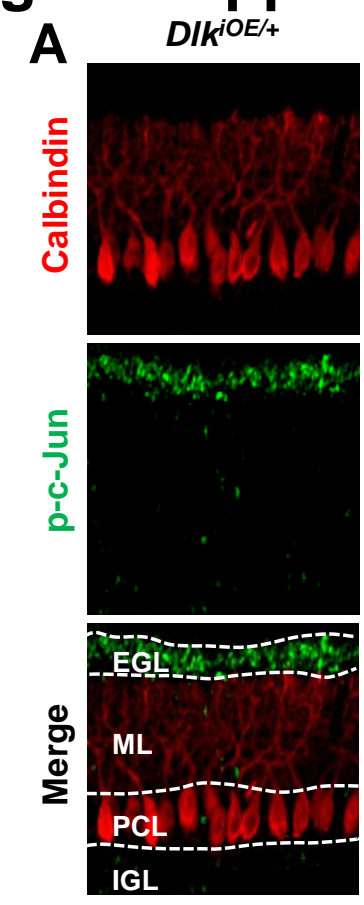

B
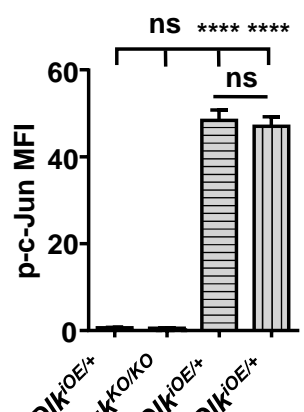

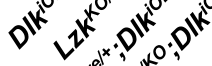
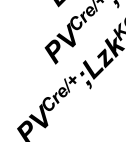

$L z k^{K O / K O}$
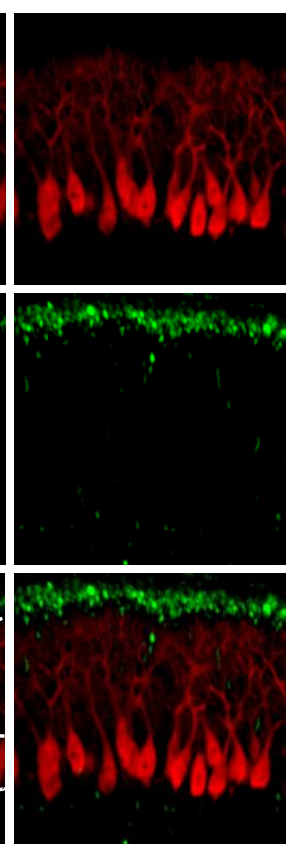

C
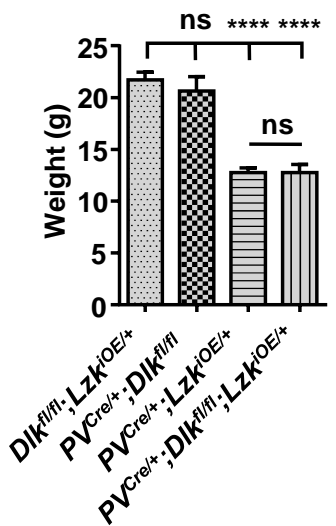

PVCre/t; PVCre/+;Dlk ${ }^{i O E /+} \quad L z k^{K O / K O} ; D I k^{i O E}$

$v v v^{v}$

vv w w w

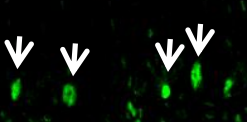

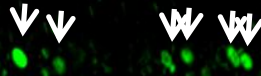

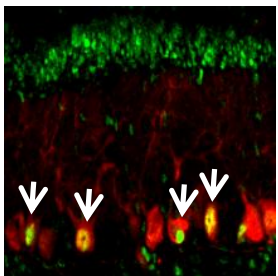

E
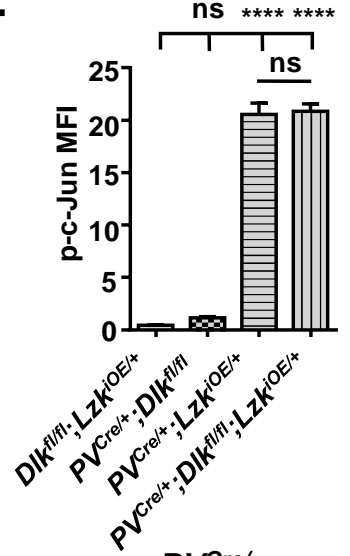

PVCre/t;

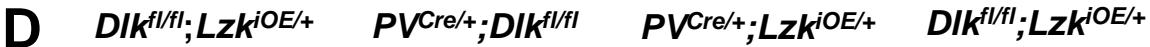

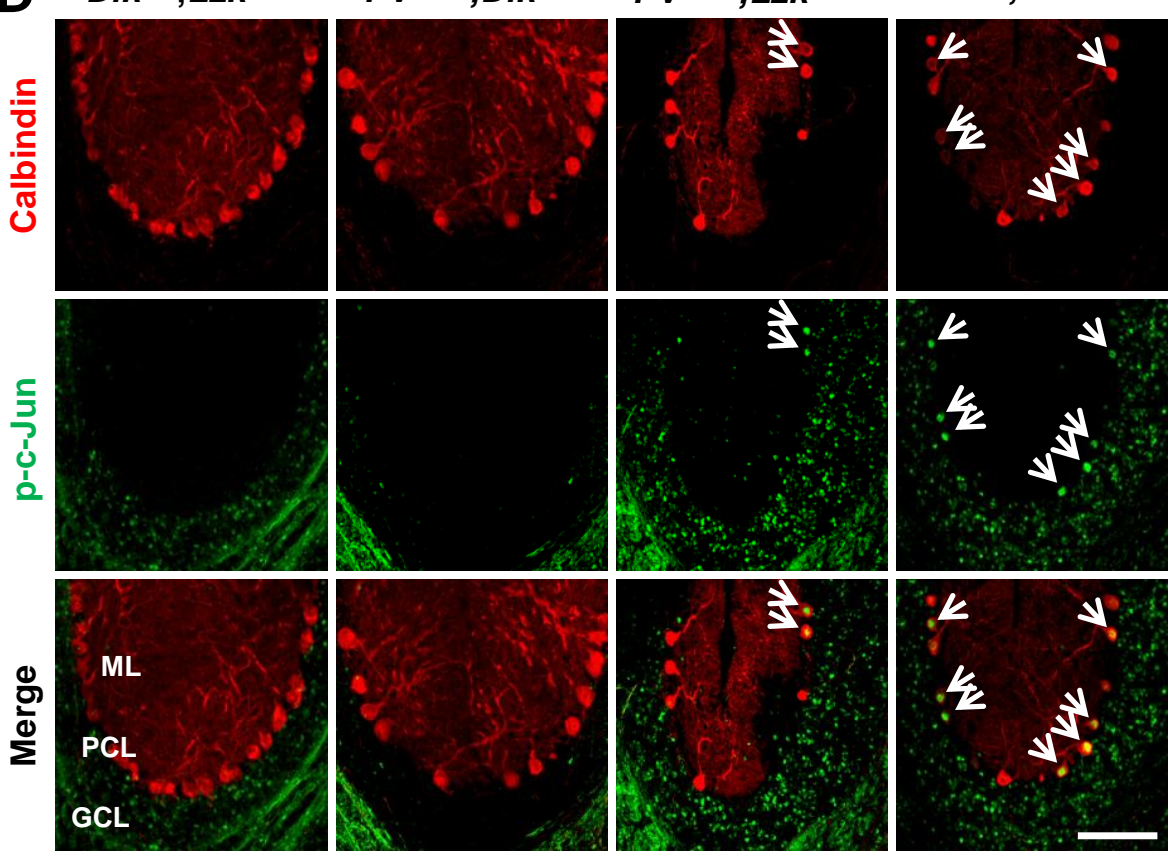

